PROGRESSIVE TRENDS IN COORDINATION, BIOINORGANIC AND APPLIED INORGANIC CHEMISTRY

XXVII International Conference on Coordination and Bioinorganic Chemistry,

June 2-7 2019, Smolenice, Slovakia

Review paper in the Coordination Chemistry Reviews

\title{
Spin crossover polymer composites, polymers and related soft materials
}

Alejandro Enriquez Cabrera, Amalia Rapakousiou, Mario Piedrahita Bello, Gábor Molnár,* Lionel Salmon,* Azzedine Bousseksou*

Laboratoire de Chimie de Coordination, CNRS UPR 8241, 205 route de Narbonne, F-31077

Toulouse, France.E-mail: lionel.salmon@lcc-toulouse.fr, gabor.molnar@lcc-toulouse.fr, azzedine.bousseksou@lcc-toulouse.fr

\begin{abstract}
We review the synthesis, properties and applications of spin crossover polymer composites, polymers and some related 'soft' materials. These materials have received recently much attention because they provide an efficient way for the processing of spin crossover complexes in various shapes at various size scales and can give rise also to unique physical properties. First, we discuss in detail the state of the art of the elaboration of spin crossover polymer composites, using either inorganic complex precursors in solution or pre-formed spin crossover powder. A particular attention is paid on the influence of the polymer matrix on the spin crossover properties and on the use of 'active' polymers for development of synergies between the properties of the matrix and the load. Polymer composite devices for applications in the fields of artificial muscles, energy harvesting and thermochromic sensors are also highlighted. Then, more recent works, in which organic polymeric chains are used as ligands for the transition metal ions are presented. Finally, we overview various related 'soft' spin crossover compounds including spin crossover dendrimers, gels, liquid crystals and Langmuir Blodgett films with particular emphasis on compounds with supramolecular interactions of alkyl chains.
\end{abstract}

Keywords: Spin crossover complexes, composite materials, polymers, soft matter

\section{HIGHLIGHTS}

- The article reviews spin crossover polymer composite materials

- Recent development in spin crossover polymers

- Elaboration of soft materials based on spin crossover compounds 
PROGRESSIVE TRENDS IN COORDINATION, BIOINORGANIC AND APPLIED INORGANIC CHEMISTRY

XXVII International Conference on Coordination and Bioinorganic Chemistry,

June 2-7 2019, Smolenice, Slovakia

Review paper in the Coordination Chemistry Reviews

\section{CONTENT}

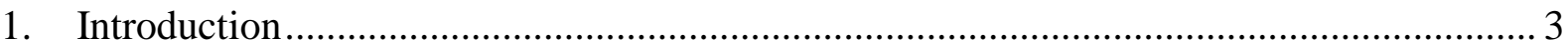

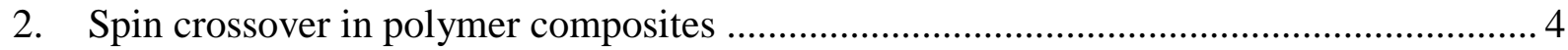

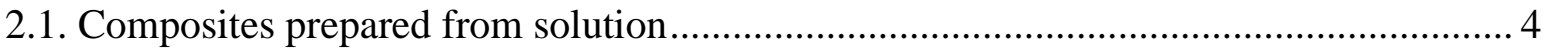

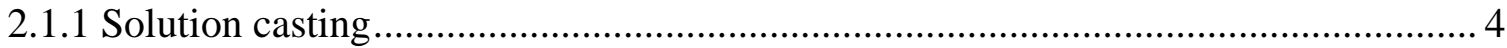

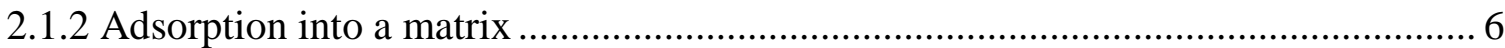

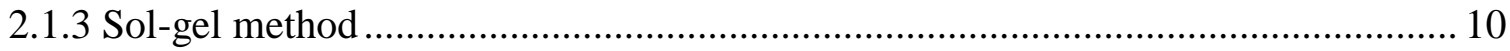

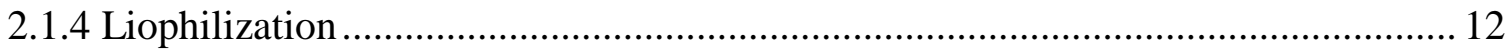

2.2. Dispersion of SCO particles in polymer matrices ................................................. 13

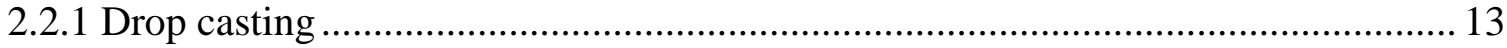

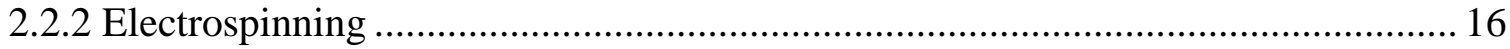

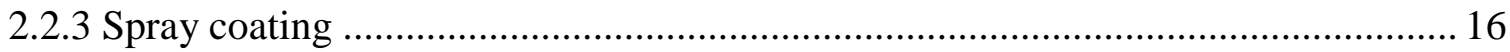

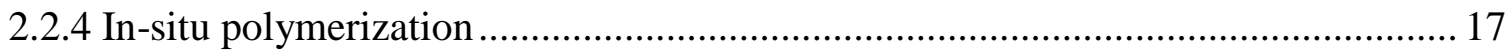

2.2.5 Electrochemically assisted self-assembly (EASA) ............................................ 18

2.2.6 Matrix-assisted pulsed laser evaporation (MAPLE) .............................................. 19

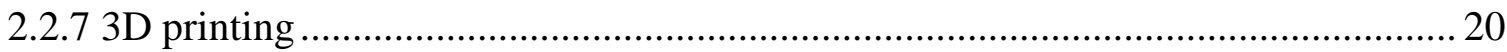

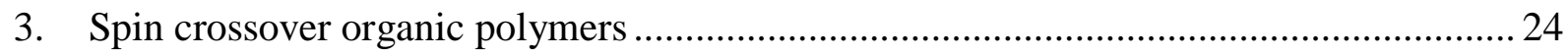

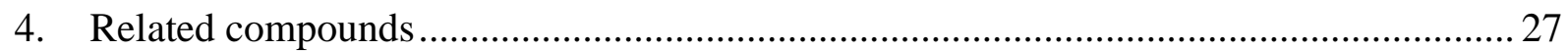

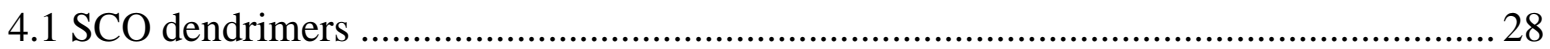

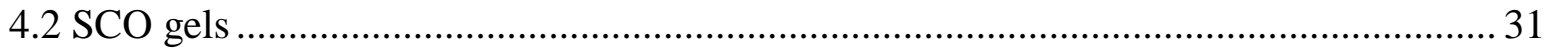

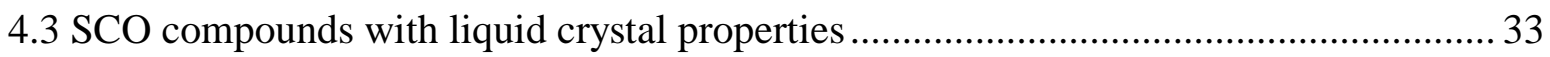

4.4 Langmuir-Blodgett films displaying SCO phenomenon ......................................... 34

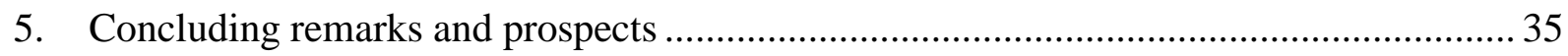

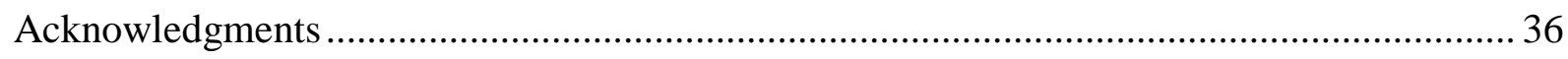

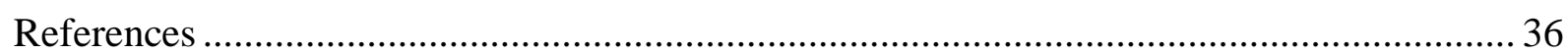




\section{Introduction}

Polymer composites are multi-phase materials wherein at least one phase is a polymer.[1] The combination of these components results in original physical properties that differ from that of the constituents alone. In the majority of cases, they are composed of organic polymers as matrix and different fillers that act as the reinforcement.[2] Indeed, often the main objective that governs the development of such materials in various fields like construction, [3] aerospace [4] and automotive [5] is the modification of their mechanical and thermal properties. Nevertheless, the scope of advanced polymer composite materials exceeds largely the thermomechanical aspects, providing opportunities to develop a large variety of original physical properties as well as material processing methods.

In the field of spin crossover (SCO) complexes of transition metal ions, [6-11] polymer composites have been developed for several reasons. In the early stages of SCO research, incorporation of SCO complexes into polymer matrixes was carried out in order to make possible some physical characterizations (e.g. photophysical measurements), which were not feasible (or meaningful) using microcrystalline powder samples or liquid solutions.[12,13] To this aim, films or pellets of SCO-polymer composites were fabricated using simple methods such as spin coating or drop casting. Following the visionary ideas of Olivier Kahn in the 90ies,[14,15] the past two decades the SCO research has moved to a considerable extent towards seeking potential technological applications of these smart, multifunctional molecular materials, exhibiting a spectacular change of their magnetic, optical, electrical, thermal and mechanical properties.[16,17] As a result, the need for device integration and processing of SCO materials in different shapes and sizes (from the nanometric to the macroscopic scale) has also significantly increased. This conjuncture has motivated considerable research for the incorporation of SCO materials and nanomaterials [18] into malleable and processable polymer matrices using increasingly sophisticated methods, such as spray coating, matrix-assisted pulsed laser evaporation, electrospinning or 3D printing. However, impacts of the nature and the mechanical properties of the polymer on the spin crossover behaviours, and vice-versa, were clearly evidenced in many cases. These findings generated research for the theoretical modelling of SCO-matrix interactions [19] and, more recently, for the development of more sophisticated SCO polymer composite materials exhibiting synergies between the properties of the SCO particles and the polymer matrix. Notably, strain-coupled electroactive polymer-SCO composites have been developed with promising properties for the development of actuators, sensors and energy harvesters.[16,20,21] Alternative to multi-phase, composite materials, several groups have also undertaken syntheses of 'spin crossover organic polymers', i.e. organic polymers functionalized by SCO entities. (N.B. We use the term 'SCO organic polymers' to avoid confusion with 'SCO coordination polymers', which refer to the well-known SCO coordination networks, such as Fe-triazole chains or Hofmann like clathrates.) The review is organized in three sections. The first section gathers a state of the art, which is aimed to be exhaustive on the synthesis and characterization of the physical properties of spin crossover polymer composites. The second chapter brings together the few reported examples of 'spin crossover organic polymers'. The last section is a non-exhaustive overview of selected examples of conceptually related 'soft' SCO materials, including SCO dendrimers, gels, liquid crystals and Langmuir Blodgett films, which display uncommon properties and allow for easier material processing when compared to 'conventional' crystalline SCO materials. 


\section{Spin crossover in polymer composites}

Embedding SCO complexes into polymer matrices is a straightforward, yet powerful and generic approach towards processable SCO materials, important for their different applications and integration into devices. From a conceptual point of view, it is interesting to separate these materials into two main categories: composites prepared from solutions (whether using a solubilized SCO complex or the corresponding precursors) and composites prepared from preformed SCO powder. In both cases, a variety of methods of different sophistication were employed, which range from simple casting techniques to state-of-the-art stereo-lithography.

\subsection{Composites prepared from solution}

\subsubsection{Solution casting}

Whenever an SCO compound and a polymer have a common solvent, this simple method provides a straightforward means for dispersing the complex within the matrix and process the composite as a film on various substrates. Yet, the resulting morphology and microstructure of the SCO complex is not always trivial to control (e.g. crystalline vs. amorphous, aggregated vs. dispersed, etc.).

Xie and Hendrickson [12] doped the complex [Fe(6-Me-py) $)_{2}(\text { py)(tren)](ClO })_{2}$ ((6-Mepy) 2 (py)(tren) ligand is a Schiff base) into PSS (polystyrene sulfonate, $6.25 \% \mathrm{wt}$ ) matrix by simply dissolving the two compounds in water and allowing the solvent evaporate on a glass substrate. The composite films were then investigated using UV-VIS spectrophotometry, Mössbauer spectroscopy and flash laser photolysis techniques. The authors noticed a change of the SCO behaviour with respect to the perchlorate salt of the complex and they evoked the possibility of specific interactions between the sulfonate groups of the polymer and the SCO cation. One can assume that such interactions can lead to an effective dilution of the complex within the matrix. Hauser et al. [13] conducted similar photophysical studies using the [Fe(2mephen $\left.)_{3}\right]^{2+}$ complex embedded in PVAc (poly-vinyl-acetate) and Nafion films. PVAc was doped by the SCO cation by co-dissolving the two compounds in methanol and then let the solution dry on a glass slide. The Nafion films were simply immersed in an aqueous solution of the cation. The (very gradual) SCO properties of the complex were found not substantially affected by the polymer matrices, albeit the photo-physical properties of the composites indicated local inhomogeneities.

With a more technological motivation, Lee et al. [22] reported on processable composites, which consisted of a mixture of PMMA (poly(methyl methacrylate)) and different loadings of the complex $\left[\mathrm{Fe}(\mathrm{hptrz})_{3}\right] \mathrm{X}_{2}$ (hptrz= 4-heptyl-1,2,4-triazole; $\mathrm{X}=\mathrm{ClO}_{4}{ }^{-}, \mathrm{BF}_{4}{ }^{-}$or $\mathrm{Br}^{-}$) obtained from DMF solutions followed by vacuum distillation. Interestingly, the spin transition curves of the complexes in the composites remained relatively abrupt and the hysteresis widths even increased (vs. the bulk microcrystalline powders), despite the fact that x-ray diffraction analysis did not reveal any evidence of crystallinity in the composites. Later, the same authors mixed $\left[\mathrm{Fe}(\mathrm{ODT})_{3}\right](\mathrm{OTs})_{2}$ or $\left[\mathrm{Fe}(\mathrm{HET})_{3}\right](\mathrm{OTs})_{2}(\mathrm{ODT}=4$-octadecyl-1,2,4-triazole, HET = 4-(2hydroxyethyl)-1,2,4-triazole, OTs = p-toluenesulfonate ) with the liquid crystalline polymer poly(oxetane) (POx) in an effort to combine both magnetic and liquid crystal transitions in a multifunctional material.[23] Following vacuum drying of the THF solutions of the materials, they obtained composites where the temperatures of the different transitions (glass transition, spin transition and isotropisation) were lowered in comparison to the bulk materials. However, 
no interplay between these phenomena was reported. In an interesting study, Chen et al. [24] prepared a composite film by mixing precursors of $\left[\mathrm{Fe}\left(\mathrm{NH}_{2} \operatorname{trz}\right)_{3}\right]\left(\mathrm{ClO}_{4}\right)_{2}$ with PVP (polyvinylpyrrolidone) in ethanol. Due to the strong hydrogen bonds formed in between the amino groups of the complex and the carbonyl groups of the PVP, a microstructure consisting of a regular stripped pattern with $0.3 \mathrm{~nm}$ inter-line distance is formed, which can be clearly seen in the transmission electron microscopy images of the composite film (

Figure la-b). Based on X-ray diffraction (XRD), infrared (IR) spectroscopy and X-ray photoelectron spectroscopy (XPS) analyses, they concluded that this structure consists of the PVP chains aligned along the Fe-aminotriazole chains in a hexagonal lattice due to the hydrogen bonds between the triazole and the PVP. This microstructure is not observed when the film is prepared with the similar complex with the Htrz ligand for which the hydrogen bonds are not feasible. This suggests that strong hydrogen bond interactions between the polymer and the SCO complex are essential for obtaining a regular structure. Remarkably, the spin transition in the composite (vs. the bulk complex) is significantly shifted towards room temperature from 210 to $250 \mathrm{~K}$ and a ca. $6 \mathrm{~K}$-wide hysteresis is also observed (

Figure 1c). These results open up interesting perspectives for the investigation of Fe-triazole compounds in different supramolecular arrangements.

Figure 1. a) Schematic representation of the PVP - Fe-aminotriazole composite where the blue dashed lines represent the hydrogen bonds. b) TEM image of the composite film with regular striped patterns. c) Temperature dependent magnetic behavior of the composite.[24]

Following a 'polymer science methodology', Rubio et al. [25] studied the effect on the physical properties of isotactic polystyrene (i-PS) when $\left[\mathrm{Fe}(\mathrm{ODT})_{3}\right]\left(\mathrm{ClO}_{4}\right)_{2}(0.5-5 \mathrm{w} \%)$ is dispersed in it. Blend films of different composition were nrenared hv mixing homnoenenus toluene colutinn

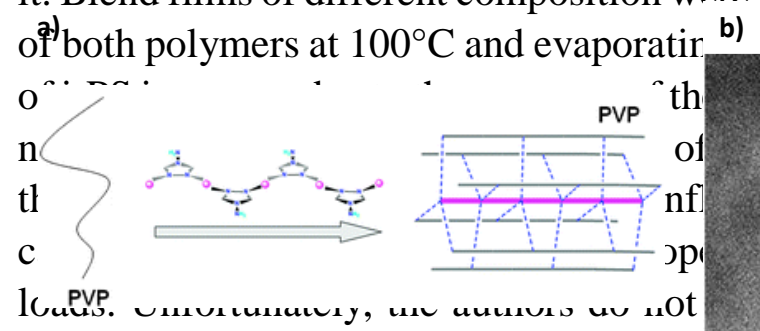

further study, Echeverria et al. [26] preptomen vicurnospun nod

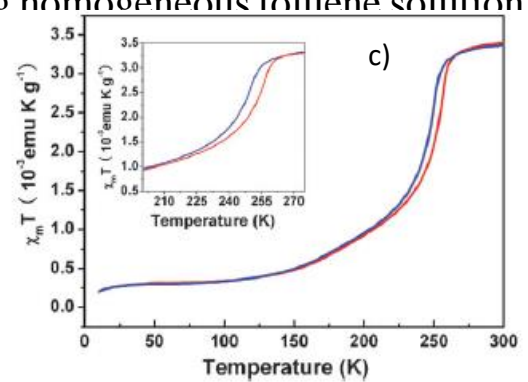

with $\left[\mathrm{Fe}(\mathrm{ODT})_{3}\right]\left(\mathrm{ClO}_{4}\right)_{2}$ for which they observed the formation of ca. $3 \mu \mathrm{m}$ diameter fibers for loadings of the complex up to $13.5 \mathrm{w} \%$. Yet, for increasing concentration of the complex the appearance of the fibers becomes less uniform. The magnetic behavior of the composite with a $13.5 \mathrm{w} \%$ SCO loading is similar to the bulk material and the glass transition temperature of the polymer remain nearly unchanged. The authors report also on structural changes in the SCO 
complex above room temperature - similar to the behavior previously reported for the isotactic polystyrene blends.[25]

Basak et al. [27] used also PS to embed a micro-patterned film of the SCO complex [Fe(Oct$\left.\mathrm{BPP})_{2}\right]\left(\mathrm{BF}_{4}\right)_{2}(4,4$ "-dioctyl 2',6'-bispyrazolylpyrine) within a flexible polymer film. First, they prepared a thin film of PS by drop casting $(1.2 \mathrm{~cm} \times 1.5 \mathrm{~cm} \times 5-6 \mu \mathrm{m})$ and then on top of it a rectangular stripe of the SCO complex was fabricated by lithographic patterning using a PDMS (polydimethylsiloxane) stamp, followed by spin coating a PS solution in top of the SCO layer. This resulted in a flexible polymer film in which the embedded SCO grating shows optical diffraction phenomena (Figure 2). Unfortunately, the authors do not report on the SCO properties of the micro-patterned material.
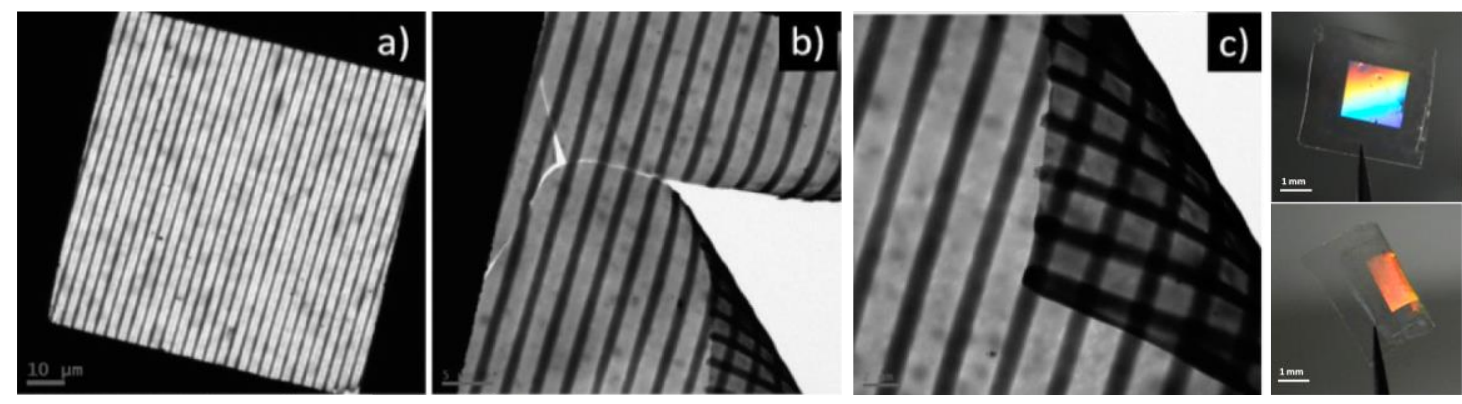

Figure 2. TEM images of regular stripes of the $\mathrm{SCO}$ complex $\left[\mathrm{Fe}(\mathrm{Oct}-\mathrm{BPP})_{2}\right]\left(\mathrm{BF}_{4}\right)_{2}$ embedded in a polystyrene film $(a, b, c)$ and photographs showing the flexibility of the thin film.[27]

Thin films (5 - 20 micron thick) of PMMA with 2, 4 and 8\% wt. loading of the valence tautomeric complex [Co $\left.{ }^{\mathrm{III}}(\mathrm{Cat}-\mathrm{N}-\mathrm{SQ})(\mathrm{Cat}-\mathrm{N}-\mathrm{BQ})\right]$ (Cat-N-BQ $=2$-(2-hydroxy-3,5-ditertbutylphenyl-imino)-4,6-ditert-butylcyclohexa-3,5-dienone and Cat-N-SQ is the dianionic radical analogue) were prepared and the spin crossover associated with the valence tautomerism was demonstrated.[28] Compared to a related toluene solution, the best interconversion was obtained with a $2 \%$ wt. loading while at $4 \%$ wt. the HS state is favored and at $8 \%$ only the HS state is observed. This was explained by the crystallization of the complex at concentrations above $2 \%$. An important remark for this system is that when heated above the glass transition temperature $\left(\mathrm{T}_{\mathrm{g}}=395 \mathrm{~K}\right)$, followed by slow cooling, the complex is allowed to crystallize in the polymer matrix. As the HS isomer is also stabilized in the crystalline form, this results in an irreversible transition. However, if the temperature of the film is kept below $\mathrm{T}_{\mathrm{g}}$, then the transition is reversible upon several cycles (Figure 3).
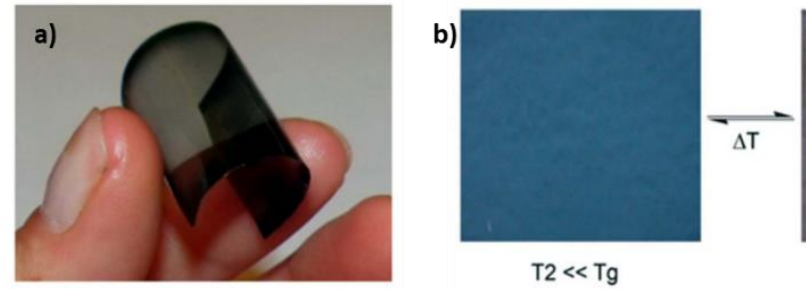

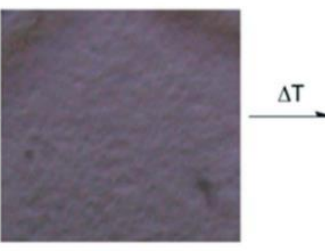

$\mathrm{T} 1$

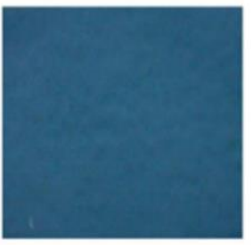

$\mathrm{T} 3 \gg \mathrm{Tg}$

Figure 3. a) Flexible PMMA thin film with $2 \%$ wt. of $\left[\mathrm{Co}^{\mathrm{III}}(\mathrm{Cat}-\mathrm{N}-\mathrm{SQ})(\mathrm{Cat}-\mathrm{N}-\mathrm{BQ})\right]$; b) photographs of a thin film representing the reversible and irreversible color change at different temperatures.[28] 


\subsubsection{Adsorption into a matrix}

This approach is developed mostly using ionomers, i.e. polymers with ionic properties (often with sulfonate, carboxylate or amino groups), which allow for the immobilization of SCO complexes or their precursors by electrostatic interactions using simple impregnation methods.

As mentioned above, Hauser et al. [13] used Nafion in which the sulfonic acids of the Nafion film acted as counter-anions for the $\left[\mathrm{Fe}(2-\text { methyl-1,10-phenanthroline })_{3}\right]^{2+}$ complex. Later on, the group of Kojima carried out a more "material-oriented" investigation of various SCONafion composites.[29-34] By a simple two-step impregnation method (first into the solution of the metal ion and then into the ligand solution), they elaborated $\mathrm{Fe}^{\mathrm{II}}(\mathrm{Htrz})_{3}-\mathrm{Nafion}$ films, providing the polymeric backbone to the final complex as shown in Figure 4a. Nafion is well known to form reverse micelles, that consist of clusters of about $4 \mathrm{~nm}$ in diameter and are separated by a distance of about $5 \mathrm{~nm}$.[35,36] It is inside these clusters that the $\mathrm{Fe}^{\mathrm{II}}(\mathrm{Htrz})_{3}$ species are likely located. The group of Kojima studied the temperature dependence of the magnetic susceptibility for the complexes $\mathrm{Fe}^{\mathrm{II}}(\mathrm{Htrz})_{3}$-Nafion and $\mathrm{Fe}^{\mathrm{II}}\left(\mathrm{NH}_{2} \text { trz }\right)_{3}$-Nafion. [29] In both cases, they observed a very gradual spin crossover below room temperature with halftransition temperatures $\left(\mathrm{T}_{1 / 2}\right)$ of $260 \mathrm{~K}$ and $198 \mathrm{~K}$, respectively (Figure $4 \mathrm{~b}$ ). Fe K-edge EXAFS spectra proved the presence of the linear Fe chain structure in the film.[30] They also investigated the photoinduced effects on the $\mathrm{Fe}^{\mathrm{II}}(\mathrm{Htrz})_{3}-\mathrm{Nafion}$ film by irradiating it at 514.5 $\mathrm{nm}$, which is close to the ${ }^{1} \mathrm{~A}_{1 \mathrm{~g}} \rightarrow{ }^{1} \mathrm{~T}_{1 \mathrm{~g}}$ absorption maximum $(540 \mathrm{~nm})$. They could observe the LIESST effect at $4.2 \mathrm{~K}$ and provided details on the relaxation kinetics of the photo-induced HS state back to the LS ground state.[30-32] The Mössbauer spectra of the composite films revealed that as much as $40 \% \mathrm{HS}$ species remains unconverted even at $10 \mathrm{~K}$. This was attributed to the (presumably) large number of terminal Fe(II) sites in the small oligomers formed in the Nafion clusters. [33] The Debye temperature $\left(\Theta_{\mathrm{D}}\right)$ for the HS and LS states were estimated from the Mössbauer spectra, resulting in $185 \mathrm{~K}$ for the LS and $176 \mathrm{~K}$ for the HS forms in the temperature range between 10 and $150 \mathrm{~K}$. Above $150 \mathrm{~K}$, $\Theta_{\mathrm{D}}$ becomes small (ca. $50 \mathrm{~K}$ ) due to the glass transition exhibited by the Nafion at 180 K.[34] Surprisingly, this relatively abrupt change of the Debye temperature does not appear to have an obvious impact on the spin transition properties of the complexes (Figure 4b). Later on, Kamebuchi et al. [37] replaced the iron-triazole complex by $\mathrm{Fe}^{\mathrm{II}}$ (diAMsar) (diAMsar = 1,8-diaminosarcophagine) in the Nafion film, providing a $\mathrm{pH}$ dependent SCO complex. Under acidic conditions, the amino groups of diAMsar are protonated resulting in an electrostatic repulsion between the ligand and the iron center leading to the absence of SCO properties. Under basic conditions at room temperature the LS state is stabilized, whereas at $\mathrm{pH}=7$, the HS state is stabilized. 
a)
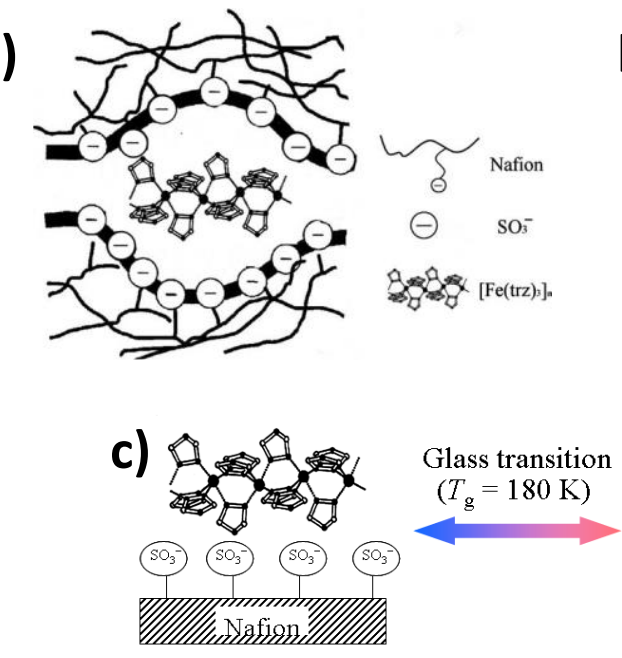

Below $180 \mathrm{~K}$ b)
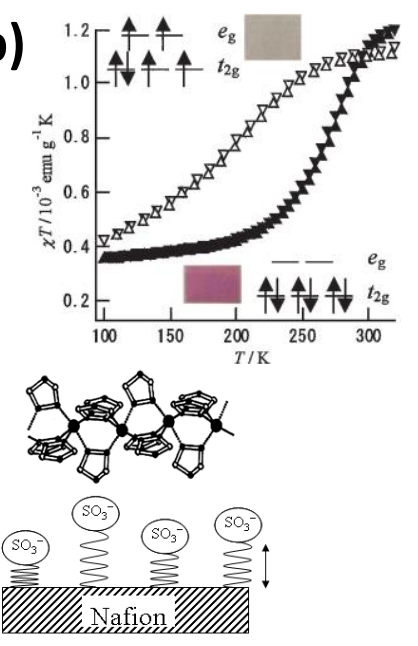

Above $180 \mathrm{~K}$

Figure 4. a) Representation of $\mathrm{Fe}^{\mathrm{II}}(\mathrm{Htrz})_{3}$-Nafion complex; b)thermal variation of $\chi \mathrm{T}$ for $\mathrm{Fe}^{\mathrm{II}}\left(\mathrm{NH}_{2} \text { trz }\right)_{3}$-Nafion $(\diamond)$ and $\mathrm{Fe}^{\mathrm{II}}(\mathrm{Htrz})_{3}-\mathrm{Nafion}(\bullet)$; c) representation of $\mathrm{Fe}^{\mathrm{II}}(\mathrm{Htrz})_{3}-\mathrm{Nafion}$ before and after the glass transition. [30,32,34]

Vishnevskaya et al. [38] studied a $\mathrm{Fe}^{\mathrm{III}}$-formazan complex immobilized in the ion-exchange polymer AN-18-10P. They suggested immobilization occurs via ion exchange between the sulfo group of the ligand and the functional groups of the resin. Using EPR spectroscopy, they revealed the gradual spin crossover properties of the composite. Durand et al. [39] prepared mesoporous composite xerogels by immersing a previously prepared monolith of silica in an $\mathrm{Fe}\left(\mathrm{BF}_{4}\right)_{2}$ solution and then in a solution of the triazole ligand. Nanoparticles of the SCO complex were formed in the pores of the silica monolith with an average size of $3.2 \mathrm{~nm}$. Remarkably, despite the very small size of the particles, the magnetic behavior of the composite showed a partially reversible spin transition with a wide hysteresis $(375 \mathrm{~K}$ on heating and 310 $\mathrm{K}$ on cooling). The spin transition was confirmed by Mössbauer measurements, which revealed also that at $200 \mathrm{~K} 32 \%$ of the $\mathrm{Fe}^{\mathrm{II}}$ centers remain in the HS state. Onggo et al. prepared macrofilms ( $20 \mathrm{~cm}$ long, $20 \mathrm{~cm}$ wide and $4-5 \mathrm{~cm}$ thick) by using 'nata de coco' sheets - a food product used in Philippines, in which the major component is cellulose fibers also known as bacterial cellulose. To impregnate the sheets with the $\mathrm{SCO}$ complexes $\left[\mathrm{Fe}(\mathrm{Htrz})_{2}(\operatorname{trz})\right]\left(\mathrm{BF}_{4}\right)$ and $\left[\mathrm{Fe}\left(\mathrm{NH}_{2} \mathrm{trz}\right)_{3}\right]\left(\mathrm{BF}_{4}\right)_{2}$, their synthetic approach was based on immersing the starting films in an aqueous solution of $\mathrm{Fe}\left(\mathrm{BF}_{4}\right)_{2} \cdot 6 \mathrm{H}_{2} \mathrm{O}$ and later into a methanol solution of the corresponding triazoles. The formation of SCO complexes inside the film, favorized by the hydrophilic properties of 'nata de coco', was confirmed by a color change due to the spin transition of the composite. The SCO complexes formed rod-shaped particles with an average diameter of 100 $\mathrm{nm}$ and $0.5-1 \mu \mathrm{m}$ length, which filled the cavities of the sheets. The magnetic behavior of the SCO composites shows an abrupt spin transition, which matches quite well with the bulk SCO materials.[40,41] 
a)

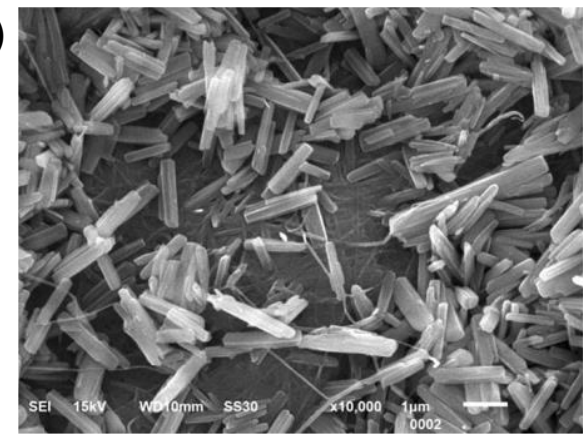

b)

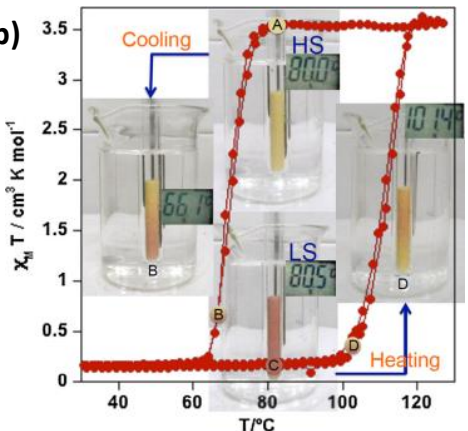

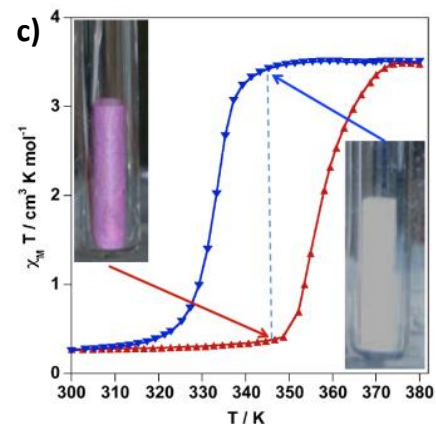

Figure 5. a) SEM image of a 'nata de coco' film containing [Fe(Htrz $\left.)_{2}(\operatorname{trz})\right]\left(\mathrm{BF}_{4}\right)$ particles (left). Magnetic measurements of the composite with b) $\left[\mathrm{Fe}(\mathrm{Htrz})_{2}(\operatorname{trz})\right]\left(\mathrm{BF}_{4}\right)$ and c) $\left[\mathrm{Fe}\left(\mathrm{NH}_{2} \mathrm{trz}\right)_{2}\right]\left(\mathrm{BF}_{4}\right)_{2} \cdot[41]$

Wang et al. [42] prepared nanorods of $\left[\mathrm{Fe}(\mathrm{Htrz})_{2}(\operatorname{trz})\right]\left(\mathrm{BF}_{4}\right)$ using a cation-exchange polymer resin, in which the sulfonate groups on the resin served as the nucleation sites for the growth of the anisotropic SCO particles. This was achieved by immersing the resin for different times in a solution of $\mathrm{Fe}\left(\mathrm{BF}_{4}\right)_{2}$ and then into a solution containing triazole and $\mathrm{NaBF}_{4}$, resulting in SCO@resin nanorods. The crystalline structure of the bulk SCO was maintained in the nanocomposite as inferred from XRD. The average length of the nanorods was ca. $250 \mathrm{~nm}$ for an immersion of $12 \mathrm{~h}$, which increased up to a length of $750 \mathrm{~nm}$ after $42 \mathrm{~h}$, reaching a saturation point. On the other hand, as shown in Figure 6, the spin transition behavior does not substantially change with the immersion time, albeit small differences occur. The spin transition temperature of the rods is similar to the bulk material, although less abrupt and with a larger hysteresis loop. The authors speculated the latter might be attributed to the close proximity among the SCO nanorods.
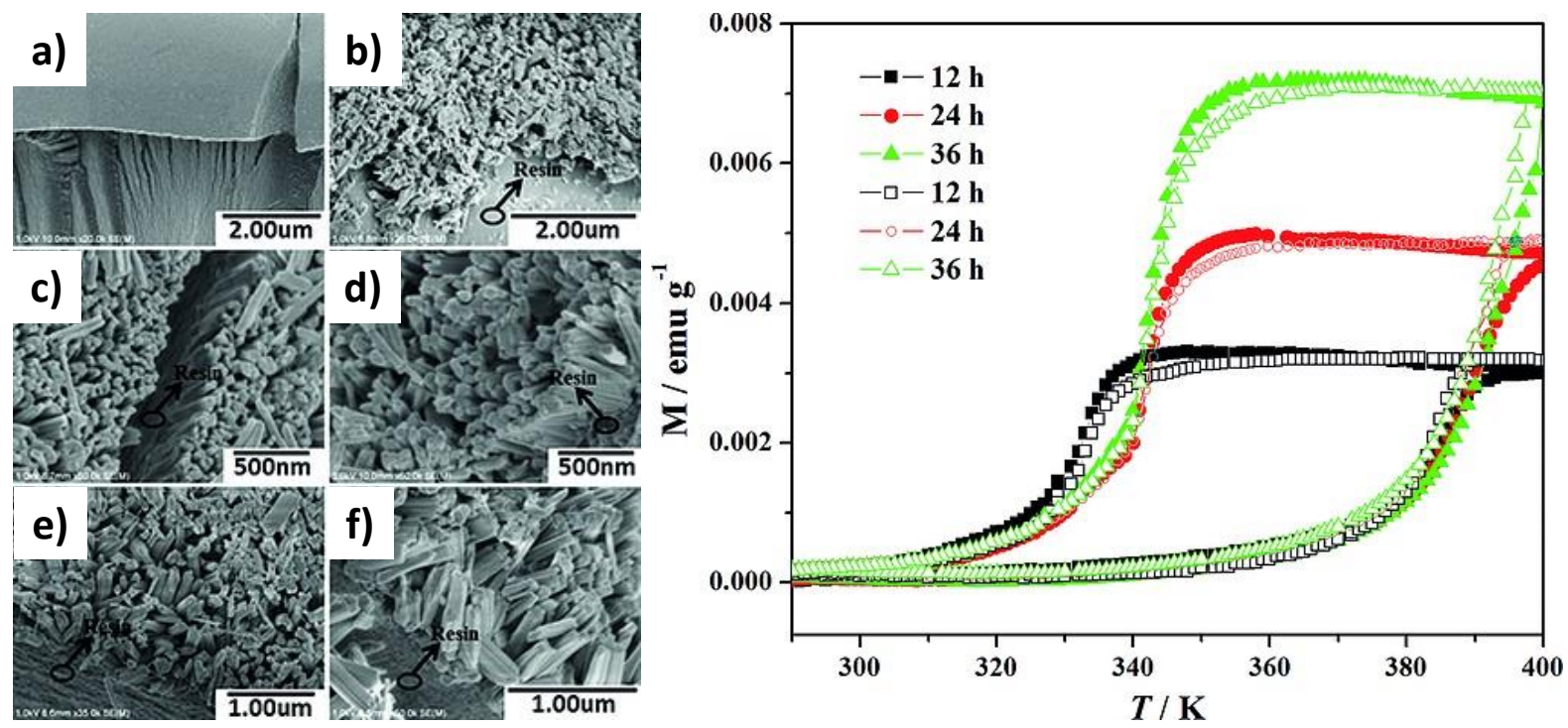

Figure 6. (left panel) SEM images of a) the blank resin and $\left[\mathrm{Fe}(\mathrm{Htrz})_{2}(\operatorname{trz})\right]\left(\mathrm{BF}_{4}\right)$ nanorod arrays with immersion times of b) 12 , c) 18 , d) 24 , e) 36 and f) $42 \mathrm{~h}$; (right panel) magnetic measurements of the SCO nanorods for different immersion times.[42]

Larionova et al. [43] reported the use of porous chitosan beads as a polymer matrix to obtain ultra-small nanoparticles (ca. $3.8 \mathrm{~nm}$ ) of the 3D spin crossover coordination polymer 
$\left[\mathrm{Fe}(\mathrm{pz})\left\{\mathrm{Ni}(\mathrm{CN})_{4}\right\}\right]$. They used a multi-step sequential assembly, which consisted of consecutive impregnations of the chitosan beads into methanol solutions of $\mathrm{Fe}\left(\mathrm{BF}_{4}\right)_{2} 6 \mathrm{H}_{2} \mathrm{O}$, pyrazine and $\left(\mathrm{N}\left(\mathrm{C}_{4} \mathrm{H}_{9}\right)_{2}\left[\mathrm{Ni}(\mathrm{CN})_{4}\right]\right.$ as depicted in Figure 7. Remarkably, the ultra-small particles displayed a well reproducible spin transition with a pronounced hysteresis near room temperature, albeit this transition remained rather incomplete.

a)
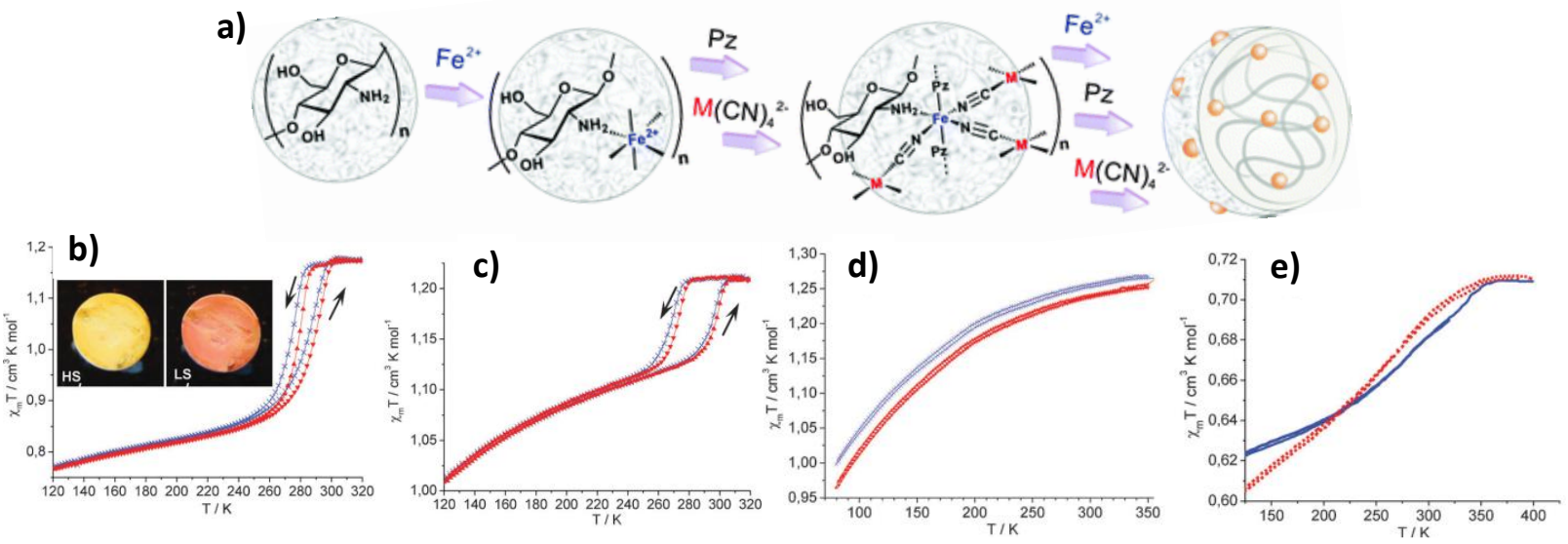

Figure 7. a) Schematic representation of the synthesis of the Hoffman-like clathrates $\left[\mathrm{Fe}(\mathrm{pz})\left\{\mathrm{M}(\mathrm{CN})_{4}\right\}\right]$ within chitosan beads. Thermal variation of $\chi \mathrm{T}$ for the nanocomposite $\left[\mathrm{Fe}(\mathrm{pz})\left\{\mathrm{M}(\mathrm{CN})_{4}\right\}\right]$-chitosan beads for b) $\mathrm{M}=\mathrm{Ni}$; c) $\mathrm{M}=\mathrm{Pd}$; d) $\mathrm{M}=\mathrm{Pt}$ and e) a nanocomposite film of $\left[\mathrm{Fe}(\mathrm{pz})\left\{\mathrm{Ni}(\mathrm{CN})_{4}\right\}\right]$-chitosan.[44]

Later on, the same authors [44] synthesized a series of nanocomposites using not only chitosan, but also alginate beads for hosting particles of the complexes $\left[\mathrm{Fe}(\mathrm{pz})\left\{\mathrm{M}(\mathrm{CN})_{4}\right\}\right](\mathrm{M}=\mathrm{Ni}, \mathrm{Pd}$, $\mathrm{Pt})$. In this case, they dried the chitosan composites either in vacuum to obtain hydrogels or under $\mathrm{CO}_{2}$ supercritical conditions obtaining aerogels, resulting in chitosan composites with an estimated amount of $35 \%$ wt for $\mathrm{Ni}, 18 \%$ wt for Pd and $16 \%$ wt for Pt of the immobilized complex and an average particle size of $2.8 \mathrm{~nm}$ for chitosan composites and $3.2 \mathrm{~nm}$ in the case of alginate. The chitosan beads were then dissolved in water at $70{ }^{\circ} \mathrm{C}$ and then placed in a petri dish for slow evaporation of the water resulting in a yellow film. In the nanocomposites, the ultra-small SCO particles are homogeneously distributed within the pores of the beads. In the magnetic measurements for the chitosan composites of $\mathrm{Ni}$ and $\mathrm{Pd}$ an abrupt spin transition is observed with a smaller hysteresis loop compared to the bulk analogues, whereas for the chitosan composite of $\mathrm{Pt}$ and the alginate composite of $\mathrm{Ni}$ a gradual and incomplete SCO transition is observed both for the beads and the film samples (Figure 7). Interestingly, Raman microspectroscopy indicated an almost complete spin transition for the chitosan composites with the Ni and Pd based compounds, whereas magnetic and Mössbauer measurements showed considerable residual fractions. This apparent discrepancy was explained by the presence of iron(II) species, which were not incorporated into the main coordination network resulting in an important SCO inactive fraction.

\subsubsection{Sol-gel method}

The sol-gel process is a widespread method for the fabrication of glassy and ceramic materials. In this process, a colloidal solution (sol) is formed, which evolves gradually towards a gel-like network from which the final form of the material is obtained using various drying and firing approaches. Common precursors are metal alkoxides and metal chlorides, from which the 
colloid is obtained by hydrolysis and poly-condensation reactions. In the context of SCO research, this method is particularly useful to synthesize SCO-silica composite materials, which can then be used for the fabrication of SCO-active films, coatings and other objects.

Faulmann et al. [45] prepared thin films and monoliths of the SCO complex $\left[\mathrm{Fe}(\mathrm{Htrz})_{2}(\mathrm{trz})\right]\left(\mathrm{BF}_{4}\right)$ by the hydrolysis of TMOS (tetramethoxysilane) or TEOS (tetraethoxysilane). After the gelation, the composite was aged during 2 days and then dried over a week at $\sim 40{ }^{\circ} \mathrm{C}$ resulting in well dispersed spherical SCO nanoparticles with a size range of 1-5 nm encapsulated in transparent silica films. The magnetic behavior of the composites showed an abrupt spin transition similar to the bulk material.

Voisin et al. [46] prepared a composite gel of sulfonate-functionalized $\mathrm{SiO}_{2}$ nanoparticles with the $\mathrm{SCO}$ complex $\left[\mathrm{Fe}\left(\mathrm{NH}_{2} \mathrm{trz}\right)_{3}\right]\left(\mathrm{SO}_{4}\right)$ by suspending the nanoparticles in a mixture of ethylene glycol : water (9:1) solution to which the iron salt and the ligand was added. After $20 \mathrm{~h}$, gelation occurred resulting in a white gel, which turned pink later. SEM images showed a good dispersion of the $\mathrm{SiO}_{2}$ nanoparticles in the matrix of the $\mathrm{SCO}$ gel, which is mostly composed of needles (Figure 8). Using freeze-fractured TEM, particle imprints are seen, indicating that the silica surface is physically interacting with the SCO coordination chains. Rheological studies conducted on the composite aged for 9 days, resulted in an average storage modulus (G') of 5-8 $\mathrm{kPa}$ and a loss modulus (G') of one order of magnitude less. The magnetic behavior of the composites showed a reversible and abrupt spin transition that is shifted to higher temperatures when compared to the pure SCO gel. In addition, a broadening of the hysteresis loop occurs. The authors observed that when drying both the SCO gel and the composite their SCO properties become comparable $\left(\mathrm{T}_{1 / 2} \uparrow=343 \mathrm{~K}, \mathrm{~T}_{1 / 2} \downarrow=329 \mathrm{~K}\right)$, but the spin transition shifts to higher temperatures when compared to their solvated counterparts. These results emphasize the sensitivity of the spin transition on multiple factors in such complex, multiphase systems.
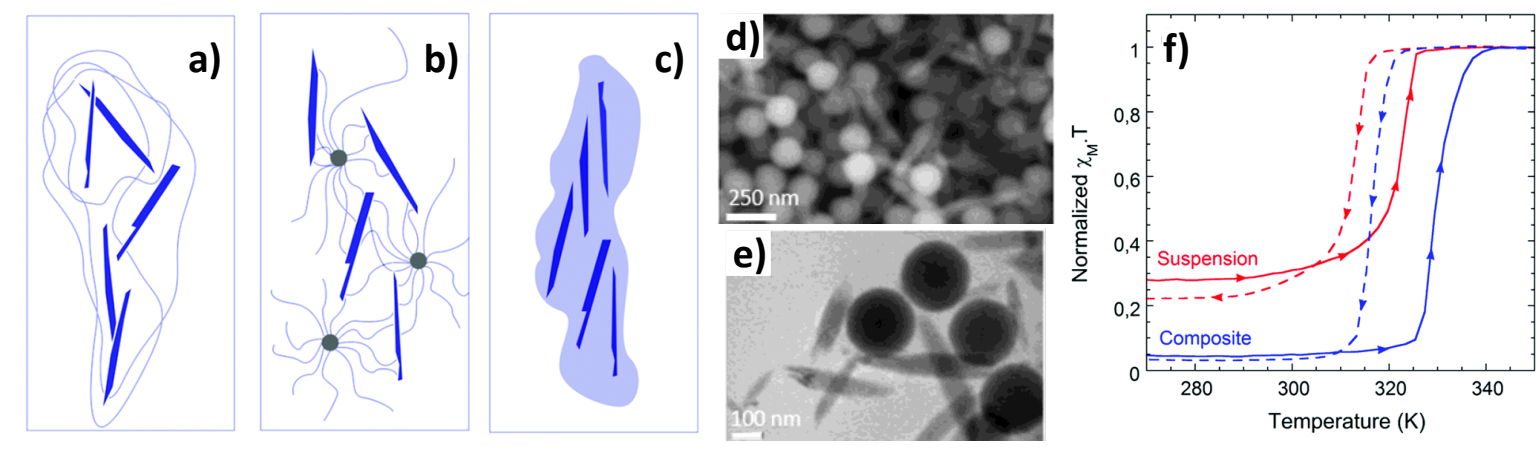

Figure 8. Schematic representation of a) the particle free suspension, b) composite gel NP$\mathrm{SiO}_{2} @ \mathrm{Fe} / \mathrm{NH}_{2}$ trz/SO $/ \mathrm{SO}_{4}$, c) dry particle free system. Composite gel NP-SiO${ }_{2} @ \mathrm{Fe} / \mathrm{NH}_{2}$ trz $/ \mathrm{SO}_{4}$ imaged by d) SEM-FEG and e) cryo-TEM; f) magnetic measurements of the composite gel NP$\mathrm{SiO}_{2} @ \mathrm{Fe} / \mathrm{NH}_{2} \mathrm{Trz} / \mathrm{SO}_{4}$ and the particle free suspension.[46]

Later on, the same authors [47] used the composite gel NP-SiO${ }_{2} @ \mathrm{Fe} / \mathrm{NH}_{2} \mathrm{Trz} / \mathrm{SO}_{4}$ [46] and casted it onto a PTFE (polytetrafluoroethylene) mold $(50 \times 25 \times 2 \mathrm{~mm})$, which was exposed to an alkoxysilane vapor in a closed desiccator to obtain a flexible macroporous hybrid silica network (Si@Si-SCO), which was eventually coated with PDMS (PDMS@Si@Si-SCO) (Figure 9). 
This way they obtained a flexible polymer nanocomposite material with PDMS protection, which provided long-term stability to the material ( $>80$ days), prevented its decomposition when immersed in hot water and allowed to preserve its SCO properties over $>15$ thermal cycles. Two parameters were essential to obtain a material with optimal mechanical properties: the nature of the alkoxysilane and the exposure time. Indeed, TMOS and TEOS produced a brittle solid, while DMDS (dimethyldimethoxysilane) or BTESE (1,2Bis(triethoxysilyl)ethane) or BTEB (1,4-Bis(triethoxysilyl)benzene) resulted in a viscous liquid. The best result was obtained for MTEOS (methyltriethoxysilane) for which a flexible solid was obtained. In addition, shorter or longer times of exposure resulted in inhomogeneous fragile gels that in some cases were oxidized with time. For more than 5 days of exposure, a homogeneous gel is obtained, with the best results after ca. 7 days of exposure. However, after 28 days, the material evolved in a brittle solid and the pink colour faded away, probably due to solvent expulsion, which could be prevented by coating it with PDMS. SEM images of the Si@Si-SCO composites showed needles and spherical nanoparticles located in the cavities of the macroporous silica matrix (Figure 9).

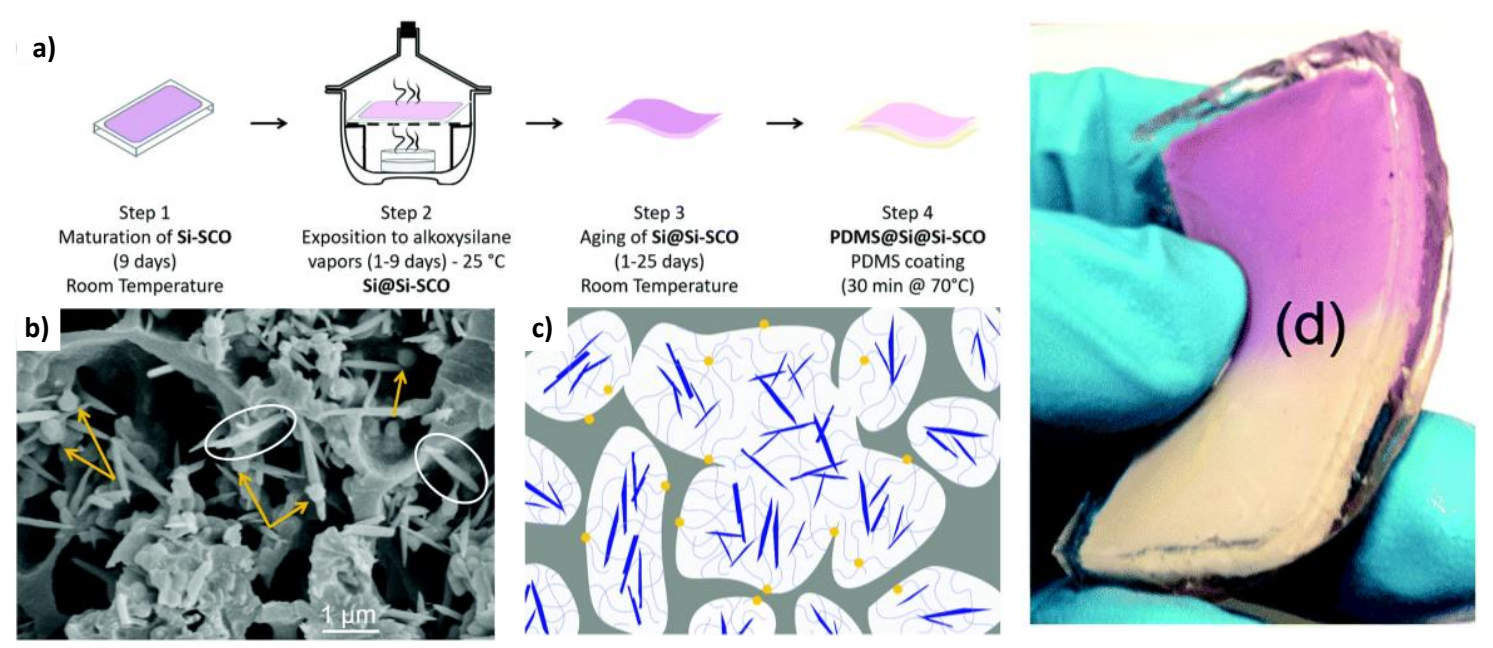

Figure 9. a) Scheme of the processing steps of PDMS protected silica-SCO nanocomposite material within silica network (PDMS@Si@Si-SCO); b) SEM image of Si@Si-SCO aged for 14 days; c) scheme of the structure of $\mathrm{Si} @ \mathrm{Si}-\mathrm{SCO}$ where the grey background represents the organosilica matrix, the yellow disks the silica NPs, the dark blue needles the crystalline SCO objects and the light purple lines the amorphous SCO network.[47]

\subsubsection{Liophilization}

Kuroiwa et al. combined a cobalt(II)-terpyridine [48] as well as the [Fe(ppi) $\left.)_{2}(\mathrm{NCS})_{2}\right](\mathrm{ppi}=\mathrm{N}-$ phenyl-2-pyridinalimine) [49] SCO complex with diblock copolypeptydes amphiphiles composed only of glutamic acid and leucine, in which the carboxylate in the glutamic residue is the counter-anion of the SCO complex (Figure 10). They were prepared by simply mixing the copolypeptide and the desired complex in solution, following a precipitation and lyophilization. 

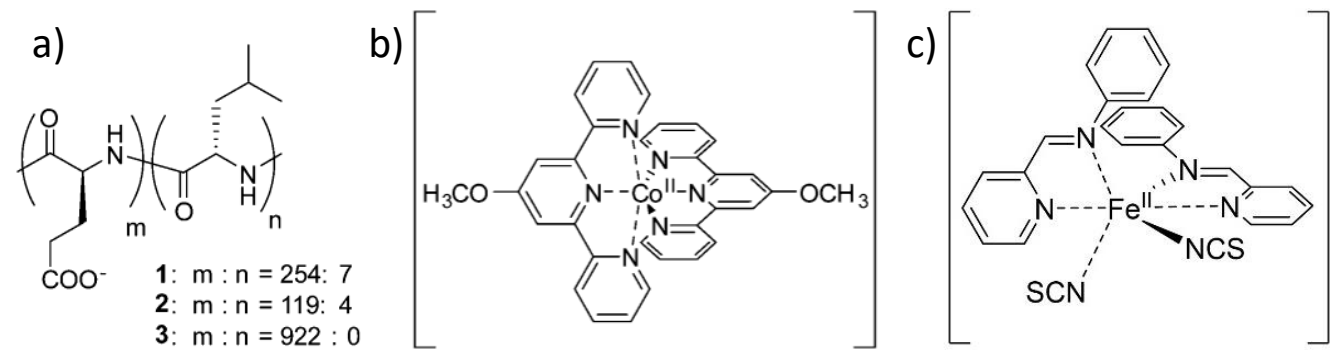

Figure 10. a) Copolypetides used as counter-anions for b) cobalt(II)-terpyridine and c) $\left[\mathrm{Fe}(\mathrm{ppi})_{2}(\mathrm{NCS})_{2}\right] .[48,49]$

For the terpyridine complex, structures with width of 0.5 to $2 \mu \mathrm{m}$ were observed by TEM except when using the polypetide without leucine. Interestingly, all the terpyridine complexes showed reverse spin transition after annealing $\left(\mathrm{T}_{1 / 2} \downarrow \approx 260 \mathrm{~K}, \mathrm{~T}_{1 / 2} \uparrow \approx 345 \mathrm{~K}\right)$ - indicative of a structural phase transition. When using the $\mathrm{Fe}^{\mathrm{II}}$ complex, a gradual SCO behavior that was completely reversible only for one of the copolypeptides was observed by UV-Vis in water solution. It was suggested that the composites in solution are composed of nanostructures consisting in cylindrical and spherical structures at $5{ }^{\circ} \mathrm{C}$, and lamellar structures at $60{ }^{\circ} \mathrm{C}$. The authors proposed a packing of $1 \mathrm{D}$ or $2 \mathrm{D}$ sheets among the metallic complexes, which is in agreement with previous crystallographic data obtained for both complexes and the supramolecular arrangement of both the glutamic acid and leucine in their corresponding $\beta$-sheets forms.

\subsection{Dispersion of SCO particles in polymer matrices}

Mixing polymers with preformed SCO powders (including both micro- and nanocrystals, nanorods, etc.) provides obviously the advantage of better control over particle morphology and SCO properties. In addition, feebly soluble SCO compounds can be also processed. On the other hand, particle aggregation may be an issue in particular for their integration and their homogeneous distribution in the composite materials.

\subsubsection{Drop casting}

Drop casting has been employed at several instances as a simple means to obtain functional SCO particle - polymer composites, which can be used as mechanical actuators, optical sensors or smart papers.

In 2013, Shepherd et al. reported on a SCO-polymer composite based bilayer mechanical actuators of PVP and PMMA, the latter with different SCO particle loadings. [50] It was shown, for the first time that the strain associated with the spin transition can be used to produce useful mechanical work. Later, the same group investigated more in detail PMMA $\left[\mathrm{Fe}(\mathrm{trz})(\mathrm{Htrz})_{2}\right]\left(\mathrm{BF}_{4}\right)(10-50 \%$ wt.) composite films in combination with a silver-based conducting polymer composite layer. The latter film was used for the electrothermal actuation of the device. Upon Joule-heating, a switching from the LS to the HS state was observed accompanied by the bending of the bilayer cantilever with frequencies up to a few $\mathrm{Hz}$ over a few hundreds of actuating cycles without noticeable fatigue (Figure 11). This 'artificial muscle' device showed a volumetric work density of ca. $150 \mathrm{~mJ} . \mathrm{cm}^{-3} .[51]$ 

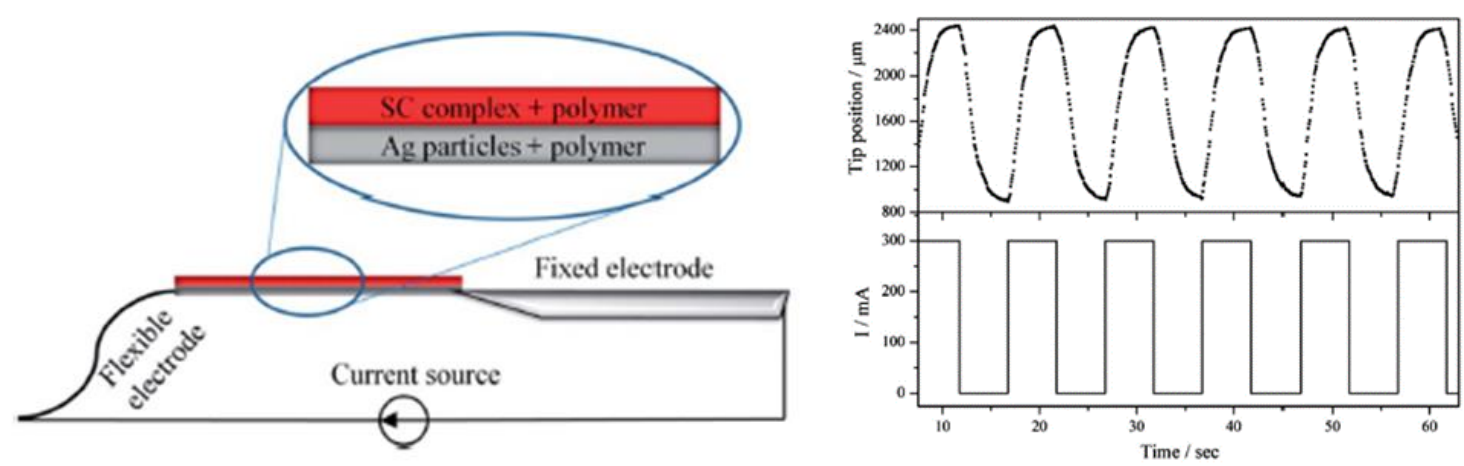

Figure 11. Schematic representation of a bilayer SCO-polymer composite cantilever with electrothermal actuation and the experimentally observed variation of the cantilever tip position (in ambient conditions) upon the application of an alternating current.[51]

Using a similar approach, Chen et al. [52] prepared a bilayer device consisting of a $\left[\mathrm{Fe}(\mathrm{Htrz})_{2}(\mathrm{trz})\right]\left(\mathrm{BF}_{4}\right) /$ Polycarbonate $(\mathrm{PC})$ composite layer and a piezoresistive layer. The mechanical stress induced by the SCO particles in the device gave rise to a change in the electrical resistance, which was detected through a Wheatstone bridge (Figure 12). Another example of the exploitation of the volume change associated with the spin transition in a polymer composite was described by Rat et al. [16] They dispersed nanoparticles $(\approx 20 \mathrm{~nm})$ of the SCO complex $\left[\mathrm{Fe}\left\{(\mathrm{Htrz})_{2}(\mathrm{trz})\right\}_{0.9}\left(\mathrm{NH}_{2} \mathrm{trz}\right)_{0.3}\right]\left(\mathrm{BF}_{4}\right)_{1.1}$ in the ferroelectric poly(vinylidene fluoride-co-trifluoroethylene) $\mathrm{P}(\mathrm{VDF}-\mathrm{TrFE}) 70-30 \%$ copolymer matrix. In this composite, the large strain associated with the spin transition is expected to give rise to an electrical response (voltage or current) due to the piezoelectric properties of the polymer matrix. Macroscopic freestanding films of the composite were first poled and then thermally cycled under shortcircuit conditions. Around the spin transition temperatures, they displayed current discharge peaks, showing the effective coupling between the SCO and piezoelectric properties. Further work [20] allowed for tuning concomitantly the spin transition temperature of the filler and the Curie temperature of the copolymer in such a way that the piezoelectric effect from the spin transition and the intrinsic pyroelectric response of the polymer could be concomitantly observed (Figure 13), providing prospects for thermal energy harvesting applications.
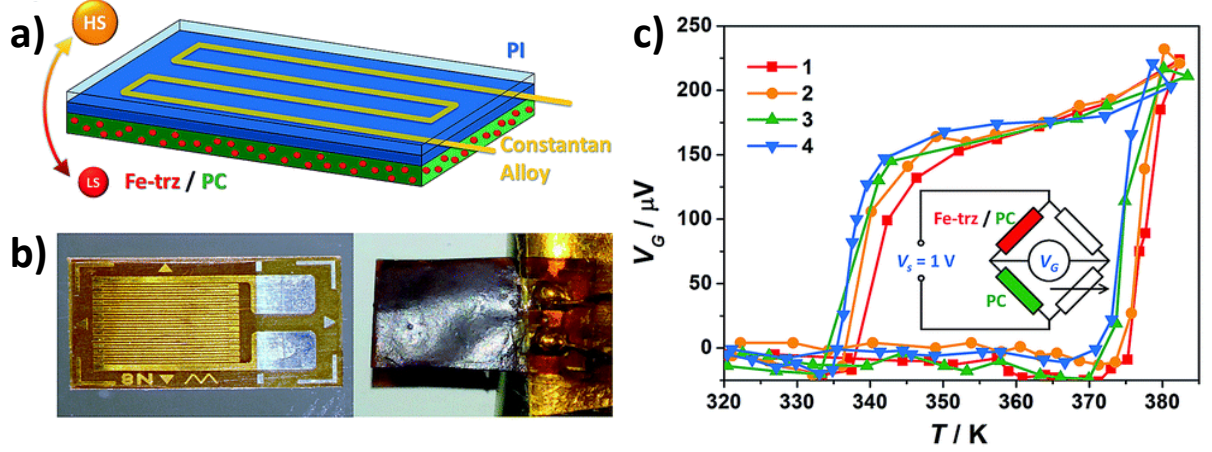

Figure 12. a) Schematic structure of the bilayer SCO-piezoresistive cantilever and (b) photos of the prefabricated polyimide/constantan alloy/polyimide stress-sensitive plate before (left) and after (right) drop-casting of the SCO-active composite. c) Bistable voltages of the Wheatstone bridge upon 4 thermal cycles.[52] 

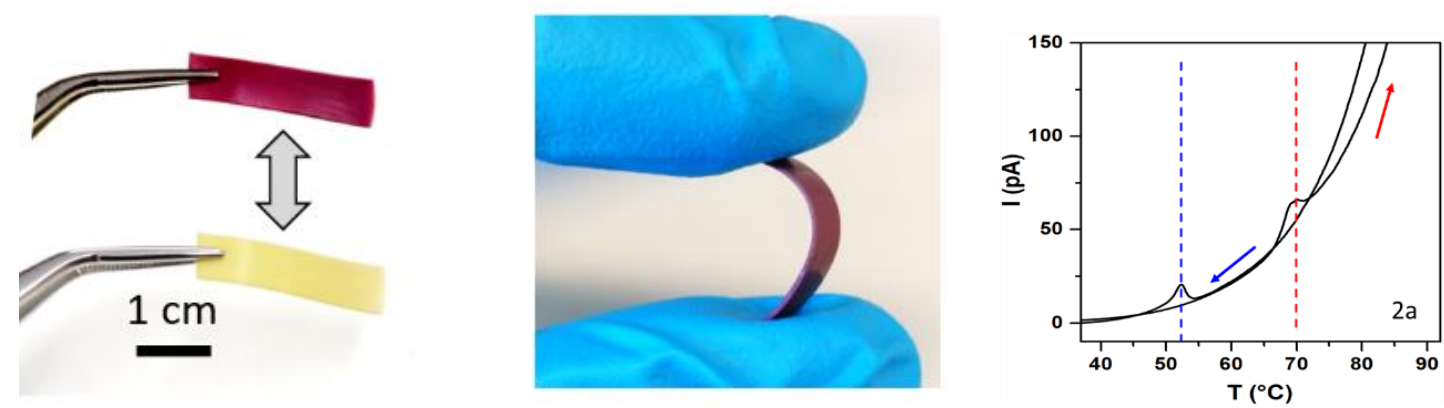

Figure 13. (a) Photographs of a freestanding SCO-P(VDF-TrFE) composite film. (b) Pyroelectric discharge cycle for a polarized SCO- P(VDF-TrFE) composite film ( $25 \mathrm{w} \%)$ when short-circuited through an electrometer. The arrows indicate heating and cooling. Dotted lines show the SCO-related discharge peaks for cooling (left) and heating (right). [16,20]

Thermochromic thin films of $\left[\mathrm{Fe}\left(\mathrm{NH}_{2} \mathrm{trz}\right)_{3}\right]\left(\mathrm{BF}_{4}\right)_{2}$ particles in different polymer matrices were studied by Lapresta-Fernández et al.[53,54]. They evaluated the effect of the interaction of the particles with the polymer matrix via the color change of the composite. Significant differences were observed in terms of aggregation and clustering when using solvents and polymers of different polarity. For example, in the case of PMMA composites, the size of the clusters are reduced when they are prepared in THF, whereas aggregation of the nanocrystals is observed when they are prepared in toluene. In contrast, in the case of hydrophilic polymers such as Nafion or polyurethane-D6, fiber-shaped particles are observed. Notably, in the case of polyurethane- $\mathrm{D}_{6}$ the particles are needle-shaped with a width of $250-500 \mathrm{~nm}$ and several micrometers in length and differ with the large clusters of ca. $500 \mathrm{~nm}$ observed for the bulk sample. Such evolution of the material morphology in the different matrixes can explain the change in the SCO properties and was used as a tool to develop a colorimetric sensor array based on a photographic digital camera. [55] Vinogradova et al. [56] used $\left[\mathrm{Fe}\left(\mathrm{NH}_{2} \mathrm{trz}\right)_{3}\right]\left(\mathrm{NO}_{3}\right)_{2}$ particles embedded in polystyrene to prepare films with a thickness above $10 \mu \mathrm{m}$. The resulting composites retained the SCO properties of the bulk material showing different spin transition temperatures depending on the water content.[57] Figure 14 shows the magnetic properties of the composite in different experimental conditions: either in vacuum (i.e. dehydrated composite) where the spin transition shows a hysteresis of $27 \mathrm{~K}$, or after being exposed to ambient air for $15 \mathrm{~min}$ and measured in a sealed capsule, where the spin transition shows a hysteresis of $2 \mathrm{~K}$. The vapochromic behavior of these films were tested, by exposing them to $\mathrm{HCl}, \mathrm{HBr}+\mathrm{Br}_{2}, \mathrm{HBr}, \mathrm{HNO}_{3}$ and $\mathrm{NH}_{3}$ vapors resulting in drastic color changes (implying the decomposition of the composite), suggesting their possible application as single-use detectors. 

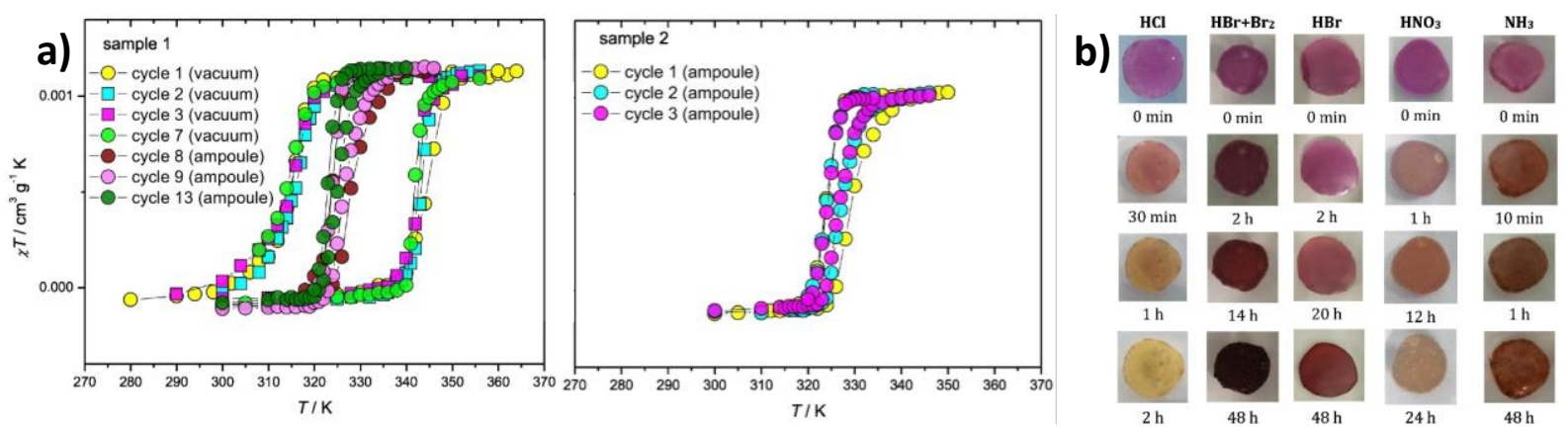

Figure 14. Magnetic properties of a PS - $\left[\mathrm{Fe}\left(\mathrm{NH}_{2} \mathrm{trz}\right)_{3}\right]\left(\mathrm{NO}_{3}\right)_{2} \cdot 0.5 \mathrm{H}_{2} \mathrm{O}$ composite (left) and vapochromic effect in the composite films (right).[56]

Nagy et al. [58] prepared linter cellulose nanocomposites from [Fe(hptrz $\left.)_{3}\right](\mathrm{OTs})_{2}$ nanoparticles doped with acridine orange dye, resulting in a thermochromic and thermofluorescent material. The SCO nanoparticles were randomly dispersed along the surface of the cellulose fibers stabilized electrostatically due to the interaction between the hydroxyl groups of the cellulose and the metal cations of the SCO complex. It is noteworthy that the nanocomposites were stable under air for several months and that no thermal quenching or photobleaching of the fluorescence was observed. Later on, the same group reported cellulose and [Fe(Htrz $\left.)_{2}(\mathrm{trz})\right]\left(\mathrm{BF}_{4}\right)$ nanocomposite sheets of $15 \mathrm{~mm}$ width and about $0.7 \mathrm{~mm}$ thickness. [59] These composites show better elongation, lower elastic modulus and higher resistance to stress when compared to normal cellulose sheets. They were able to print white patterns in the violet background of the composite sheets by heating it locally either with a focused laser beam (photothermal effect) or by a hot tip. Similarly, they could print violet patterns in the white background by local cooling. These patterns could be recycled (by erasing/rewriting through heating or cooling) over more than 100 times and they are stable upon storage at ambient conditions for long periods of time (at least 9 months) - providing scope for applications in rewritable papers. These cellulose composites with a 50\% wt. of the SCO complex were also investigate using dynamical thermomechanical analysis (DMA) and a ca. 10\% variation of the storage modulus between the LS and HS states could be detected [60].

\subsubsection{Electrospinning}

Electrospinning is an electrostatic (nano) fiber fabrication method, which uses polymer solutions, suspensions or melts. A simple setup consists of syringe needle, connected to a highvoltage power supply, a syringe pump and a grounded collector. This technique has been used to produce SCO-polymer composite fibers either from solutions [26] (see section 2.1.1) or from particle-polymer suspensions. The latter approach was used by Dreyer et al. [61] who prepared electrospun fibers from polylactic acid and $\left[\mathrm{Fe}(\mathrm{Htrz})_{2}(\mathrm{trz})\right]\left(\mathrm{BF}_{4}\right)$ or $\left[\mathrm{Fe}\left(\mathrm{NH}_{2} \mathrm{trz}\right)_{3}\right]\left(\mathrm{BF}_{4}\right)_{2}$ particles using a SCO/polymer ratio of 5\% wt. They tested the SCO behavior of the composite fibers by Mössbauer spectroscopy showing that the spin crossover behavior was preserved in the final material, for which the LS state is stabilized at room temperature, unlike the bulk material.

\subsubsection{Spray coating}

Spray coating consists of depositing microdroplets (i.e., an aerosol) of the desired material on a surface by forcing the dissolved (or dispersed) material through a nozzle. This versatile 
method allows for fabricating smooth, homogeneous coatings with well-defined compositions, and geometries on various substrates.

Hellel et al. [62] spray coated $\left[\mathrm{Fe}\left(\mathrm{NH}_{2} \operatorname{trz}\right)_{3}\right] \mathrm{Br}_{2} \cdot 3 \mathrm{H}_{2} \mathrm{O}$ and $\left[\mathrm{Fe}\left(\mathrm{NH}_{2} \operatorname{trz}\right)_{3}\right]\left(\mathrm{NO}_{3}\right)_{2} \cdot \mathrm{H}_{2} \mathrm{O}$ particles with $\sim 1 \mu \mathrm{m}$ diameter on a polyester film. They then successfully induced the spin transition from the LS to the HS state of the SCO complex via IR laser-induced heating of the matrix by means of a $\mathrm{CO}_{2}$ laser $(\lambda=10.6 \mu \mathrm{m})$. With this technique, they were able to write the letters "CNRS" in the thin film in less than $1 \mathrm{~s}$ at room temperature. As long as the temperature of the film was kept within the hysteresis loop $\left(10{ }^{\circ} \mathrm{C}<\mathrm{T}<45^{\circ} \mathrm{C}\right)$ the stored information persisted. Spray coating was also used by Manrique-Juarez et al. to deposit a composite consisting of $\left[\mathrm{Fe}(\mathrm{H}-\mathrm{trz})_{2}(\mathrm{trz})\right]\left(\mathrm{BF}_{4}\right)$ nanoparticles $(\mathrm{ca} .85 \mathrm{~nm})$ in an epoxy-based photoresist (SU-8). The composite was spray-coated over silicon micro-cantilevers (MEMS) and crosslinked by UV light exposure and consequent baking steps. Intriguingly, the spin transition in this composite showed a large hysteresis of $59^{\circ} \mathrm{C}\left(\mathrm{T}_{1 / 2} \uparrow=113^{\circ} \mathrm{C}\right.$ and $\left.\mathrm{T}_{1 / 2} \downarrow=54^{\circ} \mathrm{C}\right)$, more than twice than that of the bulk material $\left(\mathrm{T}_{1 / 2} \uparrow \approx 105^{\circ} \mathrm{C}\right.$ and $\left.\mathrm{T}_{1 / 2} \downarrow \approx 82^{\circ} \mathrm{C}\right)$. Thermally-driven actuation of the cantilevers in the MEMS was observed, resulting in an abrupt bending at the temperature of the spin transition (Figure 15d) with a stable amplitude of actuation. The actuating behavior of these SCO-MEMS devices was evaluated in static as well as in dynamic modes and a considerable change of the resonance frequency was detected at the SCO. This composite was also spraycoated over a free-standing polyester film, to develop a macroscopic bilayer actuator as shown in Figure 15e-f. Six flower-petals were cut from the bilayer, in which a reversible opening and closing of the flower together with a color change was observed by thermal cycling. [63]
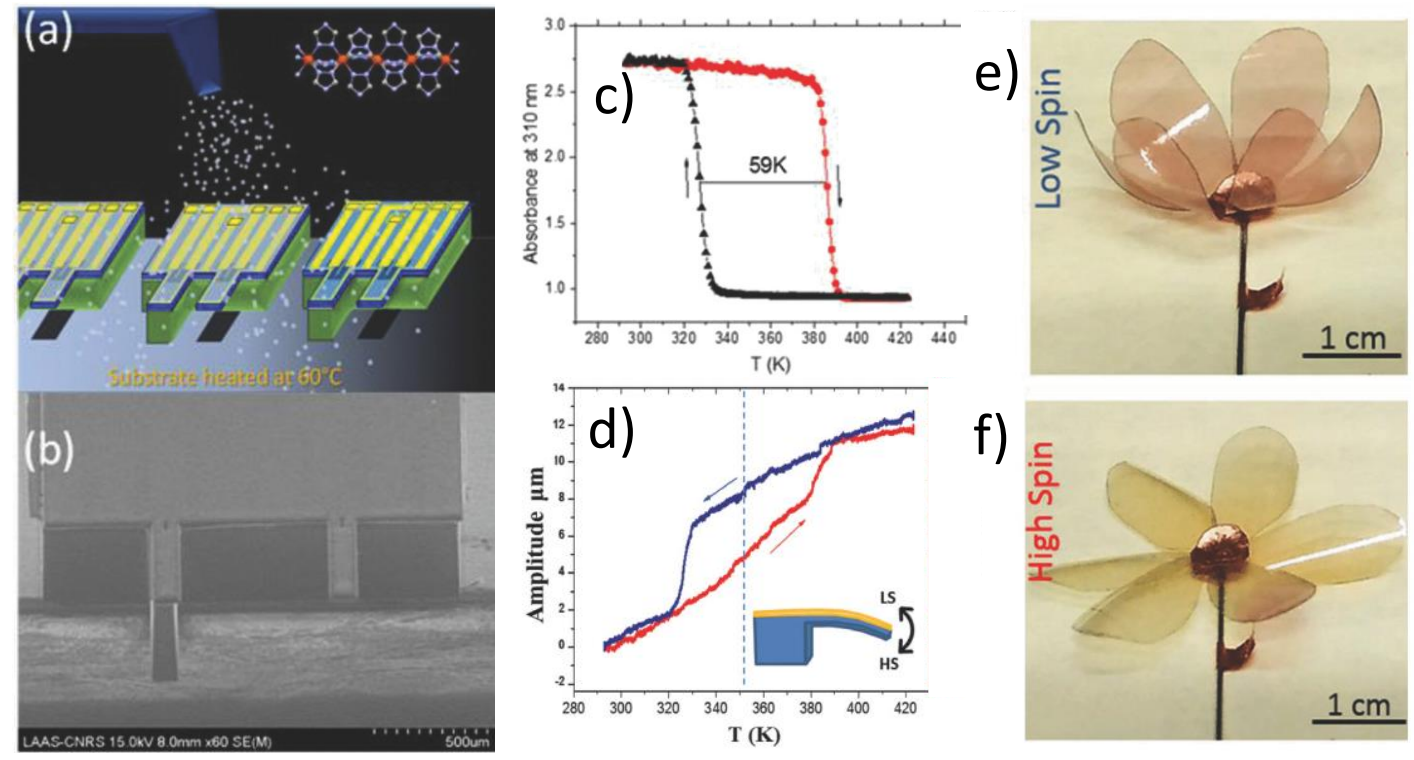

Figure 15. a) Scheme of spray-coating of an SCO-polymer composite on silicon microcantilevers, b) SEM image of the resulting MEMS, c) variable temperature UV absorption at $310 \mathrm{~nm}$ of the SCO/SU-8 composite, d) variable temperature actuation amplitude in the MEMS, e-f) macroscopic SCO/SU-8 actuator in the LS and HS states.[63]

\subsubsection{In-situ polymerization}

Suzuki et al. [64] studied the effect of PVA (poly(vinyl alcohol)) and SLS (sodium lauryl sulfate) as additives in the polymerization of TFEMA (trifluoroethylmethacrylate) mixed with 
$1 \%$ wt of a Fe(II)-triazole SCO complex. Microscopy analysis showed that the nanodispersed SCO complex, displaying bistability, was incorporated into the cores of polymer particles covered with PVA shells. SCO/ppy (polypyrrole) composite films with $\left[\mathrm{Fe}(\mathrm{H}-\operatorname{trz})_{2}(\operatorname{trz})\right]\left(\mathrm{BF}_{4}\right)$ and $\left[\mathrm{Fe}\left(\mathrm{NH}_{2} \mathrm{trz}\right)_{3}\right]\left(\mathrm{SO}_{4}\right)_{2}$ were reported by $\mathrm{Koo}$ et al. [65] The composite materials were prepared by a two-step synthetic method. First, a chemical oxidation of the py monomer takes place in the presence of the polycrystalline powder SCO complex resulting in ppy-covered SCO particles. Then, the particles are sintered into a thick film $(\mathrm{ca} .60 \mu \mathrm{m})$ with an isostatic pressure of $0.62 \mathrm{GPa}$. The magnetic properties of the complexes in the composite film were identical to those in the bulk. Remarkably, a pronounced coupling between the conductivity of the polymer matrix and the SCO properties were observed in the composite films (Figure 16), with a thermal hysteresis loop of the electrical conductivity. A dynamic widening of the hysteresis at faster scan rates, without a significant fatigue after several cycles as well as a difference between $\sigma_{\mathrm{HS}}$ and $\sigma_{L S}$ of about $60 \%$ (for $\mathrm{BF}_{4}$ ) and $50 \%$ (for $\mathrm{SO}_{4}$ ) were also reported. The coupling was attributed to a piezoresistive effect due to the volume change of the SCO complex that takes place during the spin transition. Different parameters, such as the PPY/SCO ratio, the pressure applied during the sintering process, the thickness of the film etc. were shown to have an impact on the $\sigma_{H S} / \sigma_{L S}$ ratio. This work is the first example for strain-coupling of SCO to electroactive polymers (EPA) in a composite materials, with interesting perspectives for the development of sensors, actuators and energy harvesting devices.
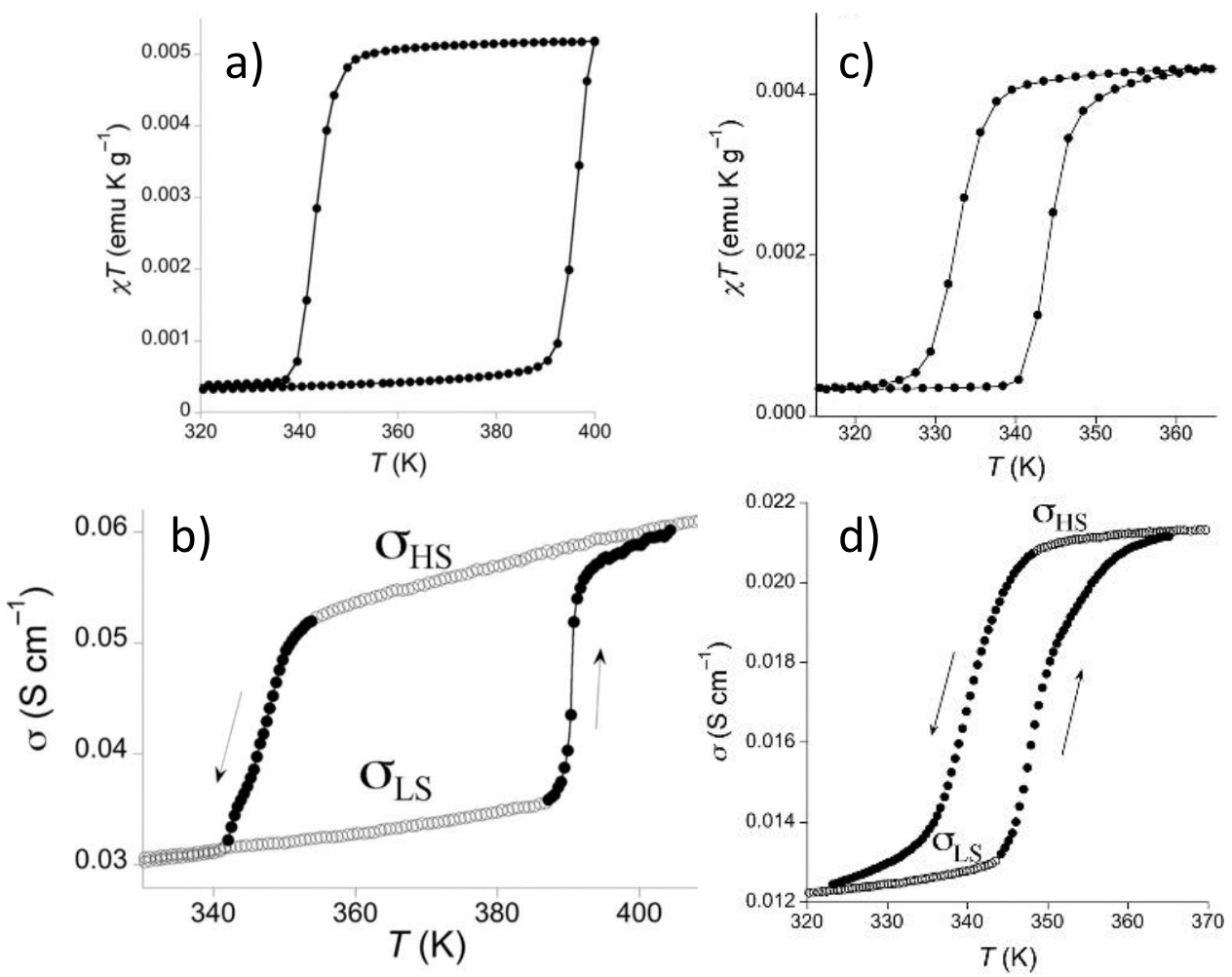

Figure 16. Variable temperature magnetic susceptibility and electrical conductivity data for ppy/SCO composites with a-b) $\left[\mathrm{Fe}(\mathrm{H}-\mathrm{trz})_{2}(\mathrm{trz})\right]\left(\mathrm{BF}_{4}\right)$ and c-d) $\left[\mathrm{Fe}\left(\mathrm{NH}_{2} \mathrm{trz}\right)_{3}\right]\left(\mathrm{SO}_{4}\right)_{2}$. [65]

\subsubsection{Electrochemically assisted self-assembly (EASA)}

Ahoulou et al. [66] observed that if the SCO complex $\mathrm{Fe}(\mathrm{Htrz})_{3}$ is used during the preparation of mesoporous silica thin films by EASA, it can act either as an additive when used at low 
concentrations $(\leq 3 \mathrm{mM})$ or as a template in higher concentrations $(5 \mathrm{mM})$. As a result, one may obtain either a vertically aligned mesostructure where the complex is incorporated with the surfactant species (low concentration) and can be removed by solvent extraction or a worm-like mesoporous film filled with the complex immobilized in the silica matrix (high concentration). This was confirmed by the cyclic voltammograms and from the XPS spectra of the mesoporous silica films before and after treatment with $\mathrm{HCl}$ to remove the complex. Interestingly, the film thickness is independent of the concentration of the complex. As observed from the TEM images (Figure 17), the films consisted of well-organized mesopore channels hexagonally packed and vertically aligned onto the electrode surface. Interestingly the film obtained at 5 $\mathrm{mM}$ showed no change in the cyclic voltammogram even after 20 consecutive cycles. Through the integration of the peak currents, the authors estimated that there are ca 110-120 complex units per mesopore in the film. As a potential application, they use the composite for the amperometric detection of hydrogen peroxide (Figure 17h), for which a linear response was observed in the concentration range of 1-160 $\mathrm{mM}$.
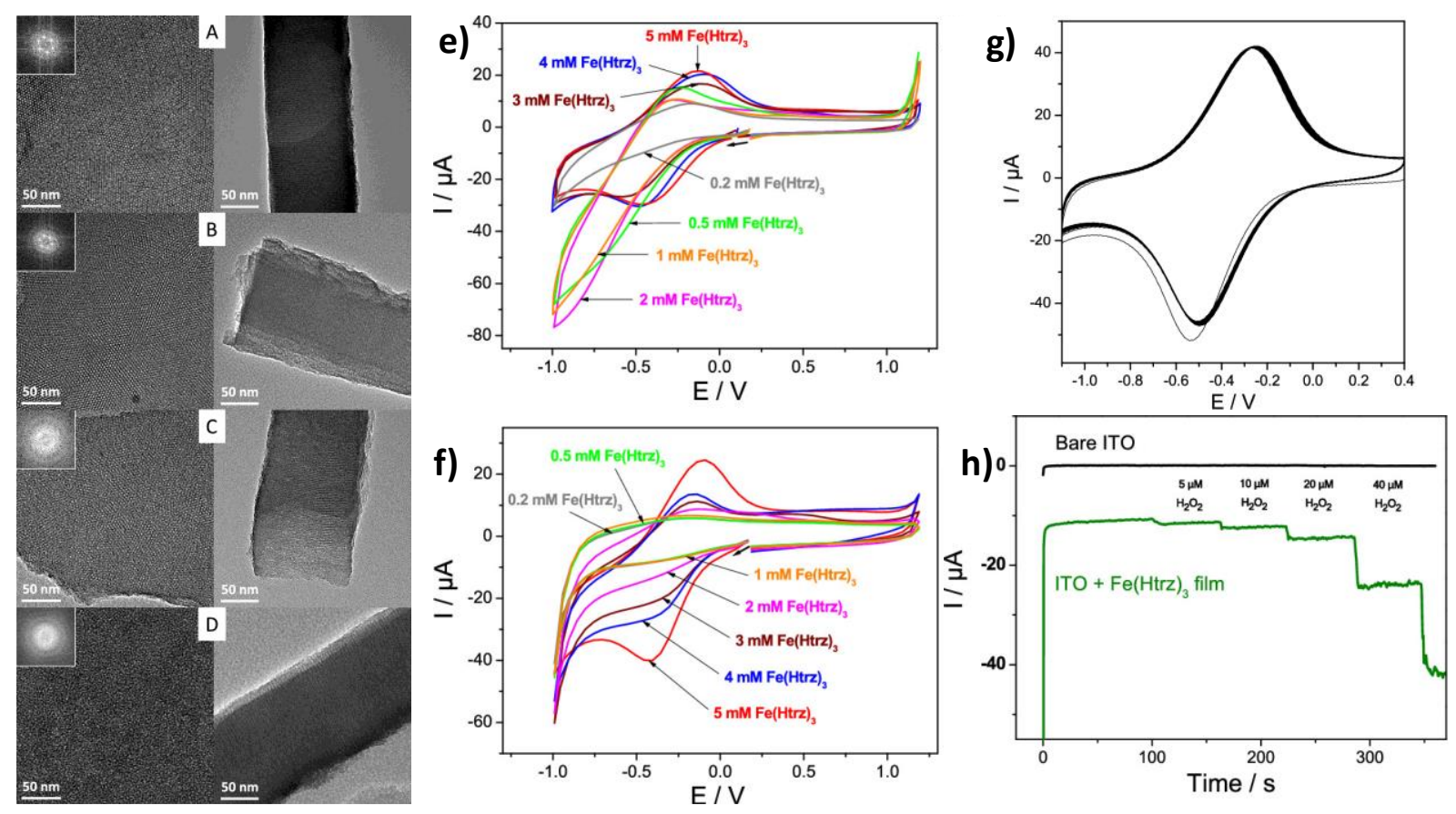

Figure 17. TEM images (top views on the left and cross-sectional views on the right) of the mesoporous silica films in the presence of increasing concentrations of $\mathrm{Fe}(\mathrm{Htrz})_{3}$ complex: 0.5 $\mathrm{mM}$ (A), $1 \mathrm{mM}$ (B), $3 \mathrm{mM}$ (C), and $5 \mathrm{mM}$ (D); Cyclic voltammograms of the mesoporous silica film-modified ITO electrodes prepared from a starting sol containing increasing concentrations of $\mathrm{Fe}(\mathrm{Htrz})_{3}$ complex before (e) and after (f) film treatment in $0.1 \mathrm{M} \mathrm{HCl}$ in ethanol; g) the 20 consecutive cycles for the film prepared with $0.5 \mathrm{mM}$; h) Amperometric responses of increasing concentrations of $\mathrm{H}_{2} \mathrm{O}_{2}$ for bare ITO and the film electrode prepared from $5 \mathrm{mM} \mathrm{Fe}(\mathrm{Htrz})_{3}$.[66]

\subsubsection{Matrix-assisted pulsed laser evaporation (MAPLE)}

MAPLE is a variant of pulsed laser deposition, which was developed to deposit thin films of soft and fragile materials. In the MAPLE approach, the target is a frozen solution or suspension of the desired material. Sawczak et al. [67] used the MAPLE technique to deposit nanocrystalline thin films of the SCO complex $\left[\mathrm{Fe}(\mathrm{pz}) \mathrm{Pt}(\mathrm{CN})_{4}\right]$ impregnated with polyethylene glycol (PEG). They used a cryogenically cooled suspension of nanocrystals of the SCO 
complex in a mixture of 1,1-dichloroethane and the polymer. The resulting 150-200 nm thick films exhibited cooperative spin transition with hysteresis centered around $155 \mathrm{~K}$ evidenced by variable temperature Raman measurements. In contrast to other technics, such approach seems to preserve the crystallinity of the compound.

\subsubsection{D printing}

Three-dimensional (3D) printing refers to a family of methods, which allow for making objects from a 3D computer model by joining materials, i.e. by additive manufacturing as opposed to subtractive manufacturing approaches. Recently, much attention has been focused on the possibility of 3D printing smart, actuating materials able to produce a shape change with time. The term '4D printing' is often used for this process, wherein the $4^{\text {th }}$ dimension refers to time. Whereas $4 \mathrm{D}$ printing has been achieved mostly using shape memory polymers, elastomers and hydrogels, SCO materials represent also an appealing scope in this context. The 3D printability of SCO materials can be most conveniently attained using polymer composites. Notably, in a recent work Piedrahita-Bello et al. [68] used a stereolithographic approach to fabricate various shaped objects from the $\mathrm{SCO}$ complex $\left[\mathrm{Fe}\left(\mathrm{NH}_{2} \mathrm{trz}\right)_{3}\right] \mathrm{SO}_{4}$ embedded in a commercial photoresist with sizes up to several $\mathrm{cm}$ and structural details down to the $80 \mu \mathrm{m}$ scale (Figure 18). Besides monolithic objects, bimorph actuators were also 3D printed and their actuation performance evaluated. The key interest of this approach is the possibility to create arbitrary planar and threedimensional geometries, which are otherwise not accessible using spin crossover complexes.

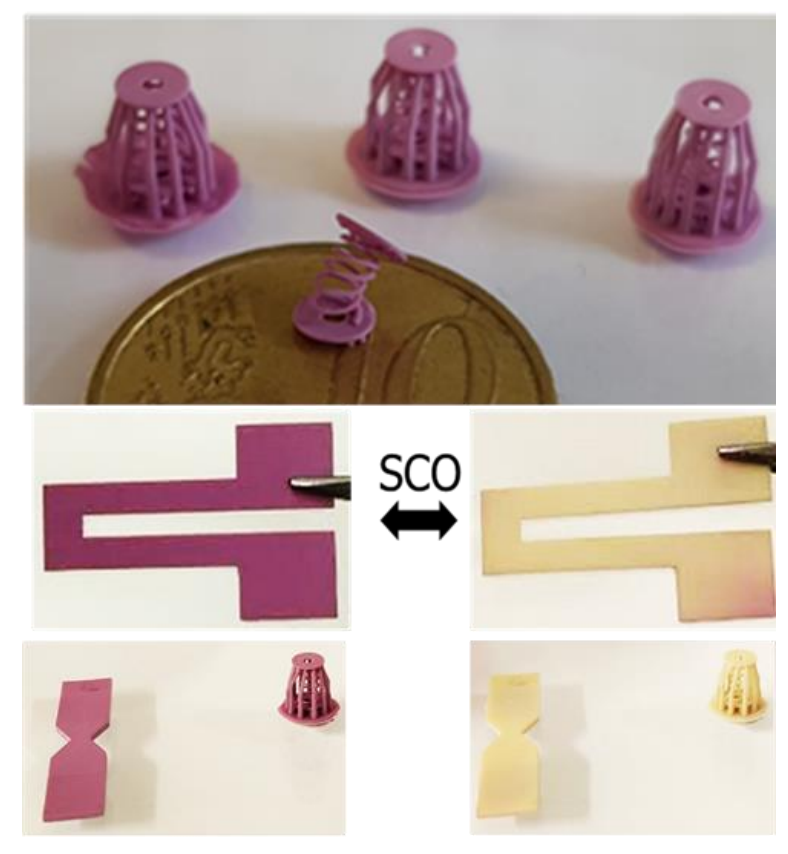

Figure 18. 3D printed objects of polymer composites of the SCO complex $\left[\mathrm{Fe}\left(\mathrm{NH}_{2} \mathrm{trz}\right)_{3}\right] \mathrm{SO}_{4 \cdot[68]}$ 
PROGRESSIVE TRENDS IN COORDINATION, BIOINORGANIC AND APPLIED INORGANIC CHEMISTRY

XXVII International Conference on Coordination and Bioinorganic Chemistry,

June 2-7 2019, Smolenice, Slovakia

Review paper in the Coordination Chemistry Reviews

Table 1. List of the most relevant SCO polymer composites and their main characteristics.

\begin{tabular}{|c|c|c|c|c|c|c|c|c|}
\hline \multirow[b]{2}{*}{ Polymer } & \multirow{2}{*}{$\mathrm{SCO}$} & \multirow{2}{*}{$\begin{array}{l}\text { Load } \\
(\% \mathrm{wt})\end{array}$} & \multicolumn{3}{|c|}{ SCO measurement } & \multirow{2}{*}{$\begin{array}{c}\mathrm{SCO} \\
\text { dissolved } \\
\end{array}$} & \multirow[t]{2}{*}{ Preparation } & \multirow[b]{2}{*}{ ref } \\
\hline & & & $\begin{array}{l}\mathrm{T}_{1 / 2} \uparrow \\
\left({ }^{\circ} \mathrm{C}\right)\end{array}$ & $\begin{array}{l}\mathrm{T}_{1 / 2 \downarrow} \downarrow \\
\left({ }^{\circ} \mathrm{C}\right)\end{array}$ & $\begin{array}{l}\Delta \mathrm{T}_{1 / 2} \\
\left({ }^{\circ} \mathrm{C}\right)\end{array}$ & & & \\
\hline \multirow{11}{*}{ PMMA } & \multirow{3}{*}[\mathrm{Fe}(\mathrm{hptrz})_{3}]{$\left(\mathrm{ClO}_{4}\right)_{2}$} & $\begin{array}{l}\text { only } \\
\text { SCO }\end{array}$ & -38 & -46 & 8 & --- & --- & \multirow{9}{*}[22]{} \\
\hline & & 10 & -37 & -51 & 14 & \multirow[b]{2}{*}{ yes } & \multirow{2}{*}{$\begin{array}{l}\text { Solution casting (drop } \\
\text { casting) }\end{array}$} & \\
\hline & & 25 & -36 & -45 & 9 & & & \\
\hline & \multirow{3}{*}[\mathrm{Fe}(\mathrm{hptrz})_{3}]{$\left(\mathrm{BF}_{4}\right)_{2}$} & $\begin{array}{l}\text { only } \\
\text { SCO }\end{array}$ & -30 & -40 & 10 & --- & --- & \\
\hline & & 10 & -24 & -45 & 21 & \multirow{2}{*}{ yes } & \multirow{2}{*}{$\begin{array}{c}\text { Solution casting (drop } \\
\text { casting) }\end{array}$} & \\
\hline & & 25 & -25 & -38 & 13 & & & \\
\hline & \multirow{3}{*}[\mathrm{Fe}(\mathrm{hptrz})_{3}]{$(\mathrm{Br})_{2}$} & $\begin{array}{l}\text { only } \\
\text { SCO }\end{array}$ & 59 & 57 & 2 & --- & --- & \\
\hline & & 10 & 57 & 46 & 11 & \multirow{2}{*}{ yes } & \multirow{2}{*}{$\begin{array}{l}\text { Solution casting (drop } \\
\text { casting) }\end{array}$} & \\
\hline & & 25 & 56 & 52 & 4 & & & \\
\hline & \multirow{2}{*}[\mathrm{Fe}(\mathrm{Htrz})_{2}(\operatorname{trz})]{$\left(\mathrm{BF}_{4}\right)$} & $\begin{array}{l}\text { only } \\
\text { SCO }\end{array}$ & 123 & 70 & 53 & --- & --- & {$[65]$} \\
\hline & & $10-50$ & $\begin{array}{c}\text { ca. } \\
123\end{array}$ & $\begin{array}{l}\text { ca. } \\
70\end{array}$ & $\begin{array}{l}\text { ca. } \\
53 \\
\end{array}$ & no & $\begin{array}{l}\text { Solution casting (dip } \\
\text { coating) }\end{array}$ & {$[51]$} \\
\hline \multirow{4}{*}{ POx } & \multirow[t]{2}{*}[\mathrm{Fe}(\mathrm{ODT})_{3}]{$(\mathrm{OTs})_{2}$} & $\begin{array}{l}\text { only } \\
\text { SCO }\end{array}$ & 37.6 & 28.2 & 9.4 & --- & --- & \multirow{4}{*}[23]{} \\
\hline & & 25 & 22.2 & 16.8 & 5.4 & & & \\
\hline & \multirow[t]{2}{*}[\mathrm{Fe}(\mathrm{HET})_{3}]{$(\mathrm{OTs})_{2}$} & $\begin{array}{l}\text { only } \\
\text { SCO }\end{array}$ & 25 & 10.6 & 14.4 & --- & --- & \\
\hline & & 25 & 17.9 & 1.6 & 16.3 & & & \\
\hline \multirow{2}{*}{ Polypyrrole } & {$\left[\mathrm{Fe}(\mathrm{Htrz})_{2}(\operatorname{trz})\right]\left(\mathrm{BF}_{4}\right)$} & \multirow{2}{*}{250} & 123 & 70 & 53 & \multirow{2}{*}{ no } & \multirow{2}{*}{ In situ polymerization } & \multirow{2}{*}[65]{} \\
\hline & {$\left[\mathrm{Fe}\left(\mathrm{NH}_{2} \mathrm{trz}\right)_{3}\right]\left(\mathrm{SO}_{4}\right)$} & & 72 & 59 & 13 & & & \\
\hline PTFEMA & $\begin{array}{c}{\left[\mathrm{Fe}(\mathrm{Htrz})_{3-}\right.} \\
\left.3 \mathrm{X}\left(\mathrm{NH}_{2} \mathrm{trz}\right)_{3 \mathrm{X}}\right]\left(\mathrm{BF}_{4}\right)_{2}\end{array}$ & 1 & \multicolumn{3}{|c|}{---- } & no & In situ polymerization & {$[64]$} \\
\hline Chitosan & $\begin{array}{c}{\left[\mathrm{Fe}(\mathrm{pz})\left\{(\mathrm{MCN})_{4}\right\}\right](\mathrm{M}=\mathrm{Ni}} \\
\mathrm{Pd}, \mathrm{Pt})\end{array}$ & NA & --- & --- & --- & yes & $\begin{array}{c}\text { Multilayer sequential } \\
\text { assembly }\end{array}$ & $\begin{array}{c}{[43,4} \\
4]\end{array}$ \\
\hline
\end{tabular}


PROGRESSIVE TRENDS IN COORDINATION, BIOINORGANIC AND APPLIED INORGANIC CHEMISTRY

XXVII International Conference on Coordination and Bioinorganic Chemistry,

June 2-7 2019, Smolenice, Slovakia

Review paper in the Coordination Chemistry Reviews

\begin{tabular}{|c|c|c|c|c|c|c|c|c|}
\hline Alginate & {$\left[\mathrm{Fe}(\mathrm{pz})\left\{(\mathrm{NiCN})_{4}\right\}\right]$} & NA & --- & --- & --- & & & \\
\hline AN-18-10P (ion exchange polymer) & $\mathrm{Fe}($ formazan $)$ & NA & \multicolumn{2}{|c|}{ ca. 123} & --- & yes & Adsorption into matrix & [38] \\
\hline $\begin{array}{c}\text { Dowex 50WX4 hydrogen form (ion } \\
\text { exchange polymer) }\end{array}$ & {$\left[\mathrm{Fe}(\mathrm{Htrz})_{2}(\operatorname{trz})\right]\left(\mathrm{BF}_{4}\right)$} & NA & 119 & 69 & 50 & yes & Adsorption into matrix & [42] \\
\hline \multirow{2}{*}{ PVP } & \multirow{2}{*}[\mathrm{Fe}(\mathrm{NH}_{2}\mathrm{trz})_{3}]{$\left(\mathrm{ClO}_{4}\right)_{2}$} & $\begin{array}{l}\text { only } \\
\text { SCO }\end{array}$ & \multicolumn{2}{|c|}{-63} & 0 & --- & --- & [69] \\
\hline & & 59 & -19 & -25 & 6 & yes & $\begin{array}{l}\text { Solution casting (dip } \\
\text { casting) }\end{array}$ & [24] \\
\hline \multirow{5}{*}{ Polystyrene } & \multirow{2}{*}[\mathrm{Fe}(\mathrm{ODT})_{3}]{$\left(\mathrm{ClO}_{4}\right)_{2}$} & $\begin{array}{l}\text { only } \\
\text { SCO }\end{array}$ & -60 & -60 & 0 & --- & --- & {$[25]$} \\
\hline & & 13.5 & -60 & -60 & 0 & yes & $\begin{array}{l}\text { Electrospun from } \\
\text { solution }\end{array}$ & [26] \\
\hline & \multirow{3}{*}[\mathrm{Fe}(\mathrm{NH}_{2}\mathrm{trz})_{3}]{$\left(\mathrm{NO}_{3}\right)_{2} \cdot 0.5 \mathrm{H}_{2} \mathrm{O}$} & $\begin{array}{l}\text { only } \\
\text { SCO }\end{array}$ & 55 & 52 & 2 & --- & -- & {$[57]$} \\
\hline & & $16-$ & 53 & 51 & 2 & \multirow{2}{*}{ no } & \multirow{2}{*}{$\begin{array}{l}\text { Solution casting (drop } \\
\text { casting) }\end{array}$} & \multirow{2}{*}{56} \\
\hline & & 17.5 & 70 & 43 & 27 & & & \\
\hline \multirow{7}{*}{ Cellulose } & \multirow{3}{*}[\mathrm{Fe}(\mathrm{hptrz})_{3}]{$(\mathrm{OTs})_{2}$} & $\begin{array}{l}\text { only } \\
\text { SCO }\end{array}$ & 37 & 38 & 1 & --- & --- & {$[70]$} \\
\hline & & NA & 54 & 51 & 3 & \multirow{4}{*}{ no } & \multirow{4}{*}{ Adsorption into matrix } & \multirow{2}{*}{ [58] } \\
\hline & & NA & 46 & 40 & 6 & & & \\
\hline & \multirow[b]{2}{*}[\mathrm{Fe}(\mathrm{Htrz})_{2}(\operatorname{trz})]{$\left(\mathrm{BF}_{4}\right)$} & 25 & 116 & 85 & 31 & & & [59] \\
\hline & & 50 & $\begin{array}{c}110- \\
115 \\
\end{array}$ & 80 & $\begin{array}{l}30- \\
35\end{array}$ & & & {$[60]$} \\
\hline & \multirow{2}{*}[\mathrm{Fe}(\mathrm{NH}_{2}\mathrm{trz})_{3}]{$\mathrm{Br}_{2}$} & $\begin{array}{l}\text { only } \\
\text { SCO }\end{array}$ & 44.6 & 32.8 & 15 & ---- & --- & [71] \\
\hline & & 30 & 32 & 25 & 7 & no & Adsorption into matrix & [59] \\
\hline \multirow{2}{*}{ Polyester } & {$\left[\mathrm{Fe}\left(\mathrm{NH}_{2} \mathrm{trz}\right)_{3}\right]\left(\mathrm{NO}_{3}\right)_{2} \cdot \mathrm{H}_{2} \mathrm{O}$} & NA & $\sim 73$ & $\sim 48$ & $\sim 25$ & \multirow[b]{2}{*}{ no } & \multirow{2}{*}{$\begin{array}{l}\text { Solution casting (spray } \\
\text { coating) }\end{array}$} & \multirow{2}{*}{ [62] } \\
\hline & {$\left[\mathrm{Fe}\left(\mathrm{NH}_{2} \mathrm{trz}\right)_{3}\right] \mathrm{Br}_{2} \cdot 3 \mathrm{H}_{2} \mathrm{O}$} & NA & $\sim 48$ & $\sim 9$ & $\sim 39$ & & & \\
\hline \multirow{2}{*}{ Bacterial cellulose ("nata de coco") } & {$\left[\mathrm{Fe}(\mathrm{Htrz})_{2}(\mathrm{trz})\right]\left(\mathrm{BF}_{4}\right)$} & NA & 112 & 72 & 40 & \multirow{2}{*}{ yes } & \multirow{2}{*}{ Adsorption into matrix } & \multirow{2}{*}[41]{} \\
\hline & {$\left[\mathrm{Fe}\left(\mathrm{NH}_{2} \mathrm{trz}\right)_{3}\right]\left(\mathrm{BF}_{4}\right)_{2}$} & NA & 95 & 60 & 35 & & & \\
\hline Polycarbonate & {$\left[\mathrm{Fe}(\mathrm{Htrz})_{2}(\operatorname{trz})\right]\left(\mathrm{BF}_{4}\right)$} & 50 & 97 & 59 & 38 & no & $\begin{array}{l}\text { Solution casting (drop } \\
\text { casting) }\end{array}$ & [52] \\
\hline
\end{tabular}


PROGRESSIVE TRENDS IN COORDINATION, BIOINORGANIC AND APPLIED INORGANIC CHEMISTRY

XXVII International Conference on Coordination and Bioinorganic Chemistry,

June 2-7 2019, Smolenice, Slovakia

Review paper in the Coordination Chemistry Reviews

\begin{tabular}{|c|c|c|c|c|c|c|c|c|}
\hline--- & \multirow{7}{*}[\mathrm{Fe}(\mathrm{NH}_{2}\operatorname{trz})_{3}]{$\left(\mathrm{BF}_{4}\right)_{2}$} & $\begin{array}{l}\text { only } \\
\text { SCO }\end{array}$ & 3.1 & -3.8 & 6.9 & --- & --- & \multirow{7}{*}[53]{} \\
\hline Nafion & & NA & 32.4 & 19.8 & 12.6 & no & \multirow{6}{*}{$\begin{array}{l}\text { Solution casting (dip } \\
\text { coating) }\end{array}$} & \\
\hline Polyurethane D6 & & NA & 6.7 & 0.2 & 6.5 & no & & \\
\hline PMMA $_{\text {toluene }}$ & & 50 & 3.6 & -5.6 & 9.2 & no & & \\
\hline $\mathrm{PMMA}_{\mathrm{THF}}$ & & 50 & 0.7 & -6.3 & 7.0 & no & & \\
\hline $\mathrm{PVC}_{\mathrm{THF}}$ & & 66 & 1.4 & -9.3 & 10.6 & no & & \\
\hline $\mathrm{PS}_{\mathrm{THF}}$ & & 45 & -0.1 & -9.6 & 9.5 & no & & \\
\hline \multirow{2}{*}{ SU-8 (3050) } & \multirow{2}{*}[\mathrm{Fe}(\mathrm{Htrz})_{2}(\operatorname{trz})]{$\left(\mathrm{BF}_{4}\right)$} & $\begin{array}{l}\text { only } \\
\text { SCO }\end{array}$ & 105 & 82 & 23 & -- & --- & \multirow{2}{*}[63]{} \\
\hline & & 30 & 113 & 54 & 59 & no & $\begin{array}{l}\text { Solution casting (spray } \\
\text { coating) }\end{array}$ & \\
\hline \multirow{2}{*}{$\mathrm{P}(\mathrm{VDF}-\mathrm{TrFE}) 70-30 \% \mathrm{~mol}$} & \multirow{2}{*}{$\begin{array}{c}{\left[\mathrm{Fe}\left\{(\mathrm{Htrz})_{2}(\operatorname{trz})\right\}_{0.9}\left(\mathrm{NH}_{2} \operatorname{trz}\right)_{0.3}\right.} \\
]\left(\mathrm{BF}_{4}\right)_{1.1}\end{array}$} & $\begin{array}{l}\text { only } \\
\text { SCO }\end{array}$ & 66 & 58 & 8 & --- & --- & \multirow{2}{*}[16]{} \\
\hline & & $\approx 25$ & 67 & 54 & 13 & no & $\begin{array}{l}\text { Solution casting (drop } \\
\text { casting) }\end{array}$ & \\
\hline \multirow{2}{*}{ Diblock copolypeptide } & $\mathrm{Co}(\mathrm{MeO} \text {-terpy })_{2}$ & --- & 72 & -13 & 85 & \multirow{2}{*}{ yes } & \multirow{2}{*}{$\begin{array}{c}\text { Solution casting } \\
\text { (lyophilization) }\end{array}$} & [48] \\
\hline & $\mathrm{Fe}(\mathrm{ppi})_{2}(\mathrm{NCS})_{2}$ & --- & \multicolumn{3}{|c|}{---} & & & [49] \\
\hline \multirow{2}{*}{ Polylatic acid } & {$\left[\mathrm{Fe}(\mathrm{Htrz})_{2}(\operatorname{trz})\right]\left(\mathrm{BF}_{4}\right)$} & \multirow{2}{*}{5} & & --- & & \multirow{2}{*}{ no } & Electrospun from & \multirow{2}{*}[61]{} \\
\hline & {$\left[\mathrm{Fe}\left(\mathrm{NH}_{2} \operatorname{trz}\right)_{3}\right]\left(\mathrm{BF}_{4}\right)_{2}$} & & & --- & & & solution & \\
\hline \multirow{6}{*}{$\mathrm{SiO}_{2}$} & {$\left[\mathrm{Fe}(\mathrm{Htrz})_{2}(\operatorname{trz})\right]\left(\mathrm{BF}_{4}\right)$} & 1 & 108 & 87 & 21 & No & Sol-gel & {$[45]$} \\
\hline & {$\left[\mathrm{Fe}(\mathrm{Htrz})_{2}(\mathrm{trz})\right]\left(\mathrm{BF}_{4}\right)$} & NA & 102 & 37 & 65 & yes & Adsorption into matrix & [39] \\
\hline & $\mathrm{Fe} / \mathrm{NH}_{2}$ trz/SO 4 & $\begin{array}{l}\text { only } \\
\text { SCO }\end{array}$ & 49 & 38 & 11 & \multirow{4}{*}{ no } & suspension & \\
\hline & NP-SiO ${ }_{2} @ \mathrm{Fe} / \mathrm{NH}_{2}$ trz/SO$_{4}$ & \multirow{3}{*}{ NA } & 57 & 43 & 14 & & Sol-gel & [46] \\
\hline & $\begin{array}{c}\mathrm{Si@NP}-\mathrm{SiO}_{2} \\
@ \mathrm{Fe} / \mathrm{NH}_{2} \mathrm{trz} / \mathrm{SO}_{4} \\
\end{array}$ & & 60 & 43 & 23 & & \multirow{2}{*}{ Sol-gel and coating } & \multirow{2}{*}[47]{} \\
\hline & $\begin{array}{c}\text { PDMS@Si@ NP-SiO } 2 \\
@ \mathrm{Fe} / \mathrm{NH}_{2} \mathrm{trz} / \mathrm{SO}_{4}\end{array}$ & & 55 & 39 & 16 & & & \\
\hline
\end{tabular}

NA: not available 


\section{Spin crossover organic polymers}

Fundamentally, we can divide 'organic polymer SCO complexes' into two basic categories based on the way the polymer is attached to the SCO complex: a) when the polymer is attached by supramolecular interactions to the SCO complex, for example representing the counteranion of the complex (polymer backbone) such as in Nafion-SCO composites and b) when the polymer is covalently attached to the SCO ligands of the SCO complex. In this section, we focus exclusively on the second approach. (The supramolecular approach was discussed in section 2.12.) The primary interests of 'SCO organic polymers' with respect to SCO-polymer composites is that phase separation, inherent to composites, is avoided and a better dispersion of the SCO centers can be achieved. On the other hand, the price to pay is that the SCO in these systems is usually not cooperative and therefore the spin crossover behavior is usually gradual an incomplete. A notable exception is the case of Fe(II)-triazole based SCO polymers, which can display rather abrupt spin transition owing to the multinuclear (chain-type) character of these complexes.

Maeda et al. [72] were the first to use ligands covalently attached to a polymer to obtain SCO complexes. They obtained different amorphous iron(III) complexes from copolymers of PVP (poly(4-vinylpyridine)) or poly(1-vinylimidazole) and various Schiff base ligands like $\mathrm{H}_{2} \mathrm{Salten}$ (Figure 19d). A color change observed at $78 \mathrm{~K}$ allowed to visually corroborate the existence of SCO in the polymers, which was also confirmed by variable-temperature Mössbauer and EPR spectroscopies. As it can be expected in such materials with "diluted" iron centers, magnetic measurements revealed that the spin crossover is very smooth, spans over a broad range of temperatures and remains largely incomplete. Later on, Davidson et al. attached terpyridine to polyphosphazenes (PP) and synthesized the corresponding iron(II) complex, resulting either in a soluble polymer with intramolecular loops (Figure 19a) or in an insoluble pink solid with probably a high degree of cross-linked polymerization. [73] The Mössbauer spectra showed the presence of a mixture of iron species, $\mathrm{Fe}^{\mathrm{II}}-\mathrm{Terpy}_{2}$ in the $\mathrm{LS}$ and $\mathrm{HS}$ states with a paramagnetic impurity consistent with a Fe ${ }^{\text {III }}$ species in the HS state. However, no spin crossover could be detected in these samples between 10 - $300 \mathrm{~K}$. Wang's group reported Fe(II) SCO complexes using PGMA (poly(glycidyl methacrylate)) [74] and MPEG-750 (methoxy polyethylene glycol) [75] based PGMA-trz and MPEG-trz ligands (Figure 19b). The variable temperature magnetic susceptibility measurements showed that, in the case of PGMA, the complex is in the HS state at room temperature and the spin crossover is gradual along a vast range of temperature (mainly 150 - 250 K), which eventually never reaches a full LS state. The most abrupt transition was obtained for the complex [Fe $\left.{ }^{\mathrm{II}}(\mathrm{MPEG}-\mathrm{trz})_{1.5}\left(\mathrm{NH}_{2} \operatorname{trz}\right)_{1.5}\right]\left(\mathrm{BF}_{4}\right)_{2}$ in which the transition temperatures are $\mathrm{T}_{1 / 2} \downarrow=248 \mathrm{~K}$ and $\mathrm{T}_{1 / 2} \uparrow=251 \mathrm{~K}$ denoting a small hysteresis $(\Delta \mathrm{T}=3 \mathrm{~K})$ as shown in Figure 19c. The group of Jäjkle reported two different supramolecular polymer complexes consisting of polystyrene terminated in either one or both sides of the polymer chain with tris(1pirazolyl)borate (Tp).[76] The Fe(II) complexes obtained from these polymers (Figure 19e-f) turned out to be pink powders with an UV-Vis absorption at $530 \mathrm{~nm}$, which corresponds to the ${ }^{1} \mathrm{~A}_{1 \mathrm{~g}} \rightarrow{ }^{1} \mathrm{~T}_{1 \mathrm{~g}}$ transition of the LS ferrous ion. However, no magnetic measurements were performed in order to investigate if the compounds display SCO behavior. Schwarzenbacher $e t$ al. [77] prepared the ligand 11-(4H-1,2,4-triazol-4-yl)-undecylmethacrylate to form the complex $\left(\mathrm{FeL}_{3}\right)\left(\mathrm{BF}_{4}\right)_{2}$, which was later polymerized in situ, obtaining an oligomer that contains ca. 6-7 monomeric units. The complexation of the ligand and the subsequent polymerization 
was followed by IR spectroscopy. The magnetic behavior of the polymerized SCO complex reveals a gradual, but fairly complete spin crossover, which remains similar to the starting monomeric complex. This similarity provides an additional proof for the lack of influence of the polymerization reaction on the SCO active part of the system. The authors attributed this successful synthesis to the relatively large distance between the groups involved in the polymerization reaction and the SCO.

a)

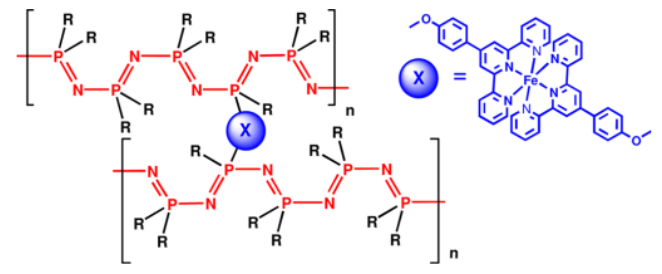

b)

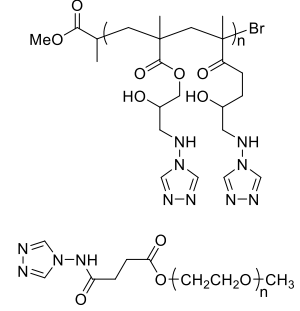

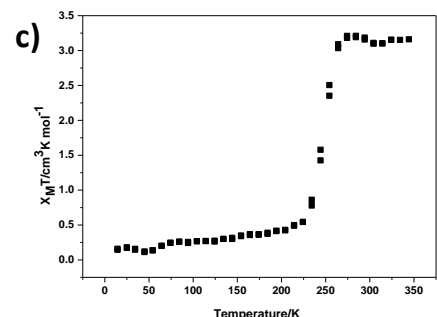
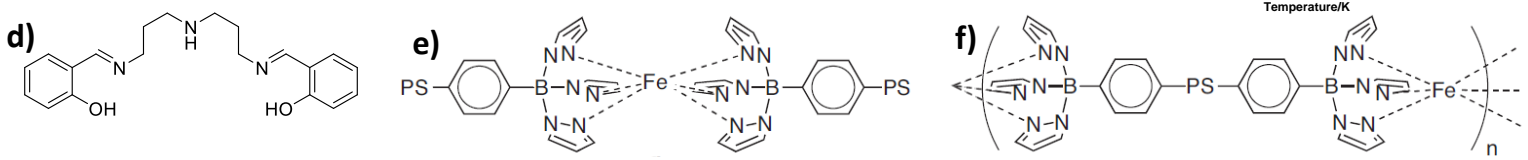

Figure 19. a) $\left[\mathrm{Fe}^{\mathrm{II}}\left(\mathrm{Terpy}_{2}-\mathrm{PP}\right)\right]\left(\mathrm{ClO}_{4}\right)_{2} ;$ b) PGMA-trz and MPEG-trz; c) $\chi \mathrm{T}$ for $\left[\mathrm{Fe}^{\mathrm{II}}(\mathrm{MPEG}-\right.$ trz $\left.)_{1.5}\left(\mathrm{NH}_{2} \text { trz }\right)_{1.5}\right]\left(\mathrm{BF}_{4}\right)_{2} ;$ d) $\mathrm{H}_{2}$ salten ligand ; e) and f) polystyrene-Tp $\mathrm{Fe}^{\mathrm{II}}$ complexes.[72-76]

An iron(III) Schiff base with pendant thienyl groups were prepared by Lemaire and Djukic.[78] A film of around $130 \mathrm{~nm}$ thickness was obtained by in situ electropolymerization of a solution of the Schiff base complex (Figure 20a) on an ITO-coated glass. The magnetic behavior of both the monomer and the polymer are similar, showing a smooth decrease of the magnetic moment when the temperature is decreased (Figure 20b). Remarkably, these systems not only display SCO, but they exhibit also a high electrical conductivity (Figure 20c). However, no clear correlation between the temperature dependence of the magnetic moment and that of the conductivity could be established. Later on, aerobic oxidation in solution allowed the formation of SCO-polymer microspheres of a similar thienyl iron (III) Schiff base,[79] which shows similar magnetic behavior to the parent monomer. 

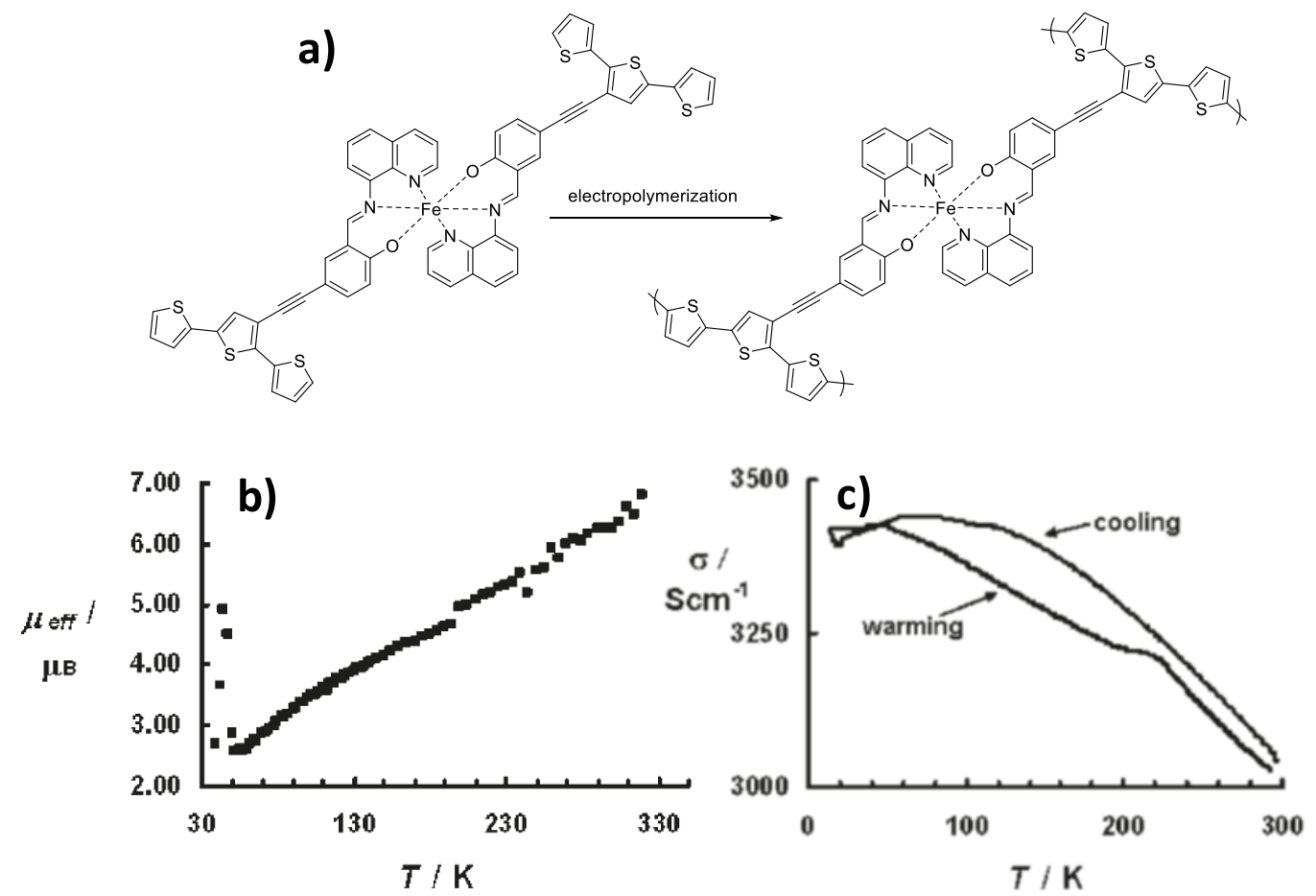

Figure 20. a) Electropolymerization of the Schiff base ligand; b) magnetic and c) conductivity properties of the SCO polymer film at variable temperature [78]

A similar approach of electropolymerization, using thiophene derivatives, was used by the same group [80] and more recently by the group of Lescouezec [81] in combination with a valence tautomeric cobalt bis(semiquinone) complex and $\left\{\mathrm{Fe}_{4} \mathrm{Co}_{4}\right\}$ cages, respectively. Both types of polymers were shown to display charge transfer-induced spin transition upon temperature variation or light irradiation. Overall, this approach of electropolymerization not only affords for processing the compound as smooth, ultrathin films, but also provides potentially an interesting means to develop synergies between the magnetic switching behavior, inherited from the metal complex, and electroactive properties arising from the polythiophene part.

An original synthetic approach was developed by the group of Weber [82], leading to materials, which can be considered either as SCO-polymers or SCO-polymer composites. Indeed, the SCO complex is chemically attached to the polymer backbone, yet phase separation occurs with welldefined crystalline SCO domains within block copolymer micelles. In a first publication, the authors used a poly(4-vinylpyridine) (P4VP) matrix in which the 1D coordination polymer $\left[\mathrm{Fe}^{\mathrm{II}} \mathrm{L}(\right.$ bipy)$]$ ( $\mathrm{L}=$ Schiff base ligand, bipy= 4,4'-bipyridine) was systematically grown by repetitive synthetic cycles.[83] This procedure resulted in microcrystals of controlled size within the polymer matrix. By increasing the number of synthetic cycles, the magnetic behavior of the polymer approaches more and more the behavior of the bulk material: after 5 cycles, an abrupt and almost complete transition with $\mathrm{T}_{1 / 2} \downarrow=226 \mathrm{~K}$ and $\mathrm{T}_{1 / 2} \uparrow=239 \mathrm{~K}$ (i.e. a hysteresis of $13 \mathrm{~K}$ ) takes place. [83] By changing the initial matrix to the block copolymer polystyrene-blockpoly(4-vinylpyridine) (PS- $b$-P4VP), Klimm et al. [84] found out that not only they can grow a 1D coordination network, but that in this case well-defined spherical nanoparticles of ca. $50 \mathrm{~nm}$ are formed (Figure 21). Their core size is independent of the quantity of coordination polymer used and is only determined by the size of the starting block-copolymer micelle. The observed 
magnetic behavior showed a gradual and incomplete spin transition. Controlling the reaction conditions can improve the crystallinity of the complex, in which case after 5 synthetic cycles a full HS state is attained at room temperature with $T_{1 / 2} \downarrow=162 \mathrm{~K}$ and $T_{1 / 2} \uparrow=170 \mathrm{~K}$ (as shown in Figure 21), resembling to the bulk system. A further study on the influence of the rigidity of the axial ligand in the formation of the nanoparticles and their SCO behavior was performed by alternating the bipy to bpea, bpee and bpey (see Figure 21).[85] The introduction of different axial ligands did not change the core-size, but did increase the solubility of the coordination complex resulting in the formation of microcrystals outside the micelle. This is also favored by changing to a solvent in which the complex is more soluble (toluene in this case). The general result is that the magnetic behavior of these polymers shows drastic differences with their corresponding bulk SCO complexes, due to the crystallization motif of the block copolymer. It is also interesting to note that the use of blockcopolymers allows an additional functionalization of the obtained nano-objects by variation of the polymer blocks. More recently, the same group reported the crystallization of smaller SCO nano-particles of ca. $15 \mathrm{~nm}$ in the micellar confinement ([Fe ${ }^{\mathrm{II}} \mathrm{L}($ bipy)]@PS-b-P4VP).[86] When the material is heated above the glass transition temperature of the PS shell, a significant improvement of the SCO properties is observed (decrease of the residual HS fraction at low temperature and wide hysteresis loop) with an increase of the transition temperatures.
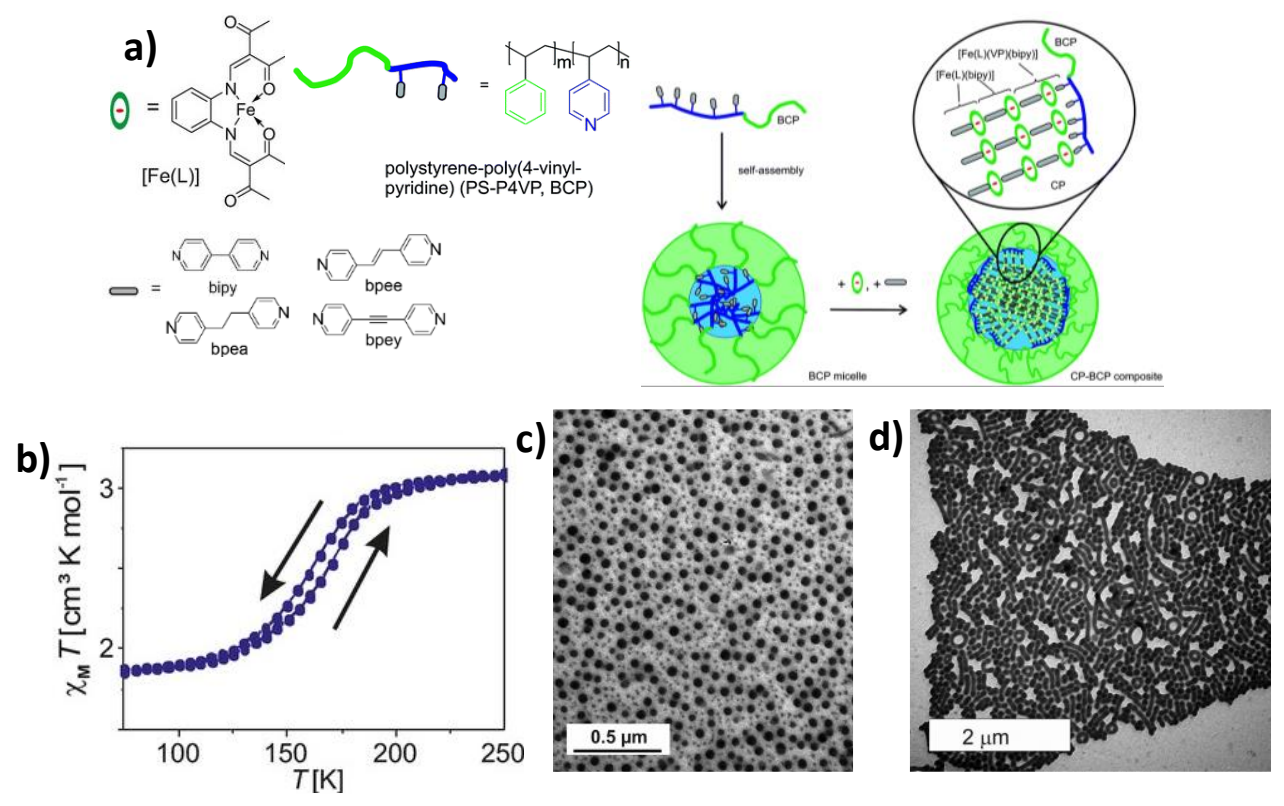

Figure 21. a) Schematic representation for the synthesis of the SCO polymer using P4VP and PS-b-P4VP as matrix and b) magnetic measurement of $\left[\mathrm{Fe}^{\mathrm{II}} \mathrm{L}\right.$ (bipy)]@PS-b-P4VP after 5 synthetic cycles; TEM photograph of c) ([FeLeq $(\text { bpey) }]_{\mathrm{n}} @ \mathrm{BCP}$ particles after 5 cycles and d) [Fe ${ }^{\mathrm{II}} \mathrm{L}($ bipy)$] @ \mathrm{BCP} .[82-85]$

\section{Related compounds}

In this section, we review different classes of 'soft' SCO compounds, which are, strictly speaking, not polymeric and cannot be classified either as polymer composites, but are closely related to them. These include SCO dendrimers, gels, liquid crystals and Langmuir-Blodgett films. The common feature of these materials that they display properties, which are typical of 'soft matter', such as liquid crystal properties, viscoelasticity and large deformability. As such, 
they allow for 'unconventional' properties in combination with the SCO phenomenon as well as easier processing with respect to 'conventional' polycrystalline SCO materials. Since these 'soft' SCO materials have been already reviewed,[87] we restrict our discussion to the most prominent and/or most recent examples.

\subsection{SCO dendrimers}

Dendrimers are globular-shaped, highly branched macromolecules with controlled molecular weight, size and number of functional groups, due to their well-defined synthetic method based on iterative reactions. Their structure consists of three distinct parts: a central core, the layers of branched repeating units (interior dendritic structure) and an exterior outer layer with functional surface groups. A generation number $G_{n}$ is increased when every branched unit is multiplied, usually by 2 ( $1 \rightarrow 2$ connectivity) or 3 ( $1 \rightarrow 3$ connectivity). Their construction starts from the focal core following either a divergent or a convergent way.[88] The convergent synthesis of dendrimers is greatly used providing a stepwise structural control and synthetic versatility. On the same line, dendronized objects can benefit from enhanced solubility and processability. It is worth mentioning that dendrimers or dendronized objects are regarded as molecular micelles or reversed micelles when the core is hydrophobic and the surface endgroups hydrophilic or vice-versa, making them ideal candidates for nanomedicine, notably for drug encapsulation. $[89,90]$ The multiple reactive sites for molecular attachment such as the periphery, core, branching points or cavities in coordination with their micellar properties make dendritic molecules very promising for various applications.[91,92] Indeed, the combination of variable size, topology, structure and conformation of dendrimers, accompanied by the resultant physical and supramolecular properties, opened the path for different research directions towards a variety of applications, such as molecular electronics, photonics, nanomedicine, sensing and catalysis. $[93,94]$ Although a previous assessment of SCO in dendritic systems was done by Gaspar and Seredyuk in 2014,[87] we have decided to incorporate here a short, updated section of dendritic SCO complexes.

Three generations $G_{n}(n=0-2)$ of poly(benzyl ether) dendrons with a triazole focal group coordinated to $\mathrm{Fe}(\mathrm{II})$ form discotic columnar core-shell assemblies of $\left(\left[\mathrm{Fe}\left(\mathrm{G}_{\mathrm{n}} \mathrm{trz}\right)_{3}\right]\left(\mathrm{MeSO}_{3}\right)_{2} \cdot 2 \mathrm{H}_{2} \mathrm{O}\right)$ (Figure 22.a).[95] They display a change of spin state of iron ions above room temperature, albeit this change is irreversible after the first heating process in all three dendritic Fe(II) complexes, most likely due to the irreversible loss of water molecules 'bonded' to the dendritic ligands (through hydrogen bonding etc.). It is noteworthy that the temperature of water loss upon heating - erroneously described by the authors as "spintransition behavior" - depend on the generation number. Indeed, the dehydration temperature $(\mathrm{Tc}=335 \rightarrow 315 \rightarrow 300 \mathrm{~K})$ is inversely dependent on the increase of generation number $(\mathrm{n}=$ $0 \rightarrow 1 \rightarrow 2$ ). On the other hand, the larger the dendron, the more restricted is the supramolecular polymerization, therefore the degree of polymerization was calculated to decrease (D.p. $=20$ $\rightarrow 10 \rightarrow 3$ ) upon the increase of dendron generation $\left(\mathrm{G}_{\mathrm{n}}, \mathrm{n}=0 \rightarrow 1 \rightarrow 2\right)$. Despite the claims of the authors, this trend cannot be correlated with the cooperativity of the spin transition as none of the compounds display spin transition in the investigated temperature range $(240-350$ $\mathrm{K})$. Interestingly, the self-organized $\left(\mathrm{G}_{1} \mathrm{trz}\right) \mathrm{Fe}$ showed extraordinary large $\Delta \mathrm{H}$ and $\Delta \mathrm{S}$ values in comparison with the other generations, which indicates a coupled structural transition upon the dehydration. 
a)

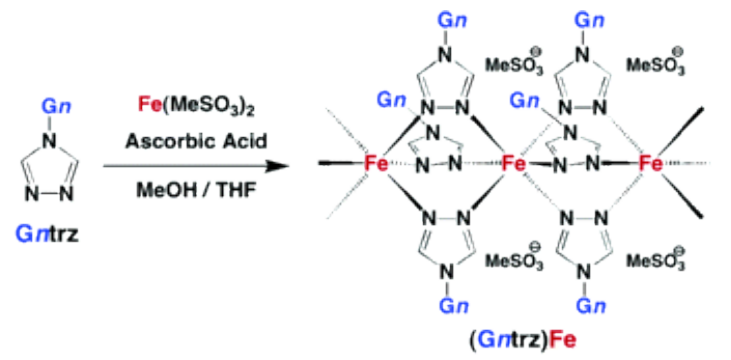

b)

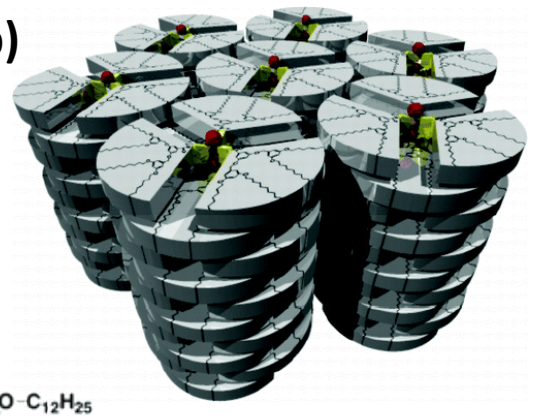

$\mathrm{O}-\mathrm{C}_{12} \mathrm{H}_{25}$

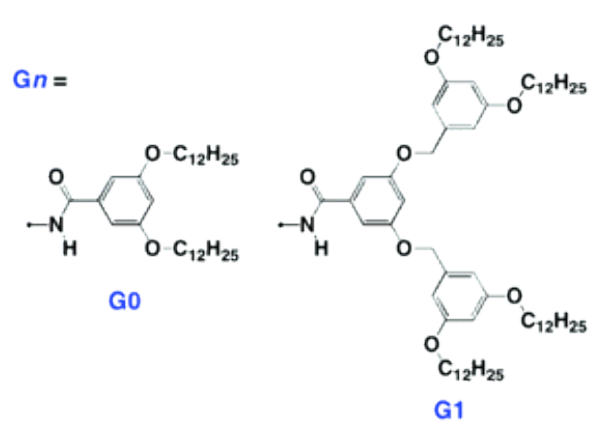

$$
\mathrm{H}_{25} \mathrm{C}_{12}
$$
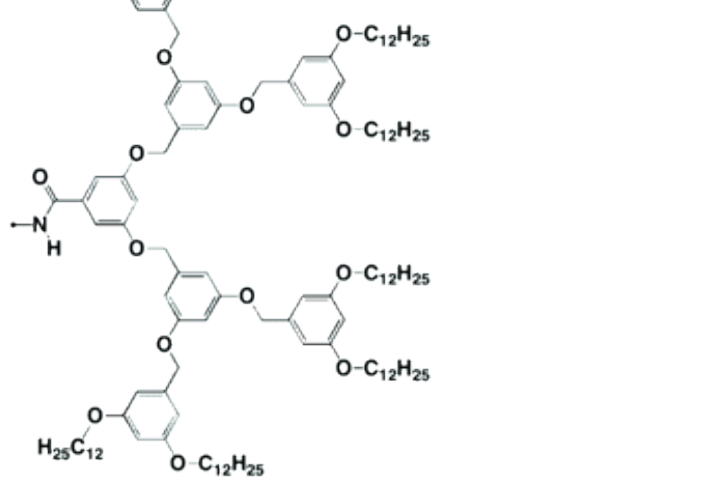

G2

Figure 22. a) Synthetic method of $\left(\left[\mathrm{Fe}\left(\mathrm{G}_{\mathrm{n}} \mathrm{trz}\right)_{3}\right]\left(\mathrm{MeSO}_{3}\right)_{2} \cdot 2 \mathrm{H}_{2} \mathrm{O}\right)$, where $\mathrm{n}=1-3$ and $\mathrm{b}$ ) schematic representation of their discotic columnar core-shell assemblies.[95]

Later, Schlüter and Gütlich reported a series of dendronized iron(II) complexes, making comparative studies by varying the type of dendron ligands, generation number and the nature of the counter-anion, targeting a reversible spin transition.[96] They first synthesized two series of two generations $\left(\mathrm{G}_{1}\right.$ and $\left.\mathrm{G}_{2}\right)$ of $\left[\mathrm{Fe}\left(\mathrm{G}_{\mathrm{n}}, 2-\mathrm{PBE}\right) \mathrm{A}_{2} \cdot \mathrm{xH}_{2} \mathrm{O}\right]$ (with $\mathrm{G}_{1}-\mathrm{PBE}=4-[3,5-$ bis(benzyloxy)benzyl]-4H-1,2,4-triazole) containing the counter-anions (A) of $\mathrm{p}$ toluenesulfonate or trifluorosulfonate (Figure 23). An important aspect of their work is that the bridging ligands containing aliphatic groups aim to minimize the interactions with water and therefore their influence on the spin-state of the complexes. The SCO behavior of the compounds was studied by magnetometry revealing a largely incomplete and very gradual spin crossover below $200 \mathrm{~K}$ in each compound, whereas an abrupt decrease of the $\chi_{M} \mathrm{~T}$ product below $50 \mathrm{~K}$ was attributed to zero-field splitting effects through ${ }^{57} \mathrm{Fe}$ Mössbauer measurements. Later, they extended the study on the structure-property relationship, with respect to the spincrossover behavior, by synthesizing various first generation triazole-dendritic iron(II) complexes and consequently studying their thermal and magnetic properties.[97] In particular, they varied the nature of the ligand (Figure 23a), together with three different counter-anions (tosylate, triflate and tetrafluoroborate). Remarkably, the dependence of the magnetic behavior on the bonded water molecules was straightforward to establish throughout all the synthesized complexes. Specifically after the water molecules were released upon the first heating up to 350 $\mathrm{K}$, the spin-transition in the second heating became gradual. A fair comparison could be performed between all these dendritic SCO complexes, showing that the structure of dendritic ligands and of the spacer between triazole and dendrons, as well as the nature of counter-anions influence significantly the magnetic behaviour. Notably, bonded water molecules influence 
more importantly the magnetic behavior of the complexes containing tosylate instead of triflate counter-anion and/or ligand B instead of ligand C (Figure 23).

a)
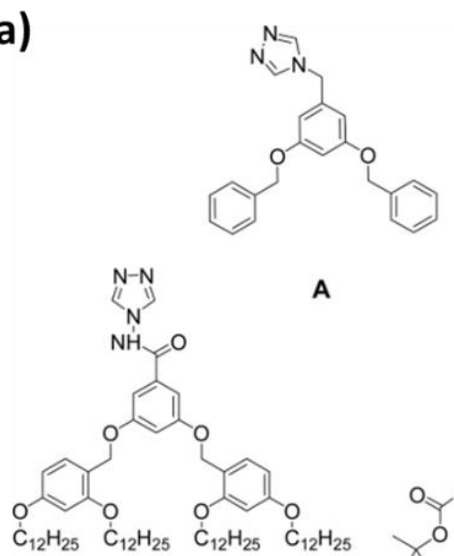

B

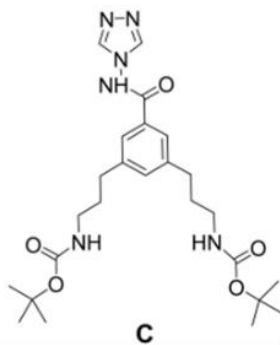

C b)

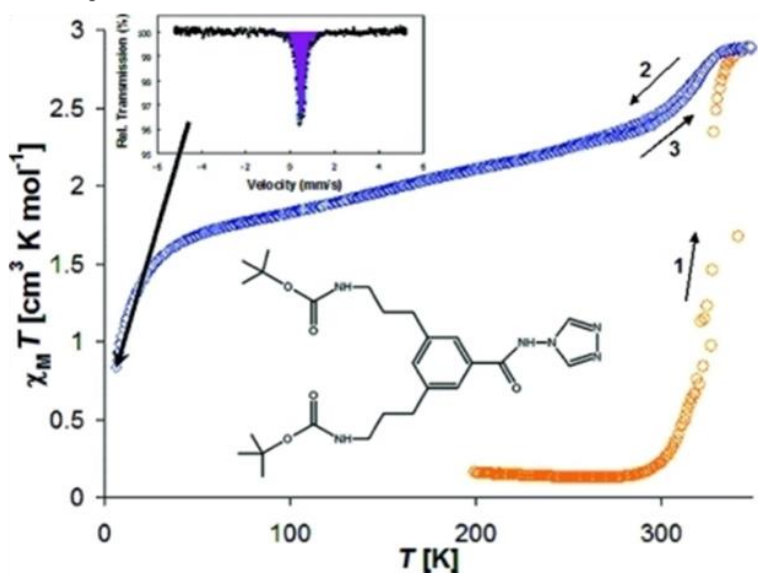

Figure 23. a) Molecular structures of different dendritic triazoles: $\mathrm{G}_{1}-\mathrm{PBE}(\mathbf{A}), \mathrm{G}_{1}$-DPBE (B) and $\mathrm{G}_{1}$-BOC $(\mathbf{C})$ and $\left.b\right)$ temperature dependence of $\chi_{M} \mathrm{~T}$ of the complex $[\mathrm{Fe}(\mathrm{G} 1-$ DPBE $\left.)_{3}\right](\mathrm{OTs})_{2} \cdot \mathrm{xH}_{2} \mathrm{O}$ upon the first two heating-cooling cycles (onset: ${ }^{57} \mathrm{Fe}$ Mössbauer spectrum acquired at $4 \mathrm{~K})$.[97]

Later on, Gruzdev et al. have investigated several Fe(III) dendronized complexes in which the SCO function is found at the focal point of the dendritic structures. First, they have prepared and studied a Schiff-base, bis-chelate Fe(III) complex, based on branched esters with an octahedral coordination of Fe(III).[98] The cyclohexyl termini of the dendrons sterically hindered the complex exhibiting irreversible endothermic solid-solid phase transitions. The magnetic properties of this complex were extensively studied by variable temperature EPR and Mössbauer spectroscopies,[99] suggesting that there is a sequence of magnetic ordering, magneto-electric and spin transition phenomena, making it an intriguing multifunctional material. EPR revealed three magnetically active iron centers, one low spin (LS) and two high spin (HS). Antiferromagnetic exchange interactions between LS-LS, LS-HS and HS-HS centers are observed in the temperature range between $4.2-50 \mathrm{~K}$, magnetoelectric behavior is likely to occur in the range of $50-200 \mathrm{~K}$ and finally, spin-transition from the LS to the HS state was detected in the third temperature range between 200 and $330 \mathrm{~K}$. Another series of dendronized SCO $\left[\left(\mathrm{FeL}_{2}\right) \mathrm{PF}_{6}\right]$ complexes was developed in the same group, with the same core structure whereas the terminal groups were now long alkyl chains $\left(-\mathrm{OC}_{14} \mathrm{H}_{29}\right)$, giving a more complete dendritic structure, with various counter-anions.[100-102] The authors enriched the studies of the magnetic properties of the dendrimeric materials using also magnetometry together with EPR and Mössbauer spectroscopies. The EPR spectra of the $\mathrm{PF}_{6}{ }^{-}$and $\mathrm{Cl}^{-}$complexes show the presence of three different magnetic iron species (two HS and one LS); while for the $\mathrm{ClO}_{4}{ }^{-}$only one HS and LS iron center is observed. To gather more information about the spin transition process, the temperature dependence on the integrated intensity (I) of the EPR sprectrum lines was calculated for the whole EPR spectrum and for the independent iron centers (HSI, HSII and $\mathrm{LS}$ ). For $\mathrm{PF}_{6}{ }^{-}$and $\mathrm{Cl}^{-}$the temperature dependences of the EPR parameters and that of the magnetic susceptibility resemble and indicate no (or very incomplete) SCO. On the other hand, the EPR of $\mathrm{ClO}_{4}^{-}$shows a more obvious, yet partial, spin crossover between 150 and $300 \mathrm{~K}$. An 
explanation to what was observed is proposed by the authors in terms of molecular packing. $\mathrm{Cl}^{-}$ and $\mathrm{PF}_{6}{ }^{-}$ions are able to form a network of hydrogen bonds with the amine groups of the ligand, producing a bilayered packing within a chain structure of ionic bilayers (Figure 24b). This effect is more pronounced with the chloride anions due to their inherent small size resulting in a closer chain packing with higher interactions within the bilayers. Thereof, a low dimensional structure was formed, which stabilized the HS state. Although the perchlorate anions form stronger hydrogen bonds, their bigger size favors the formation of dimeric structures (Figure 24c). Consequently, the size of the counter-anion and its ability to participate effectively in a hydrogen bonding network determines the packing motif of the $\left[\mathrm{Fe}(\mathrm{L})_{2}\right]^{+}$complexes and therefore the magnetic properties of the compound.
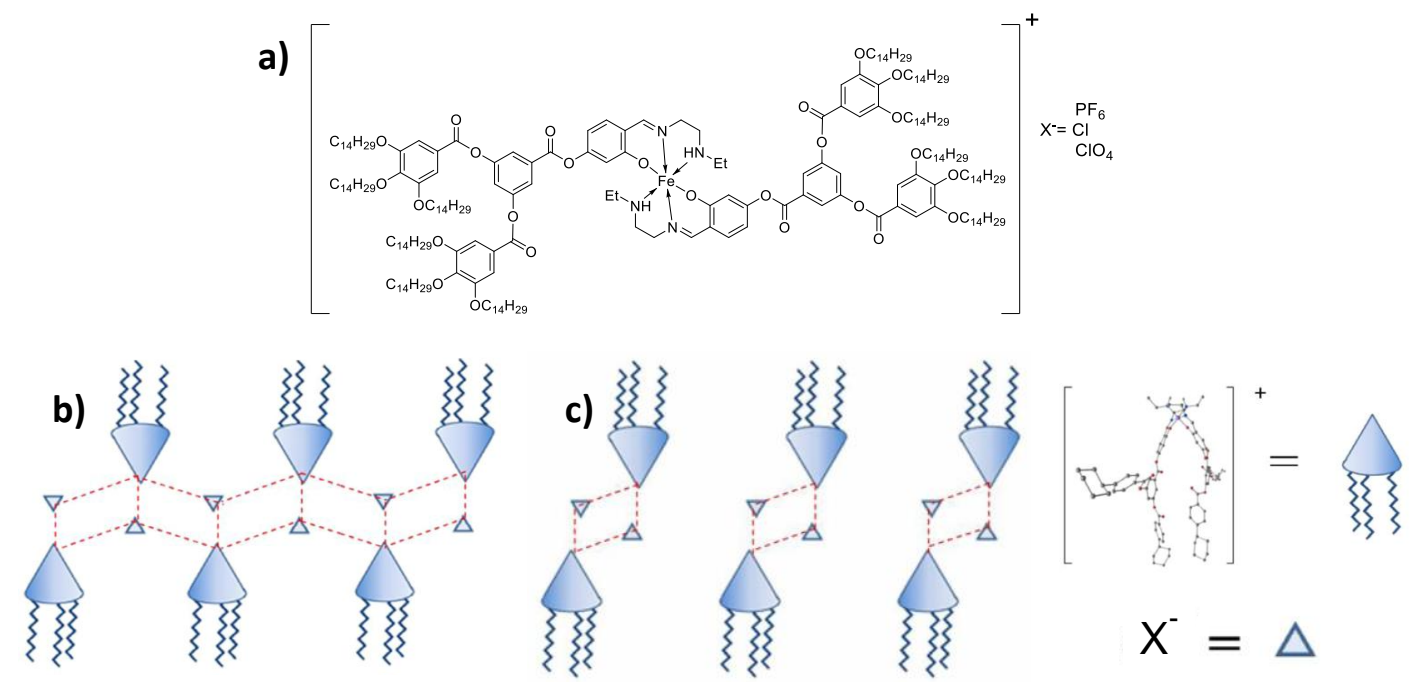

Figure 24. a) General structure of the dendrimers; proposed packing for b) $\left[\mathrm{Fe}(\mathrm{L})_{2}\right] \mathrm{Cl}$ and c) $\left[\mathrm{Fe}(\mathrm{L})_{2}\right] \mathrm{ClO}_{4} \cdot[100]$

\subsection{SCO gels}

Supramolecular or physical gels are formed by intermolecular interactions between molecules or structural motifs that are called 'low weight molecular gelators' (LWMG). These structures are directed through noncovalent bonding interactions (hydrogen bonding, metal bonding, van der Waals ...) of functional groups. The gelation process is considered to be a hierarchical assembly that usually follows the subsequent steps: 1) dimerization of two individual molecules, 2) oligomer formation by interaction of dimers with further molecules, 3) formation of polymer fibrils, 4) fiber formation by bundling of fibrils, 5) interaction of fibers to give an infinite, interconnected network along the entire sample and 6) immobilization of the solvent by the fiber network.[103,104]

Although several examples of SCO gels have been reported in the literature,[46,70,104-114] it is noteworthy that mostly $\mathrm{Fe}$ (II)-triazole complexes containing long or bulky aliphatic ligands or counter-anions were reported to form gels. It is commonly assumed that these types of compounds are efficient gelators due to lipophilic interactions between the aliphatic part of the SCO complexes and the chosen solvents. Yet, at least two examples exist, the $\left[\mathrm{Fe}\left(\mathrm{NH}_{2} \mathrm{trz}\right)_{3}\right](2 \mathrm{~ns})_{2}$ and $\left[\mathrm{Fe}\left(\mathrm{NH}_{2} \mathrm{trz}\right)_{3}\right](\mathrm{OTs})_{2} \quad$ (2ns= 2-naphtalene sulphonate, OTs = ptoluenesulfonate) complexes, wherein gel formation was reported despite the absence of lipophilic properties.[70,112] These results indicate that gel forming ability is perhaps an 
intrinsic property of $\mathrm{Fe}(\mathrm{II})$-triazole complexes. Unfortunately, these complexes have in general poor solubility, which makes difficult to conduct more extensive investigations.

The complex $\left[\mathrm{Fe}(\mathrm{ODT})_{3}\right]^{2+}$, with various counter-anions, is probably the most deeply investigated compound capable to form gels in different solvents. [87,109-111] The group of López et al. studied the physical properties of the corresponding perchlorate complex.[109] They observed that the gel formed in toluene consists of rod-like structures that are randomly oriented. They have a radius in the range of 17-20 $\AA$ that is independent of the temperature and concentration of the gel (consistent with individual fibers of the complex) and a length up to $255 \AA$, which decreases when the temperature or the concentration increases.[111] A hybrid thermo-reversible gel was obtained by combining $\left[\mathrm{Fe}(\mathrm{ODT})_{3}\right]\left(\mathrm{ClO}_{4}\right)_{2}$ with isotactic polystyrene in cis-decalin, resulting in the independent gelation of both systems in the hybrid gel with an interpenetrated network.[115] Among the prominent examples, we can mention also the lipophilic spin-crossover complex $\left[\mathrm{Fe}\left(\mathrm{C}_{12} \mathrm{H}_{25} \mathrm{OC}_{3} \mathrm{H}_{6} \text { - } \mathrm{trz}\right)_{3}\right] \mathrm{Cl}_{2}$.[107] The complex forms gels only when it is dissolved in chloroform or dichloromethane exhibiting a pale yellow color, characteristic of the HS state, whereas the powder form is LS at room temperature. Through casting of this gel, smooth and uniform films exhibiting spin transition at $\mathrm{T}_{\mathrm{SCO}} \sim 321 \mathrm{~K}$ are obtained. Casting the complex with equimolar dodecanol or tetradecanol led to films displaying spin transition with hysteresis, which was attributed to the coupling of the SCO to structural transformations between lamellar and hexagonal structures. The shorter alkyl chain complex $\left[\mathrm{Fe}(\mathrm{hptrz})_{3}\right](\mathrm{OTs})_{2}$ was prepared in chloroform and a fast gelation was observed.[70] This could be avoided by adding a small portion of methanol $(5 \% \mathrm{v} / \mathrm{v})$ that resulted in a stable solution of the complex presenting a slow precipitation within few hours. If this solution is kept at $5{ }^{\circ} \mathrm{C}$ for 1 week, a reversible gel with a gradual spin transition between $305-315 \mathrm{~K}$ physically evolved. Instead of using long chains, bulky alkyl substituents may also give rise to gelation. Notably, Gural'skiy et al. [113] prepared a gel from the chiral spin crossover complex [ $\left.\mathrm{Fe}\left(\mathrm{NH}_{2} \mathrm{trz}\right)_{3}\right](L-$ $\mathrm{CSA})_{2}(L-\mathrm{CSA}=L$-camphorsulphonate $)$ in a $6 \% \mathrm{v} / \mathrm{v}$ solution of DMSO in chloroform. It shows a more gradual transition and a smaller hysteresis $\left(\mathrm{T}_{1 / 2} \uparrow=313 \mathrm{~K}\right.$ and $\left.\mathrm{T}_{1 / 2} \downarrow=310 \mathrm{~K}\right)$ compared to the bulk system. Interestingly, the spin transition could also be observed by circular dichroism (CD) with a negative peak at $540 \mathrm{~nm}$ for the LS state, which disappears when it passes to the HS state. As mentioned above, the complex $\left[\mathrm{Fe}\left(\mathrm{NH}_{2} \mathrm{trz}\right)_{3}\right](2 \mathrm{~ns})_{2}$ represents a particular case.[116] It gelates in DMF under high iron concentration or high $\mathrm{NH}_{2}$ trz/Fe ratios, forming rigid rods with a hexagonal columnar packing $\left(\mathrm{Col}_{h}\right)$, which exhibit $\mathrm{SCO}$ with $\mathrm{T}_{1 / 2} \uparrow=321 \mathrm{~K}$ and $\mathrm{T}_{1 / 2} \downarrow=310 \mathrm{~K}$. If a layer of toluene is added to the gelation process, while the complex is still in solution, a second type of gel is obtained, which displays $\mathrm{SCO}$ with $\mathrm{T}_{1 / 2} \uparrow=328 \mathrm{~K}$ and $\mathrm{T}_{1 / 2 \downarrow} \downarrow=315 \mathrm{~K}$. From this second gel type, xerogels can be obtained using the critical-point drying technique, preserving the original shape with only $\sim 30 \%$ reduction in volume and the SCO with $\mathrm{T}_{1 / 2} \uparrow=305 \mathrm{~K}$ and $\mathrm{T}_{1 / 2} \downarrow=293 \mathrm{~K}$. If the xerogel is annealed at $523 \mathrm{~K}$, the crystalline structure changes from $\mathrm{Col}_{\mathrm{h}}$ to a rectangular columnar packing $\left(\mathrm{Col}_{\mathrm{r}}\right)$ as seen in Figure 25.[112] 
a)

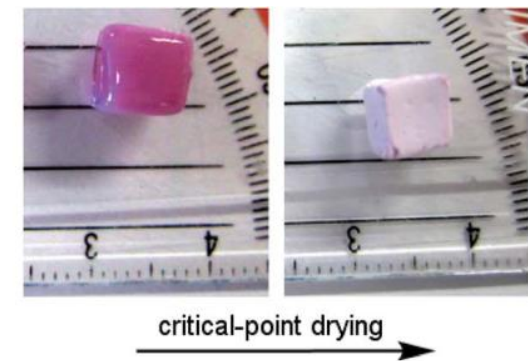

b)

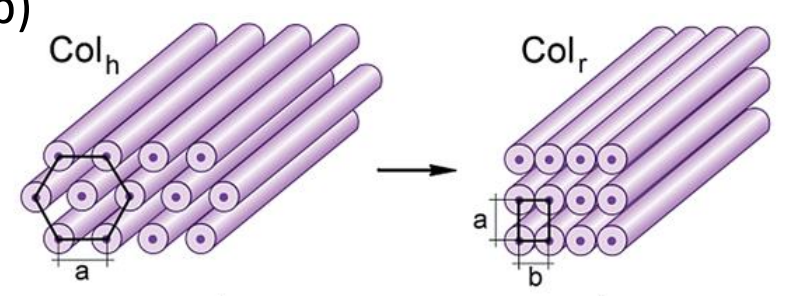

c)

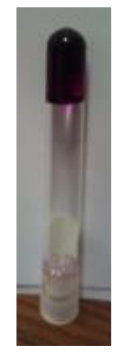

Figure 25. a) Xerogel obtained from a gel of $\left[\mathrm{Fe}\left(\mathrm{NH}_{2} \mathrm{trz}\right)_{3}\right](2 \mathrm{~ns})_{2}$; b) Representation of the Col $\mathrm{C}_{\mathrm{h}}$ crystalline packing in the xerogel that transfoms into $\mathrm{Col}_{\mathrm{r}}$ after heating at $523 \mathrm{~K}$; c) gel of $\left[\mathrm{Fe}\left(\mathrm{NH}_{2} \mathrm{trz}\right)_{3}\right](\mathrm{OTs})_{2 \cdot[70,112]}$

\subsection{SCO compounds with liquid crystal properties}

In contrast to compounds with gel properties corresponding to a three-dimensional network of entangled solid diluted in liquid, compounds with liquid crystal properties concern a state a matter which combines the properties of a conventional liquid and those of a crystallized solid. These compounds received attention of the SCO community as they provide scope for the synthesis of multifunctional materials with, in best case scenario, an interplay between the spin transition and (various) liquid crystal transitions.

The first example of an SCO compound obtained in the form of liquid crystal film thanks to a drop casting technic was reported in 2001 by Galyametdinov et al. [117] In this iron(III) complex whose coordination sphere is completed by two L Schiff base ligands resulting from the condensation of 4-(dodecyloxybenzoyloxy)-2-hydroxybenzaldehyde with $\mathrm{N}$ ethylethylenediamine $\left[\mathrm{Fe}^{\mathrm{III}} \mathrm{L}_{2}\left(\mathrm{PF}_{6}\right)\right]$, the long chain of the ligand is responsible for the liquid crystal properties of the complex. The obtained mesophase is of the smectic type, which corresponds to molecules organized in layers with an order of orientation and position, therefore close to the crystalline solid state. (In contrast, a nematic mesophase has only an orientation order and is closer to an isotropic liquid.) In this case, the spin and liquid crystal transition properties do not operate in the same temperature range. The compound displays a gradual spin conversion between 300 and $80 \mathrm{~K}$, while the smectic phase forms around $400 \mathrm{~K}$. Hayami et al. also obtained a liquid crystal with the iron(II) complex [Fe(3C16-L $\left.)_{2}(\mathrm{NCS})_{2}\right]$ with $3 \mathrm{C} 16-\mathrm{L}=$ 3,4,5-tris (hexadecyloxy)-N-((pyridin-2-yl) methylene) benzenamine, a Schiff base obtained by condensation of 3,4,5-tris(hexadecyloxy)aniline with pyridine-2-carboxyaldehyde.[118] This compound presents a photo-induced effect at low temperature, a gradual SCO centered at 230 $\mathrm{K}$ and a smectic phase above $350 \mathrm{~K}$. In 2006, Seredyuk et al. reported a compound with a more cooperative spin transition and concomitant spin and liquid crystal transition properties.[119] They used a triazole ligand functionalized by aromatic/alkyl chains (3,5-dialkoxy-N-4H-1,2,4triazol-4-ylbenzamide ligand) leading to the one-dimensional coordination network $\left[\mathrm{Fe}\left(\mathrm{C}_{\mathrm{n}^{-}}\right.\right.$ trz) $\left.{ }_{3}\right]\left(4-\mathrm{MeC}_{6} \mathrm{H}_{4} \mathrm{SO}_{3}\right)_{2}$ (where $\mathrm{n}=8,10,12$ corresponds to the carbon number of the alkyl chain). Thermochromic films could be obtained by evaporation of a solution in chloroform on a glass substrate (Figure 26). This compound exhibits an abrupt spin transition near $330 \mathrm{~K}$ and a discotic phase (mesophase of the smectic type in column form) from $230 \mathrm{~K}$, then an isotropisation (mesophase-liquid transition) around $500 \mathrm{~K}$. Nevertheless, it has been concluded that the phase change from the crystalline state to the liquid crystal state is not the driving force of the spin transition behavior of these compounds.[120] The groups of Hayami [121] and 
Clérac [122] synthesized similar more cooperative systems by modifying the nature and the length of the aliphatic chain of the ligand. Hayami et al. $[123,124]$ reported the synthesis of the cobalt(II) derivatives, $\left[\mathrm{Co}\left(\mathrm{C}_{\mathrm{n}} \text {-terpy }\right)_{2}\right]\left(\mathrm{BF}_{4}\right)$, with various terpyridine ligands with branched chains of different lengths $\mathrm{n}$. In these cases, the spin transition behavior is triggered by the structural phase transition. Finally, the first examples of two-dimensional hetero-metallic compounds $\left[\mathrm{Fe}^{\mathrm{II}} \mathrm{L}_{2}\left(\mathrm{M}^{\mathrm{I}} /{ }^{\mathrm{II}}(\mathrm{CN})_{\mathrm{x}}\right]\right.$ with $\mathrm{L}=4$-(4-alkoxyphenyl)pyridine, 4-(3,4-dialkoxyphenyl) pyridine or 4-(3,4,5-trisalkoxyphenyl) pyridine were reported by Seredyuk et al. [125] These compounds exhibit gradual SCO with transition temperatures dissociated from the crystalsmectic phase transition temperature.

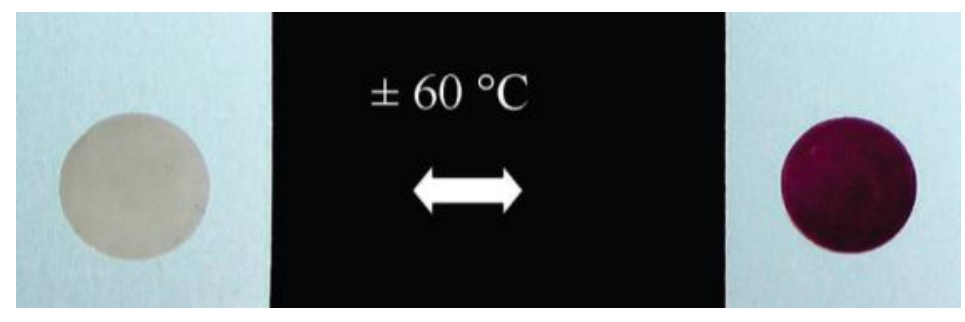

Figure 26. Thermochromic effect of the liquid crystal film $\left[\mathrm{Fe}\left(\mathrm{C}_{12}-\operatorname{trz}\right)_{3}\right](4-$ $\left.\mathrm{MeC}_{6} \mathrm{H}_{4} \mathrm{SO}_{3}\right)_{2} \cdot[119]$

\subsection{Langmuir-Blodgett films displaying SCO phenomenon}

One of the first approaches for the development of SCO films was the Langmuir-Blodgett technique. This technique consists in forming a monolayer of compound on the surface of an aqueous solution thanks to the presence of amphiphilic molecules, then transferring it to a solid surface by soaking a substrate in the solution. Either monolayer or multilayer films can be formed by this approach.

From 1988, the first Langmuir-Blodgett film production trials were carried out with iron(II) compounds carrying amphiphilic ligands derived from phenanthroline. Notably, the $\left(\mathrm{Fe}(\mathrm{OP} 3)_{2}(\mathrm{NCS})_{2}\right.$ complex $(\mathrm{OP} 3=1,10$-phenanthroline (phen) substituted by three linear aliphatic chains with 18 carbon atoms) [126] and the triazole-derivative complex [Fe $\left.(\mathrm{ODT})_{3}\right](\mathrm{X})_{2}\left(\mathrm{X}=\mathrm{ClO}_{4}\right.$, OTf or OTs [127] were deposited on a quartz or $\mathrm{CaF}_{2}$ substrates. The instability of these compounds at the air-water interface does not allow the production of films. In 1998, Soyer and collaborators worked on the modification of the interface and the first films of the compound $\mathrm{Fe}^{\mathrm{II}}$ (trans-hsbpy) $)_{2}(\mathrm{NCS})_{2}$ (trans-nhbpy = 4-heptadecyl-4'-trans-styryl-2,2'bipyridine) were obtained at the air-formamide/water interface and transferred to $\mathrm{CaF}_{2}$ substrates.[128] However, the produced mono- and multilayers quickly deteriorated. The following year, the same group reported more stable films by modifying the chemical structure of the complex (substitution of the bipyridine ligand by methyl or $\left(-\mathrm{CH}_{2}\right)_{12}\left(\mathrm{CF}_{2}\right)_{5} \mathrm{CF}_{3}$ and by depositing the films on polyethylene terephthalate (Mylar) substrates.[129] The magnetic study carried out on a 1200-layer deposit revealed the influence of the architecture of the LangmuirBlodgett films on the spin transition properties of these compounds, which could ultimately be used as a new parameter to control the properties of spin transition in these materials. Roubeau and collaborators reported for the first time Langmuir-Blodgett films active at room temperature based on the compound $\left[\mathrm{Fe}^{\mathrm{II}}(\mathrm{ODT})_{3}\right]\left(\mathrm{NO}_{3}\right)_{2}$.[130] Obtaining these films was made possible due to the presence of an excess of iron nitrate in the aqueous phase, which ensures the recoordination of the polymeric species during the transfer of the film onto the substrate (Mylar 
or glass or $\mathrm{CaF}_{2}$ made hydrophobic by treatment with arachidic acid). In 2010, Kitchen and collaborators published the development of stable films based on the monomeric complex $\mathrm{Fe}^{\mathrm{II}}(\mathrm{C} 16 \mathrm{dpt})_{2}(\mathrm{NCS})_{2} \quad(\mathrm{C} 16 \mathrm{dpt}=\mathrm{N}$-hexadecyl-3,5-di(2-pyridyl)-4H-1,2,4-triazole), which exhibits a gradual spin conversion around room temperature.[131] Despite the few successes in the development of ultra-thin active films with mono- or polynuclear compounds, the development of this technique suffers from the sensitivity of the compounds to the gas-liquid interfaces during transfer to the substrates and above all limitation of the number of amphiphilic molecules with spin transition due to drastic changes, or even the loss of spin transition properties during the insertion of hydrophobic chains on already known compounds.[132]

\section{Concluding remarks and prospects}

Driven to a large extent by the need for versatile methods for processing spin crossover complexes into films, micro/nano-structures and other technologically relevant objects, SCOpolymer composites and related soft materials have gained considerable interest in the past two decades. Following the achievements we reviewed in this paper, several important perspectives can be highlighted at the frontiers of coordination chemistry, polymer science and engineering:

- From the onset of this research line, it has become clear that the SCO properties are often substantially altered by the confinement/organization of the metal complexes within the polymer matrices. Vice versa, the physical properties of the matrix are modified by the presence of the SCO complexes and these interactions between the polymer and the filler are spin-state dependent. Yet, we have to admit that our understanding of these fundamental aspects remains currently in a rudimentary stage. Mechano-elastic effects are often suspected to play a pivotal role in this context,[133] but only a few deep investigations have been conducted to analyse the relevant physicochemical phenomena in these complex, heterogeneous and dynamical systems. Notably, it turns out that most of the reported work were done either by specialists of SCO or by polymer scientists, and a tighter collaboration between these two communities would be thus highly beneficial.

- We have seen that SCO-polymer composites and, in general, 'soft SCO materials' have been successfully processed into different shapes at different size scales. This has led to numerous application ideas and even a few 'proof of concept' devices (e.g. sensors, actuators, displays, etc.). However, to our best knowledge, no technologically relevant examples have been reported up to now. A critical assessment of these technological prospects should be thus carried out through the detailed performance analysis of functional SCO-polymer based devices.

- Beyond material processing, SCO-polymer composites provide scope also for material engineering. In particular, electroactive polymers were reported to display interesting synergies with SCO materials through electro-mechanical couplings. In general, we expect that engineering through strain coupling will play an increasing role in this field with appealing prospects for the development of smart, multifunctional materials. In this context, emerging graphene-based SCO composites will likely play also an important role, exploiting couplings to the unique electrical, mechanical and thermal properties of graphene.[134-136] 
- Whereas reports on SCO-polymer composites and 'soft SCO materials' functionalized with alkyl chains are numerous, less attention have been devoted to the synthesis of "SCO-organic polymers". We believe such compounds hold important promises, in particular for biomedical and life sciences, and we expect that their development will intensify in the near future.

\section{Acknowledgments}

Financial support from the ANR project 19-CE09-0008-01, from the CONACYT (AEC), Occitanie Région and the Federal University of Toulouse (MPB) is acknowledged.

\section{References}

[1] J. Ahmad, Machining of Polymer Composites, Springer US, Boston, MA, 2009, pp. 1315 https://doi.org/10.1007/978-0-387-68619-6.

[2] K.P. Ashik, R.S. Sharma, A Review on Mechanical Properties of Natural Fiber Reinforced Hybrid Polymer Composites, J. Miner. Mater. Charact. Eng. 03 (2015) 420-426. https://doi.org/10.4236/jmmce.2015.35044.

[3] L.C. Hollaway, M.K. Chryssanthopoulos, S.S.J. Moy, eds., Advanced polymer composites for structural applications in construction, Woodhead Publishing Limited, 2004.

[4] P.E. Irving, C. Soutis, eds., Polymer Composites in the Aerospace Industry, Elsevier, 2014. https://doi.org/10.1016/C2013-0-16303-9.

[5] K. Friedrich, A.A. Almajid, Manufacturing Aspects of Advanced Polymer Composites for Automotive Applications, Appl. Compos. Mater. 20 (2013) 107-128. https://doi.org/10.1007/s10443-012-9258-7.

[6] P. Gütlich, H.A. Goodwin, eds., Spin Crossover in Transition Metal Compounds I, 1st ed., Springer Berlin Heidelberg, Berlin, Heidelberg, 2004. https://doi.org/10.1007/b40394-9.

[7] P. Gütlich, H.A. Goodwin, eds., Spin Crossover in Transition Metal Compounds II, 1st ed., Springer Berlin Heidelberg, Berlin, Heidelberg, 2004. https://doi.org/10.1007/b93641.

[8] P. Gütlich, H.A. Goodwin, eds., Spin Crossover in Transition Metal Compounds III, 1st ed., Springer Berlin Heidelberg, Berlin, Heidelberg, 2004. https://doi.org/10.1007/b96439.

[9] M.A. Halcrow, Spin-Crossover Materials: Properties and Applications, John Wiley \& Sons Ltd, Oxford, UK, 2013. https://doi.org/10.1002/9781118519301.

[10] A. Bousseksou, Spin crossover phenomenon, Comptes Rendus Chim. 21 (2018) 10551300 .

[11] A. Bousseksou, G. Molnár, L. Salmon, W. Nicolazzi, Molecular spin crossover phenomenon: recent achievements and prospects, Chem. Soc. Rev. 40 (2011) 3313. https://doi.org/10.1039/c1cs15042a.

[12] C.L. Xie, D.N. Hendrickson, Mechanism of Spin-State Interconversion in Ferrous 
Spin-Crossover Complexes: Direct Evidence for Quantum Mechanical Tunneling, J. Am. Chem. Soc. 109 (1987) 6981-6988. https://doi.org/10.1021/ja00257a013.

[13] A. Hauser, J. Adler, P. Gütlich, Light-induced excited spin state trapping (LIESST) in $\left[\mathrm{Fe}(2-\text {-mephen })_{3}\right]^{2+}$ embedded in polymer matrices, Chem. Phys. Lett. 152 (1988) 468472. https://doi.org/10.1016/0009-2614(88)80443-3.

[14] O. Kahn, J. Kröber, C. Jay, Spin Transition Molecular Materials for displays and data recording, Adv. Mater. 4 (1992) 718-728. https://doi.org/10.1002/adma.19920041103.

[15] O. Kahn, C.J. Martinez, Spin-transition polymers: From molecular materials toward memory devices, Science. 279 (1998) 44-48. https://doi.org/10.1126/science.279.5347.44.

[16] S. Rat, M. Piedrahita-Bello, L. Salmon, G. Molnár, P. Demont, A. Bousseksou, Coupling Mechanical and Electrical Properties in Spin Crossover Polymer Composites, Adv. Mater. 30 (2018) 1705275. https://doi.org/10.1002/adma.201705275.

[17] K. Senthil Kumar, M. Ruben, Emerging trends in spin crossover (SCO) based functional materials and devices, Coord. Chem. Rev. 346 (2017) 176-205. https://doi.org/10.1016/j.ccr.2017.03.024.

[18] L. Salmon, L. Catala, Spin-crossover nanoparticles and nanocomposite materials, Comptes Rendus Chim. 21 (2018) 1230-1269. https://doi.org/10.1016/j.crci.2018.07.009.

[19] C. Enachescu, W. Nicolazzi, Elastic models, lattice dynamics and finite size effects in molecular spin crossover systems, Comptes Rendus Chim. 21 (2018) 1179-1195. https://doi.org/10.1016/j.crci.2018.02.004.

[20] M. Piedrahita-Bello, L. Salmon, G. Molnar, P. Demont, B. Martin, A. Bousseksou, Mechano-electric coupling in $\mathrm{P}(\mathrm{VDF}-\mathrm{TrFE}) / \mathrm{spin}$ crossover composites, J. Mater. Chem. C. (2020). https://doi.org/10.1039/D0TC00780C.

[21] S. Park, H. Kim, M. Vosgueritchian, S. Cheon, H. Kim, J.H. Koo, T.R. Kim, S. Lee, G. Schwartz, H. Chang, Z. Bao, Stretchable energy-harvesting tactile electronic skin capable of differentiating multiple mechanical stimuli modes, Adv. Mater. 26 (2014) 7324-7332. https://doi.org/10.1002/adma.201402574.

[22] S.W. Lee, J.W. Lee, S.H. Jeong, I.W. Park, Y.M. Kim, J.I. Jin, Processable magnetic plastics composites - Spin crossover of PMMA/Fe(II)-complexes composites, Synth. Met. 142 (2004) 243-249. https://doi.org/10.1016/j.synthmet.2003.09.011.

[23] S.H. Jeong, K.N. Kim, J.S. Kang, C.S. Hong, D.H. Choi, J. Il Jin, I.W. Park, M.G. Kim, Storing spin-crossover and LC phase transitions information by hybridizing spincrossover complexes with a thermotropic polymer matrix - A novel case of multiple switching, Mol. Cryst. Liq. Cryst. 471 (2007) 3-10. https://doi.org/10.1080/15421400701544422.

[24] Y. Chen, J.G. Ma, J.J. Zhang, W. Shi, P. Cheng, D.Z. Liao, S.P. Yan, Spin crossovermacromolecule composite nano film material, Chem. Commun. 46 (2010) 5073-5075. https://doi.org/10.1039/b927191k.

[25] M. Rubio, R. Hernández, A. Nogales, A. Roig, D. López, Structure of a spin-crossover 
$\mathrm{Fe}(\mathrm{II})-1,2,4-$ triazole polymer complex dispersed in an isotactic polystyrene matrix, Eur. Polym. J. 47 (2011) 52-60. https://doi.org/10.1016/j.eurpolymj.2010.10.029.

[26] C. Echeverria, M. Rubio, G.R. Mitchell, A. Roig, D. Lõpez, Hybrid polystyrene based electrospun fibers with spin-crossover properties, J. Polym. Sci. Part B Polym. Phys. 53 (2015) 814-821. https://doi.org/10.1002/polb.23702.

[27] S. Basak, P. Hui, R. Chandrasekar, Flexible and optically transparent polymer embedded nano/micro scale spin crossover Fe(II) complex patterns/arrays, Chem. Mater. 25 (2013) 3408-3413. https://doi.org/10.1021/cm401058s.

[28] F. Novio, E. Evangelio, N. Vazquez-Mera, P. González-Monje, E. Bellido, S. Mendes, N. Kehagias, D. Ruiz-Molina, Robust spin crossover platforms with synchronized spin switch and polymer phase transition, Sci. Rep. 3 (2013) 1-7.

https://doi.org/10.1038/srep01708.

[29] N. Kojima, S. Toyazaki, M. Itoi, Y. Ono, W. Aoki, Y. Kobayashi, M. Seto, T. Yokoyama, Search on Multi-Functional Properties of Spin-Crossover System, Mol. Cryst. Liq. Cryst. 376 (2002) 567-574. https://doi.org/10.1080/713738447.

[30] A. Nakamoto, Y. Ono, N. Kojima, D. Matsumura, T. Yokoyama, Spin crossover complex film, [Fe $\left.{ }^{\mathrm{II}}(\mathrm{H}-\mathrm{trz})_{3}\right]-\mathrm{Nafion}$, with a spin transition around room temperature, Chem. Lett. 32 (2003) 336-337. https://doi.org/10.1246/cl.2003.336.

[31] X.J. Liu, Y. Moritomo, A. Nakamura, T. Hirao, S. Toyazaki, N. Kojima, Photoinduced phase transition and relaxation behavior in a spin-crossover Fe (II) complex Nafion[Fe(Htrz) $)_{3}$ film, J. Phys. Soc. Japan. 70 (2001) 2521-2524. https://doi.org/10.1143/JPSJ.70.2521.

[32] A. Nakamoto, N. Kojima, L. Xiaojun, Y. Moritomo, A. Nakamura, Demonstration of the thermally induced high spin-low spin transition for a transparent spin crossover complex film [Fe(II)(H-trz) 3 ]-Nafion (trz = triazole), Polyhedron. 24 (2005) 29092912. https://doi.org/10.1016/j.poly.2005.03.040.

[33] A. Nakamoto, Y. Ono, N. Kojima, D. Matsumura, T. Yokoyama, X.J. Liu, Y. Moritomo, Spin transition and its photo-induced effect in spin crossover complex film based on [Fe(II)(trz) 3 ], Synth. Met. 137 (2003) 1219-1220. https://doi.org/10.1016/S0379-6779(02)01058-5.

[34] A. Nakamoto, H. Kamebuchi, M. Enomoto, N. Kojima, Study on the spin crossover transition and glass transition for Fe(II) complex film, [Fe(II)(H-triazole) 3 ] Nafion, by means of Mössbauer spectroscopy, Hyperfine Interact. 205 (2012) 41-45. https://doi.org/10.1007/s10751-011-0477-3.

[35] T.D. Gierke, G.E. Munn, F.C. Wilson, The morphology in nafion perfluorinated membrane products, as determined by wide- and small-angle x-ray studies, J. Polym. Sci. Polym. Phys. Ed. 19 (1981) 1687-1704. https://doi.org/10.1002/pol.1981.180191103.

[36] C. Heitner-Wirguin, Recent advances in perfluorinated ionomer membranes: structure, properties and applications, J. Memb. Sci. 120 (1996) 1-33. https://doi.org/10.1016/0376-7388(96)00155-X.

[37] H. Kamebuchi, T. Jo, H. Shimizu, A. Okazawa, M. Enomoto, N. Kojima, Development 
of pH-sensitive spin-crossover iron(II) complex films, [Fe (diAMsar)] Nafion: Manipulation of the spin state by proton concentration, Chem. Lett. 40 (2011) 888889. https://doi.org/10.1246/cl.2011.888.

[38] G.P. Vishnevskaya, E.N. Frolova, I. V. Ovchinnikov, I.G. Pervova, Z.G. Rezinskikh, The spin-transition properties of $\mathrm{Fe}(\mathrm{III})$ complexes with hetarylformazan in an ionexchange polymer: An EPR study, Russ. J. Phys. Chem. A. 84 (2010) 1388-1394. https://doi.org/10.1134/S0036024410080200.

[39] P. Durand, S. Pillet, E.E. Bendeif, C. Carteret, M. Bouazaoui, H. El Hamzaoui, B. Capoen, L. Salmon, S. Hébert, J. Ghanbaja, L. Aranda, D. Schaniel, Room temperature bistability with wide thermal hysteresis in a spin crossover silica nanocomposite, J. Mater. Chem. C. 1 (2013) 1933-1942. https://doi.org/10.1039/c3tc00546a.

[40] D. Onggo, O.K. Putri, M. Aminah, Utilization of nata de coco as a matrix for preparation of thin film containing spin crossover iron (II) complexes, IOP Conf. Ser. Mater. Sci. Eng. 79 (2015). https://doi.org/10.1088/1757-899X/79/1/012021.

[41] D. Onggo, I. Mulyani, F.J. Valverde-Muñoz, J.A. Real, G. Molnar, Bistable thermochromic and magnetic spin crossover microcrystals embedded in nata de coco bacterial cellulose biofilm, Cellulose. 24 (2017) 2205-2213. https://doi.org/10.1007/s10570017-1248-3.

[42] Y.X. Wang, D. Qiu, Z.H. Li, Z.G. Gu, X. Ren, Z. Li, Resin-Assisted Constructive Synthesis of Spin-Crossover Nanorod Arrays, Eur. J. Inorg. Chem. 2016 (2016) 45814585. https://doi.org/10.1002/ejic.201600774.

[43] J. Larionova, L. Salmon, Y. Guari, A. Tokarev, K. Molvinger, G. Molnár, A. Bousseksou, Towards the ultimate size limit of the memory effect in spin-crossover solids, Angew. Chem. Int. Ed. 47 (2008) 8236-8240. https://doi.org/10.1002/anie.200802906.

[44] A. Tokarev, J. Long, Y. Guari, J. Larionova, F. Quignard, P. Agulhon, M. Robitzer, G. Molnár, L. Salmon, A. Bousseksou, Spin crossover polysaccharide nanocomposites, New J. Chem. 37 (2013) 3420-3432. https://doi.org/10.1039/c3nj00534h.

[45] C. Faulmann, J. Chahine, I. Malfant, D. De Caro, B. Cormary, L. Valade, A facile route for the preparation of nanoparticles of the spin-crossover complex $\left[\mathrm{Fe}(\mathrm{Htrz})_{2}(\operatorname{trz})\right]\left(\mathrm{BF}_{4}\right)$ in xerogel transparent composite films, Dalton Trans. 40 (2011) 2480-2485. https://doi.org/10.1039/c0dt01586e.

[46] H. Voisin, C. Aimé, A. Vallée, A. Bleuzen, M. Schmutz, G. Mosser, T. Coradin, C. Roux, Preserving the spin transition properties of iron-triazole coordination polymers within silica-based nanocomposites, J. Mater. Chem. C. 5 (2017) 11542-11550. https://doi.org/10.1039/c7tc04194b.

[47] H. Voisin, C. Aimé, A. Vallée, T. Coradin, C. Roux, A flexible polymer-nanoparticle hybrid material containing triazole-based $\mathrm{Fe}$ (II) with spin crossover properties for magneto-optical applications, Inorg. Chem. Front. 5 (2018) 2140-2147. https://doi.org/10.1039/C8QI00494C.

[48] K. Kuroiwa, T. Arie, S. Sakurai, S. Hayami, T.J. Deming, Supramolecular control of reverse spin transitions in cobalt(II) terpyridine complexes with diblock copolypeptide 
amphiphiles, J. Mater. Chem. C. 3 (2015) 7779-7783.

https://doi.org/10.1039/c5tc00677e.

[49] A. Tsubasa, S. Otsuka, T. Maekawa, R. Takano, S. Sakurai, T.J. Deming, K. Kuroiwa, Development of hybrid diblock copolypeptide amphiphile/magnetic metal complexes and their spin crossover with lower-critical-solution-temperature(LCST)-type transition, Polymer. 128 (2017) 347-355.

https://doi.org/10.1016/j.polymer.2016.12.079.

[50] H.J. Shepherd, I.A. Gural'skiy, C.M. Quintero, S. Tricard, L. Salmon, G. Molnár, A. Bousseksou, Molecular actuators driven by cooperative spin-state switching, Nat. Commun. 4 (2013) 2607. https://doi.org/10.1038/ncomms3607.

[51] I.A. Gural'Skiy, C.M. Quintero, J.S. Costa, P. Demont, G. Molnár, L. Salmon, H.J. Shepherd, A. Bousseksou, Spin crossover composite materials for electrothermomechanical actuators, J. Mater. Chem. C. 2 (2014) 2949-2955. https://doi.org/10.1039/c4tc00267a.

[52] Y.C. Chen, Y. Meng, Z.P. Ni, M.L. Tong, Synergistic electrical bistability in a conductive spin crossover heterostructure, J. Mater. Chem. C. 3 (2015) 945-949. https://doi.org/10.1039/c4tc02580f.

[53] A. Lapresta-Fernández, M.P. Cuéllar, J.M. Herrera, A. Salinas-Castillo, M.D.C. Pegalajar, S. Titos-Padilla, E. Colacio, L.F. Capitán-Vallvey, Particle tuning and modulation of the magnetic/colour synergy in Fe(II) spin crossover-polymer nanocomposites in a thermochromic sensor array, J. Mater. Chem. C. 2 (2014) 72927303. https://doi.org/10.1039/c4tc00969j.

[54] A. Lapresta-Fernández, S. Titos-Padilla, J.M. Herrera, A. Salinas-Castillo, E. Colacio, L.F. Capitán Vallvey, Photographing the synergy between magnetic and colour properties in spin crossover material $\left[\mathrm{Fe}\left(\mathrm{NH}_{2} \mathrm{trz}\right)_{3}\right]\left(\mathrm{BF}_{4}\right)_{2}:$ a temperature sensor perspective, Chem. Commun. 49 (2013) 288-290.

https://doi.org/10.1039/C2CC36320H.

[55] M.P. Cuéllar, A. Lapresta-Fernández, J.M. Herrera, A. Salinas-Castillo, M.D.C. Pegalajar, S. Titos-Padilla, E. Colacio, L.F. Capitán-Vallvey, Thermochromic sensor design based on $\mathrm{Fe}$ (II) spin crossover/polymers hybrid materials and artificial neural networks as a tool in modelling, Sensors Actuators B Chem. 208 (2015) 180-187. https://doi.org/10.1016/j.snb.2014.11.025.

[56] K.A. Vinogradova, D.P. Pishchur, I. V. Korolkov, M.B. Bushuev, Magnetic properties and vapochromism of a composite on the base of an iron(II) spin crossover complex, Inorg. Chem. Commun. 105 (2019) 82-85.

https://doi.org/10.1016/j.inoche.2019.04.035.

[57] M.B. Bushuev, D.P. Pishchur, I. V. Korolkov, K.A. Vinogradova, Prototypical iron(II) complex with 4-amino-1,2,4-triazole reinvestigated: an unexpected impact of water on spin transition, Phys. Chem. Chem. Phys. 19 (2017) 4056-4068.

https://doi.org/10.1039/C6CP06854E.

[58] V. Nagy, K. Halász, M.T. Carayon, I.A. Gural'skiy, S. Tricard, G. Molnár, A. Bousseksou, L. Salmon, L. Csóka, Cellulose fiber nanocomposites displaying spincrossover properties, Colloids Surfaces A Physicochem. Eng. Asp. 456 (2014) 35-40. 
https://doi.org/10.1016/j.colsurfa.2014.05.007.

[59] V. Nagy, I. Suleimanov, G. Molnár, L. Salmon, A. Bousseksou, L. Csóka, Cellulosespin crossover particle composite papers with reverse printing performance: A proof of concept, J. Mater. Chem. C. 3 (2015) 7897-7905. https://doi.org/10.1039/c5tc01246e.

[60] S. Rat, V. Nagy, I. Suleimanov, G. Molnár, L. Salmon, P. Demont, L. Csóka, A. Bousseksou, Elastic coupling between spin-crossover particles and cellulose fibers, Chem. Commun. 52 (2016) 11267-11269. https://doi.org/10.1039/c6cc06137k.

[61] B. Dreyer, D. Natke, S. Klimke, S. Baskas, R. Sindelar, G. Klingelhöfer, F. Renz, Implementation of spin crossover compounds into electrospun nanofibers, Hyperfine Interact. 239 (2018) 2-9. https://doi.org/10.1007/s10751-017-1483-x.

[62] W. Hellel, A. Ould Hamouda, J. Degert, J.F. Létard, E. Freysz, Switching of spin-state complexes induced by the interaction of a laser beam with their host matrix, Appl. Phys. Lett. 103 (2013). https://doi.org/10.1063/1.4824028.

[63] M.D. Manrique-Juárez, F. Mathieu, A. Laborde, S. Rat, V. Shalabaeva, P. Demont, O. Thomas, L. Salmon, T. Leichle, L. Nicu, G. Molnár, A. Bousseksou, MicromachiningCompatible, Facile Fabrication of Polymer Nanocomposite Spin Crossover Actuators, Adv. Funct. Mater. 28 (2018) 1801970. https://doi.org/10.1002/adfm.201801970.

[64] A. Suzuki, M. Fujiwara, M. Nishijima, High spin/low spin phase transitions of a spincrossover complex in the emulsion polymerization of trifluoroethylmethacrylate (TFEMA) using PVA as a protective colloid, Colloid Polym. Sci. 286 (2008) 525-534. https://doi.org/10.1007/s00396-007-1796-4.

[65] Y.S. Koo, J.R. Galán-Mascarós, Spin crossover probes confer multistability to organic conducting polymers, Adv. Mater. 26 (2014) 6785-6789.

https://doi.org/10.1002/adma.201402579.

[66] S. Ahoulou, N. Vilà, S. Pillet, D. Schaniel, A. Walcarius, Coordination Polymers as Template for Mesoporous Silica Films: A Novel Composite Material Fe(Htrz) ${ }_{3} @ \mathrm{SiO}_{2}$ with Remarkable Electrochemical Properties, Chem. Mater. 31 (2019) 5796-5807. https://doi.org/10.1021/acs.chemmater.9b01879.

[67] M. Sawczak, R. Jendrzejewski, D. Maskowicz, Y. Garcia, A.C. Ghosh, M. Gazda, J. Czechowski, G. Śliwiński, Nanocrystalline Polymer Impregnated [Fe(pz)Pt(CN) $\left.)_{4}\right]$ Thin Films Prepared by Matrix-Assisted Pulsed Laser Evaporation, Eur. J. Inorg. Chem. 2019 (2019) 3249-3255. https://doi.org/10.1002/ejic.201900231.

[68] M. Piedrahita-Bello, J.E. Angulo Cervera, R. Courson, G. Molnár, L. Malaquin, C. Thibault, B. Tondu, L. Salmon, A. Bousseksou, 4D printing with spin crossover polymer composite, J. Mater. Chem. C. (2020). https://doi.org/10.1039/D0TC01532F

[69] V.A. Varnek, L.G. Lavrenova, Mössbauer study of the influence of ligands and anions of the second coordination sphere in Fe(II) complexes with 1,2,4-triazole and 4-amino1,2,4-triazole on the temperature of the ${ }^{1} \mathrm{~A}_{1} \leftrightarrows{ }^{5} \mathrm{~T}_{2}$ spin transitions, J. Struct. Chem. 36 (1995) 104-111. https://doi.org/10.1007/BF02577756.

[70] I.A. Gural'Skiy, C.M. Quintero, G. Molnár, I.O. Fritsky, L. Salmon, A. Bousseksou, Synthesis of spin-crossover nano- and micro-objects in homogeneous media, Chem. Eur. J. 18 (2012) 9946-9954. https://doi.org/10.1002/chem.201201063. 
[71] A. Rotaru, F. Varret, A. Gindulescu, J. Linares, A. Stancu, J.F. Létard, T. Forestier, C. Etrillard, Size effect in spin-crossover systems investigated by FORC measurements, for surfacted $\left[\mathrm{Fe}\left(\mathrm{NH}_{2} \text {-trz }\right)_{3}\right](\mathrm{Br})_{2} \cdot 3 \mathrm{H}_{2} \mathrm{O}$ nanoparticles: reversible contributions and critical size, Eur. Phys. J. B. 84 (2011) 439-449. https://doi.org/10.1140/epjb/e201110903-x.

[72] Y. Maeda, M. Miyamoto, Y. Takashima, H. Oshio, Spin-crossover behaviour of iron(III) complexes with pendant type polymeric ligands, Inorganica Chim. Acta. 204 (1993) 231-237. https://doi.org/10.1016/S0020-1693(00)82930-8.

[73] R.J. Davidson, E.W. Ainscough, A.M. Brodie, G.B. Jameson, M.R. Waterland, H.R. Allcock, M.D. Hindenlang, B. Moubaraki, K.S. Murray, K.C. Gordon, R. Horvath, G.N.L. Jameson, Toward an iron(II) spin-crossover grafted phosphazene polymer, Inorg. Chem. 51 (2012) 8307-8316. https://doi.org/10.1021/ic300853f.

[74] W.P. Wang, Z.Q. Zhang, B.B. Ji, H.H. Zhao, G.Q. Li, L.X. Ma, H.X. Zhao, Synthesis and characterization of novel coordination spin crossover poly(glycidyl methacrylate) with pendant iron(II)-4-amino-1,2,4-triazole groups, Inorg. Chem. Commun. 56 (2015) 125-128. https://doi.org/10.1016/j.inoche.2015.04.005.

[75] W. Wang, B. Ji, C. Zhang, X. Cao, New spin crossover polymeric composite and another way to describe the result, Inorg. Chem. Commun. 67 (2016) 55-59. https://doi.org/10.1016/j.inoche.2016.03.007.

[76] Y. Qin, P.O. Shipman, F. Jäkle, Self-assembly of borane end-functionalized polystyrene through tris(1-pyrazolyl)borate (Tp) iron(II) linkages, Macromol. Rapid Commun. 33 (2012) 562-567. https://doi.org/10.1002/marc.201100628.

[77] G. Schwarzenbacher, M.S. Gangl, M. Goriup, M. Winter, M. Grunert, F. Renz, W. Linert, R. Saf, Preparation and Radical Oligomerization of anFe(II) Complex without Loss of Spin-Crossover Properties, Monatshefte Fuer Chemie/Chemical Mon. 132 (2001) 519-529. https://doi.org/10.1007/s007060170114.

[78] B. Djukic, M.T. Lemaire, Hybrid spin-Crossover conductor exhibiting unusual variable-temperature electrical conductivity, Inorg. Chem. 48 (2009) 10489-10491. https://doi.org/10.1021/ic9015542.

[79] B. Djukic, M.A. Singh, M.T. Lemaire, Formation of hybrid spin crossover polymer microspheres, Synth. Met. 160 (2010) 825-828. https://doi.org/10.1016/j.synthmet.2009.12.009.

[80] T.J. O’Sullivan, B. Djukic, P.A. Dube, M.T. Lemaire, A conducting metallopolymer featuring valence tautomerism, Chem. Commun. (2009) 1903-1905. https://doi.org/10.1039/b818952h.

[81] A. Benchohra, Switchable Spin-CrossOver complexes based Metallo-polymers a new class of functional molecular materials, Sorbonne University, 2019.

[82] B. Weber, Synthesis of Coordination Polymer Nanoparticles using Self-Assembled Block Copolymers as Template, Chem. Eur. J. 23 (2017) 18093-18100. https://doi.org/10.1002/chem.201703280.

[83] C. Göbel, T. Palamarciuc, C. Lochenie, B. Weber, Synthesis of microcrystals of the $[\mathrm{Fe}(\mathrm{L})($ bipy $)]$ spin crossover coordination polymer in a poly-4-vinylpyridine matrix, 
Chem. Asian J. 9 (2014) 2232-2238. https://doi.org/10.1002/asia.201402144.

[84] O. Klimm, C. Göbel, S. Rosenfeldt, F. Puchtler, N. Miyajima, K. Marquardt, M. Drechsler, J. Breu, S. Förster, B. Weber, Synthesis of [Fe(L)(bipy)]n spin crossover nanoparticles using blockcopolymer micelles, Nanoscale. 8 (2016) 19058-19065. https://doi.org/10.1039/c6nr06330f.

[85] C. Göbel, O. Klimm, F. Puchtler, S. Rosenfeldt, S. Förster, B. Weber, Synthesis of $\left[\mathrm{Fe}\left(\mathrm{L}_{\mathrm{eq}}\right)\left(\mathrm{L}_{\mathrm{ax}}\right)\right]_{\mathrm{n}}$ coordination polymer nanoparticles using blockcopolymer micelles, Beilstein J. Nanotechnol. 8 (2017) 1318-1327. https://doi.org/10.3762/bjnano.8.133.

[86] C. Göbel, C. Hils, M. Drechsler, D. Baabe, A. Greiner, H. Schmalz, B. Weber, Confined Crystallization of Spin-Crossover Nanoparticles in Block-Copolymer Micelles, Angew. Chem. Int. Ed. 59 (2020) 5765-5770. https://doi.org/10.1002/anie.201914343.

[87] A.B. Gaspar, M. Seredyuk, Spin crossover in soft matter, Coord. Chem. Rev. 268 (2014) 41-58. https://doi.org/10.1016/j.ccr.2014.01.018.

[88] S.M. Grayson, J.M.J. Fréchet, Convergent dendrons and dendrimers: From synthesis to applications, Chem. Rev. 101 (2001) 3819-3867. https://doi.org/10.1021/cr990116h.

[89] G.R. Newkome, Z. Yao, G.R. Baker, V.K. Gupta, Micelles. Part 1. Cascade molecules: a new approach to micelles. A [27]-arborol, J. Org. Chem. 50 (1985) 2003-2004. https://doi.org/10.1021/jo00211a052.

[90] S. Mignani, S. El Kazzouli, M. Bousmina, J.P. Majoral, Expand classical drug administration ways by emerging routes using dendrimer drug delivery systems: A concise overview, Adv. Drug Deliv. Rev. 65 (2013) 1316-1330. https://doi.org/10.1016/j.addr.2013.01.001.

[91] A.M. Caminade, A. Ouali, M. Keller, J.P. Majoral, Organocatalysis with dendrimers, Chem. Soc. Rev. 41 (2012) 4113-4125. https://doi.org/10.1039/c2cs35030k.

[92] D. Astruc, L. Liang, A. Rapakousiou, J. Ruiz, Click dendrimers and triazole-related aspects: Catalysts, mechanism, synthesis, and functions. A bridge between dendritic architectures and nanomaterials, Acc. Chem. Res. 45 (2012) 630-640. https://doi.org/10.1021/ar200235m.

[93] D. Astruc, E. Boisselier, C. Ornelas, Dendrimers Designed for Functions: From Physical, Photophysical, and Supramolecular Properties to Applications in Sensing, Catalysis, Molecular Electronics, Photonics, and Nanomedicine, Chem. Rev. 110 (2010) 1857-1959. https://doi.org/10.1021/cr900327d.

[94] D. Astruc, Electron-transfer processes in dendrimers and their implication in biology, catalysis, sensing and nanotechnology, Nat. Chem. 4 (2012) 255-267. https://doi.org/10.1038/nchem.1304.

[95] T. Fujigaya, D.L. Jiang, T. Aida, Spin-crossover dendrimers: Generation numberdependent cooperativity for thermal spin transition, J. Am. Chem. Soc. 127 (2005) 5484-5489. https://doi.org/10.1021/ja050275k.

[96] P. Sonar, C.M. Grunert, Y.L. Wei, J. Kusz, P. Gütlich, A.D. Schlüter, Iron(II) spin transition complexes with dendritic ligands, Part I, Eur. J. Inorg. Chem. (2008) 1613- 
1622. https://doi.org/10.1002/ejic.200700822.

[97] Y. Wei, P. Sonar, M. Grunert, J. Kusz, A.D. Schlüter, P. Gütlich, Iron(II) spintransition complexes with dendritic ligands, part II, Eur. J. Inorg. Chem. (2010) 39303941. https://doi.org/10.1002/ejic.201000067.

[98] M.S. Gruzdev, N.E. Domracheva, U. V. Chervonova, A.M. Kolker, A.S. Golubeva, Bis-chelate Fe(III) complex of an azomethine at the focal point of a branched ester functionalized with cyclohexylbenzoic acid, J. Coord. Chem. 65 (2012) 1812-1820. https://doi.org/10.1080/00958972.2012.682158.

[99] N.E. Domracheva, A. V. Pyataev, V.E. Vorobeva, E.M. Zueva, Detailed EPR study of spin crossover dendrimeric iron(III) complex, J. Phys. Chem. B. 117 (2013) 78337842. https://doi.org/10.1021/jp403682p.

[100] N.E. Domracheva, V.E. Vorobeva, V.I. Ovcharenko, A.S. Bogomyakov, E.M. Zueva, M.S. Gruzdev, U. V. Chervonova, A.M. Kolker, Counterion effect on the spintransition properties of the second generation iron(III) dendrimeric complexes, Inorganica Chim. Acta. 459 (2017) 131-142. https://doi.org/10.1016/j.ica.2017.02.008.

[101] N. Domracheva, V. Vorobeva, A. Pyataev, R. Tamura, K. Suzuki, M. Gruzdev, U. Chervonova, A. Kolker, Magnetic properties of novel dendrimeric spin crossover iron(III) complex, Inorganica Chim. Acta. 439 (2016) 186-195. https://doi.org/10.1016/j.ica.2015.10.024.

[102] V.E. Vorobeva, N.E. Domracheva, A. V. Pyataev, M.S. Gruzdev, U. V. Chervonova, Coexistence of spin crossover and magnetic ordering in a dendrimeric Fe(III) complex, Low Temp. Phys. 41 (2015). https://doi.org/10.1063/1.4906311.

[103] M.M. Piepenbrock, G.O. Lloyd, N. Clarke, J.W. Steed, Metal- and Anion-Binding Supramolecular Gels, Chem. Rev. 110 (2010) 1960-2004. https://doi.org/10.1021/cr9003067.

[104] J. Zhang, C.Y. Su, Metal-organic gels: From discrete metallogelators to coordination polymers, Coord. Chem. Rev. 257 (2013) 1373-1408. https://doi.org/10.1016/j.ccr.2013.01.005.

[105] O. Roubeau, A. Colin, V. Schmitt, R. Clérac, Thermoreversible Gels as MagnetoOptical Switches, Angew. Chemie. 116 (2004) 3345-3348. https://doi.org/10.1002/ange.200454050.

[106] O. Roubeau, A. Colin, V. Schmitt, R. Clérac, Thermoreversible gels as magneto-optical switches, Angew. Chem. Int. Ed. 43 (2004) 3283-3286. https://doi.org/10.1002/anie.200454050.

[107] K. Kuroiwa, T. Shibata, S. Sasaki, M. Ohba, A. Takahara, T. Kunitake, N. Kimizuka, Supramolecular control of spin-crossover phenomena in lipophilic Fe(II)-1,2,4-triazole complexes, J. Polym. Sci. Part A Polym. Chem. 44 (2006) 5192-5202. https://doi.org/10.1002/pola.21601.

[108] T. Fujigaya, D.L. Jiang, T. Aida, Spin-crossover physical gels: A quick thermoreversible response assisted by dynamic self-organization, Chem. Asian J. 2 (2007) 106-113. https://doi.org/10.1002/asia.200600371. 
[109] M. Rubio, D. López, Effect of solvent on the gelation properties of a metallo-organic polymer of [Fe(II) (4-octadecyl-1,2,4-triazole $\left.)_{3}\left(\mathrm{ClO}_{4}\right)_{2}\right]_{\mathrm{n}}$, Eur. Polym. J. 45 (2009) 3339-3346. https://doi.org/10.1016/j.eurpolymj.2009.10.013.

[110] P. Grondin, O. Roubeau, M. Castro, H. Saadaoui, A. Colin, R. Clérac, Multifunctional gels from polymeric spin-crossover metallo-gelators, Langmuir. 26 (2010) 5184-5195. https://doi.org/10.1021/la903653d.

[111] C. Echeverría, M. Rubio, G.R. Mitchell, D. López, Structure of a spin-crossover Fe(II)1,2,4-triazole polymer complex gel in toluene. Small angle neutron scattering and viscoelastic studies, Eur. Polym. J. 53 (2014) 238-245. https://doi.org/10.1016/j.eurpolymj.2014.01.034.

[112] A. Sánchez-Ferrer, I. Bräunlich, J. Ruokolainen, M. Bauer, R. Schepper, P. Smith, W. Caseri, R. Mezzenga, Gels, xerogels and films of polynuclear iron(II)-aminotriazole spin-crossover polymeric complexes, RSC Adv. 4 (2014) 60842-60852. https://doi.org/10.1039/c4ra10060c.

[113] I.A. Gural'Skiy, V.A. Reshetnikov, A. Szebesczyk, E. Gumienna-Kontecka, A.I. Marynin, S.I. Shylin, V. Ksenofontov, I.O. Fritsky, Chiral spin crossover nanoparticles and gels with switchable circular dichroism, J. Mater. Chem. C. 3 (2015) 4737-4741. https://doi.org/10.1039/c5tc00161g.

[114] G. Bovo, I. Bräunlich, W.R. Caseri, N. Stingelin, T.D. Anthopoulos, K.G. Sandeman, D.D.C. Bradley, P.N. Stavrinou, Room temperature dielectric bistability in solutionprocessed spin crossover polymer thin films, J. Mater. Chem. C. 4 (2016) 6240-6248. https://doi.org/10.1039/c6tc01646d.

[115] C. Echeverría, M. Rubio, D. López, Thermo-reversible hybrid gels formed from the combination of isotactic polystyrene and $\left.[\mathrm{Fe}(\mathrm{II}) \text { (4-octadecyl-1,2,4-triazole })_{3}\left(\mathrm{ClO}_{4}\right)_{2}\right]_{\mathrm{n}}$ metallo-organic polymer: Thermal and viscoelastic properties, Polymers (Basel). 11 (2019). https://doi.org/10.3390/polym11060957.

[116] P.J. van Koningsbruggen, Y. Garcia, E. Codjovi, R. Lapouyade, O. Kahn, L. Fournès, L. Rabardel, Non-classical $\mathrm{Fe}^{\mathrm{II}}$ spin-crossover behaviour in polymeric iron(II) compounds of formula $\left[\mathrm{Fe}\left(\mathrm{NH}_{2} \mathrm{trz}\right)_{3}\right] \mathrm{X}_{2} \mathrm{XH}_{2} \mathrm{O}\left(\mathrm{NH}_{2} \operatorname{trz}=4\right.$-amino-1,2,4-triazole; $X=$ derivatives of naphthalene sulfonate), J. Mater. Chem. 7 (1997) 2069-2075. https://doi.org/10.1039/a702690k.

[117] Y. Galyametdinov, V. Ksenofontov, A. Prosvirin, I. Ovchinnikov, G. Ivanova, P. Gütlich, W. Haase, First Example of Coexistence of Thermal Spin Transition and Liquid-Crystal Properties, Angew. Chemie. 113 (2001) 4399-4401. https://doi.org/10.1002/1521-3757(20011119)113:22<4399::AIDANGE4399>3.0.CO;2-6.

[118] S. Hayami, K. Danjobara, K. Inoue, Y. Ogawa, N. Matsumoto, Y. Maeda, A photoinduced spin transition iron(II) complex with liquid-crystal properties, Adv. Mater. 16 (2004) 869-872. https://doi.org/10.1002/adma.200306632.

[119] M. Seredyuk, A.B. Gaspar, V. Ksenofontov, S. Reiman, Y. Galyametdinov, W. Haase, E. Rentschler, P. Gütlich, Room temperature opperational thermochromic liquid crystals, Chem. Mater. 18 (2006) 2513-2519. https://doi.org/10.1021/cm052632w. 
[120] M. Seredyuk, A.B. Gaspar, V. Ksenofontov, Y. Galyametdinov, M. Verdaguer, F. Villain, P. Gütlich, One-dimensional iron(II) compounds exhibiting spin crossover and liquid crystalline properties in the room temperature region, Inorg. Chem. 47 (2008) 10232-10245. https://doi.org/10.1021/ic8006266.

[121] Y.H. Lee, Y. Komatsu, Y. Yamamoto, K. Kato, T. Shimizu, A. Ohta, T. Matsui, S. Hayami, Spin crossover polymeric iron(II) complex based on triazole with branched long alkyl chain, Inorg. Chem. Commun. 14 (2011) 1498-1500. https://doi.org/10.1016/j.inoche.2011.05.055.

[122] P. Grondin, D. Siretanu, O. Roubeau, M.F. Achard, R. Clérac, Liquid-crystalline zinc(II) and iron(II) alkyltriazoles one-dimensional coordination polymers, Inorg. Chem. 51 (2012) 5417-5426. https://doi.org/10.1021/ic300404r.

[123] S. Hayami, R. Moriyama, A. Shuto, Y. Maeda, K. Ohta, K. Inoue, Spin transition at the mesophase transition temperature in a cobalt(II) compound with branched alkyl chains, Inorg. Chem. 46 (2007) 7692-7694. https://doi.org/10.1021/ic700754s.

[124] S. Hayami, Y. Yamamoto, Y. Kojima, K. Inoue, Spin transition induced by crystal Liquid crystal transition, J. Phys.: Conf. Ser. 200 (2010). https://doi.org/10.1088/17426596/200/8/082008.

[125] M. Seredyuk, A.B. Gaspar, V. Ksenofontov, Y. Galyametdinov, M. Verdaguer, F. Villain, P. Gütlich, Spin-Crossover and Liquid Crystal Properties in 2D CyanideBridged Fe ${ }^{\mathrm{II}}-\mathrm{M}^{\mathrm{I} / \mathrm{II}}$ Metalorganic Frameworks, Inorg. Chem. 49 (2010) 10022-10031. https://doi.org/10.1021/ic101304v.

[126] A. Ruaudel-Teixier, A. Barraud, P. Coronel, O. Kahn, Spin transition in a magnetic Langmuir-Blodgett film, Thin Solid Films. 160 (1988) 107-115. https://doi.org/10.1016/0040-6090(88)90052-1.

[127] F. Armand, C. Badoux, P. Bonville, A. Ruaudel-Teixier, O. Kahn, Langmuir-Blodgett Films of Spin Transition Iron(II) Metalloorganic Polymers. 1. Iron(II) Complexes of Octadecyl-1,2,4-triazole, Langmuir. 11 (1995) 3467-3472. https://doi.org/10.1021/la00009a032.

[128] H. Soyer, C. Mingotaud, M.L. Boillot, P. Delhaes, Spin crossover of a LangmuirBlodgett film based on an amphiphilic iron(II) complex, Langmuir. 14 (1998) 58905894. https://doi.org/10.1021/la9803934.

[129] H. Soyer, E. Dupart, C.J. Gómez-García, C. Mingotaud, P. Delhaès, First Magnetic Observation of a Spin Crossover in a Langmuir-Blodgett Film, Adv. Mater. 11 (1999) 382-384. https://doi.org/10.1002/(sici)1521-4095(199903)11:5<382::aidadma382>3.0.co;2-u.

[130] O. Roubeau, B. Agricole, R. Clérac, S. Ravaine, Triazole-based magnetic LangmuirBlodgett films: Paramagnetic to spin-crossover behavior, J. Phys. Chem. B. 108 (2004) 15110-15116. https://doi.org/10.1021/jp048194i.

[131] J.A. Kitchen, N.G. White, C. Gandolfi, M. Albrecht, G.N.L. Jameson, J.L. Tallon, S. Brooker, Room-temperature spin crossover and Langmuir-Blodgett film formation of an iron(II) triazole complex featuring a long alkyl chain substituent: The tail that wags the dog, Chem. Commun. 46 (2010) 6464-6466. https://doi.org/10.1039/c0cc01008a. 
[132] P.N. Martinho, I.A. Kühne, B. Gildea, G. McKerr, B. O’Hagan, T.E. Keyes, T. Lemma, C. Gandolfi, M. Albrecht, G.G. Morgan, Self-Assembly Properties of Amphiphilic Iron(III) Spin Crossover Complexes in Water and at the Air-Water Interface, Magnetochemistry. 4 (2018) 49.

https://doi.org/10.3390/magnetochemistry4040049.

[133] A. Tissot, C. Enachescu, M.L. Boillot, Control of the thermal hysteresis of the prototypal spin-transition $\mathrm{Fe}^{\mathrm{II}}(\text { phen })_{2}(\mathrm{NCS})_{2}$ compound via the microcrystallites environment: Experiments and mechanoelastic model, J. Mater. Chem. 22 (2012) 20451-20457. https://doi.org/10.1039/c2jm33865c.

[134] D. Qiu, D.H. Ren, L. Gu, X.L. Sun, T.T. Qu, Z.G. Gu, Z. Li, Spin crossover-graphene nanocomposites: Facile syntheses, characterization, and magnetic properties, RSC Adv. 4 (2014) 31323-31327. https://doi.org/10.1039/c4ra04257c.

[135] Y. Murashima, M.R. Karim, N. Saigo, H. Takehira, R. Ohtani, M. Nakamura, M. Koinuma, L.F. Lindoy, K. Kuroiwa, S. Hayami, Graphene oxide and reduced graphene oxide hybrids with spin crossover iron(III) complexes, Inorg. Chem. Front. 2 (2015) 886-892. https://doi.org/10.1039/c5qi00097a.

[136] K. Senthil Kumar, I. Šalitroš, Z. Boubegtiten-Fezoua, S. Moldovan, P. Hellwig, M. Ruben, A spin crossover (SCO) active graphene-iron(II) complex hybrid material, Dalton Trans. 47 (2018) 35-40. https://doi.org/10.1039/c7dt03623j. 